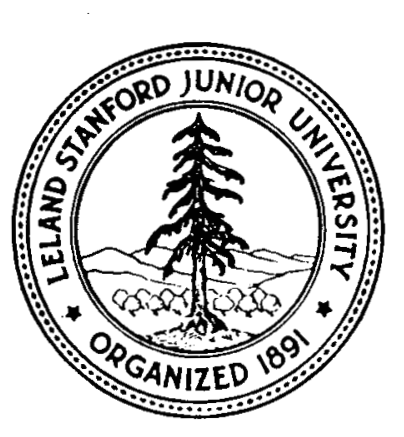

\title{
TRACER TEST ANALYSIS OF THE KLAMATH FALLS GEOTHERMAL RESOURCE: A COMPARISON OF MODELS
}

Stephen E. Johnson

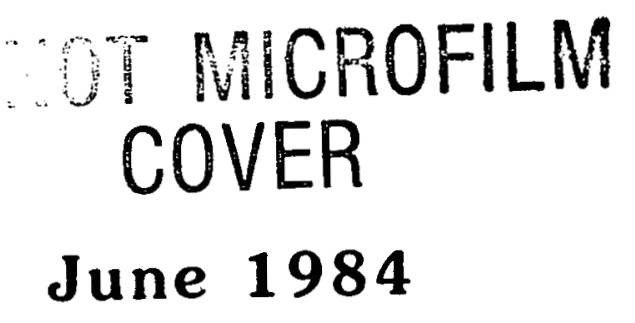

Stanford Geothermal Program INTERDISCIPLINARY RESEARCH IN ENGINEERING AND EARTH SCIENCES Stanford University, Stanford, California 


\section{DISCLAIMER}

This report was prepared as an account of work sponsored by an agency of the United States Government. Neither the United States Government nor any agency Thereof, nor any of their employees, makes any warranty, express or implied, or assumes any legal liability or responsibility for the accuracy, completeness, or usefulness of any information, apparatus, product, or process disclosed, or represents that its use would not infringe privately owned rights. Reference herein to any specific commercial product, process, or service by trade name, trademark, manufacturer, or otherwise does not necessarily constitute or imply its endorsement, recommendation, or favoring by the United States Government or any agency thereof. The views and opinions of authors expressed herein do not necessarily state or reflect those of the United States Government or any agency thereof. 


\section{DISCLAIMER}

Portions of this document may be illegible in electronic image products. Images are produced from the best available original document. 
TRACER TEST ANALYSIS OF THE RLAMATH FALLS GEOTHERMAL RESOURCE: A COMPARISON OF MODELS

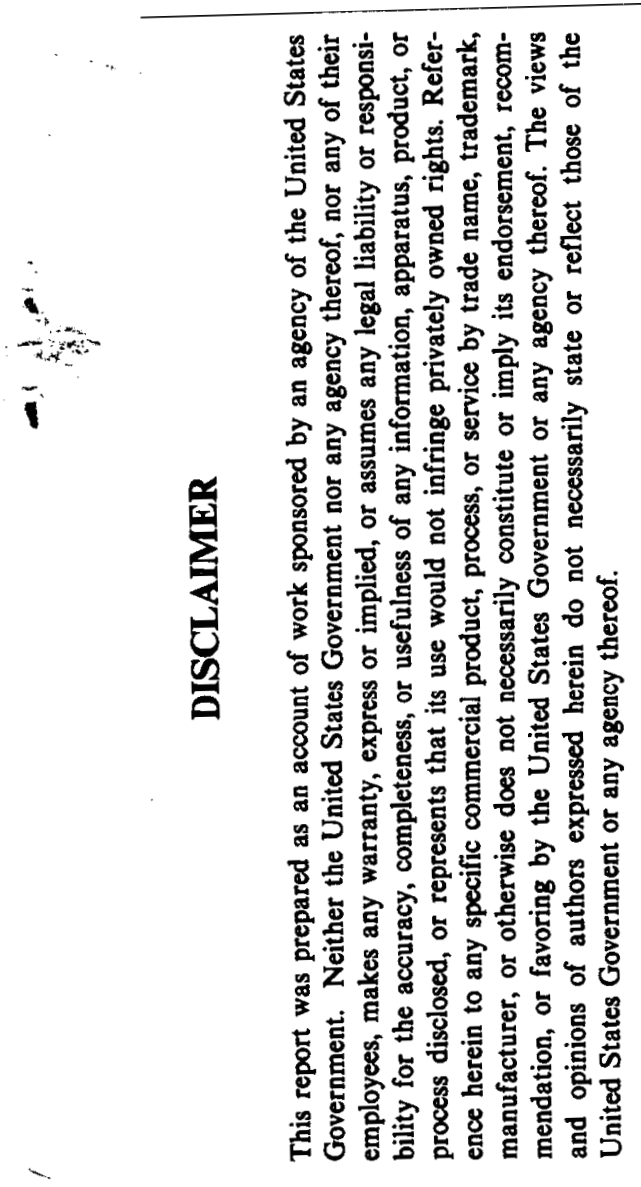

By

Stephen E. Johnson

June 1984

8.

Financial support was provided through the stanford Geothermal Program under Department of Energy Contract No. DE-AT03-80SF11459 and by the Department of Petroleum Engineering, Stanford University. 


\section{TABLE OF CONTENTS}

SECTION

PAGE

ABSTRACT

LIST OF TABLES

LIST OF FIGURES

1.0 INTRODUCTION

2.0 LITERATURE SURVEY 3

3.0 GEOTHERMAL RESOURCE OF KLAMATH FALLS 6

4.0 MATHEMATICAL DEVELOPMENT OF FLOW MODELS 10

4.1 POROUS MEDIA FLOW MODEL 15

4.2 SINGLE FRACTURE RETENTION MODEL 20

4.3 DUAL FRACTURE FLOW PATH MODEL 26

5.0 KLAMATH UNION HIGH SCHOOL TEST DESCRIPTION 32

$\begin{array}{ll}\text { 6.0 DISTRICT TEST DESCRIPTION } & 38\end{array}$

7.0 RESULTS AND ANALYSIS $\quad 40$

7.1 CURVE MATCHING

7.2 POROUS MEDIA MODEL ANALYSIS

7.3 FRACTURED MEDIA FLOW MODELS 45

$\begin{array}{ll}\text { 8.0 DISCUSSION } & 49\end{array}$

9.0 CONCLUSIONS 51

REFERENCES

NOMENCLATURE

$\begin{array}{ll}\text { FIGURES } & 57\end{array}$

$\begin{array}{ll}\text { TABLES } & 89\end{array}$

APPENDICES

A) POROUS MEDIA PROGRAM 105 
Two tracer tests on doublet systems in a fractured geothermal system were carried out in Klamath Falls, Oregon. The purpose of the tests were to obtain data which would lead to information about the reservoir and to test the applicability of current tracer flow models. The results show rapid breakthrough times and indicate fracture flow with vigorous mixing of injector fluid before production of same. This leads to the idea that thermal breakthrough is not directly related to tracer breakthrough in the Klamath Union doublet system. There has been no long-term enthalpy loss from exploiting the resource for 40 years. In order to reduce the data, models were developed to analyze the results. Along with a porous media flow model two mathematical models developed to analyze fractured geothermal systems are used to help decipher the various tracer return curves. The flow of tracers in doublet systems was investigated. A mathematical description is used for tracer flow through fractures as a function of time and various nonlinear parameters which can be found using a curve fitting technique. This allows the reservoir to be qualitatively defined. These models fit the data well, but point to the fact that future improvement needs to be considered for a clearer and more quantitative understanding of fractured geothermal systems. 


\section{LIST OF TABLES}

LISTING

DESCRIPTION

PAGE

$\begin{array}{lll}\text { TABLE } & \text { R.1 RETENTION MODEL OUTPUT } & 89\end{array}$

TABLE 6.2 DUAL FLOW PATH MODEL OUTPUT 89

TABLE 6.3 TRACER DATA FOR KLAMATH UNION TEST 90

TABLE 6.4 TRACER DATA FOR DISTRICT TEST 90

TABLE 6.5 MEAN TRACER VELOCITIES (KUHS) 91

TABLE 6.6 MEAN TRACER VELOCITIES (DISTRICT TEST) 91

TABLE A CREAMERY WELL DATA (KUHS TEST) 92

TABLE B FRIESEN WELL DATA (DISTRICT TEST)

TABLE C KLAMATH UNION WELL DATA (KUHS TEST) 96

TABLE D CREAMERY WELL DATA (DISTRICT TEST) 98

TABLE E KLAMATH UNION WELL DATA FLUORESCEIN (KUHS TEST) 99 


\section{IUST OF FIGURES}

Figure Number

Description

Page

FIGURE 2.1 Location of Klamath Falls

57

FIGURE 2.2 Areal geology of Klamath Falls area 58

FIGURE 3.1 Equipotential and Streamlines for Flow between wells 59

FIGURE 3.2 Streamline Definition for Infinite Source Sink 60

FIGURE 3.3 Fracture flow geometry 61

FIGURE $3.4 \quad$ Fracture geometry 62

FIGURE $3.5 \quad$ Diffusion of tracer into rock matrix 63

FIGURE 4.1 Hot well area of Kamath Falls 64

FIGURE 4.2 KUHS doublet system $\quad 65$

FIGURE 4.3 Location of wells 66

FIGURE 4.4 KUHS well data

FIGURE 4.5 Trecer comparison profiles for KUHS well 68

FIGURE 4.6 Creamery well data 69

FIGURE 6.1 Friesen well dual flow match 70

$\begin{array}{lll}\text { FIGURE 6.2 Dispersion constant comparison } & 71\end{array}$

FIGURE 6.3 KUHS porous model match 72

FIGURE 6.4 KUHS porous model match 73

FIGURE 6.5 Croamery well porous model match 74

FIGURE 6.6 Friesen well porous model match 75

FIGURE 6.7 KUHS retention model match 76

FIGURE 6.8 KUHS retention model match 77

FIGURE 6.9 Creamery well retention model match, KUHS test 78

FIGURE 6.10 Creamery well retention model match, district test 79 


\section{HST OF FIGURES}

Figure Number

Description

Page

FIGURE 6.11 Friesen well retention model match 80

FIGURE 6.12 KUHS single flow path model match 81

FIGURE 6.13 KUHS single flow path model match 82

FIGURE 6.14 KUHS dual flow path model match 83

FIGURE 6.15 KUHS dual flow path model match 84

FIGURE 6.16 Creamery well single flow path model match 85

FIGURE 6.17 Friesen well single flow path model match 86

FIGURE $6.18 \quad$ (s) Creamery single flow path model match 87

FIGURE $6.19 \quad$ (s) Creamery dual flow path model match 88 


\subsection{INTRODUCTION}

The exploitation of geothermal resources is becoming more widespread throughout the world. Of importance to the engineer is how to maximize the output from a geothermal reservoir. In dealing with this problem pressure maintenance is important as is the disposal of spent fluids. Injection of spent geothermal fluids can serve two purposes. First the used fluids are disposed of and second, the injected fluids can maintain the reservoir pressure. It is important to minimize any detrimental effects of injecting cooler spent geothermal fluids, such as, reducing the enthalpy of reservoir. In an effort to understand the possible effects of injection in geothermal reservoirs the tracer studies reported here were undertaken. By placing a tracer into the reinjected fluid and monitoring its production from the reservoir knowledge, of flow mechanics and reservoir properties can be obtained.

The end result of a tracer test are data which needs to be reduced in order to have meaning. Several mathematical models have been developed that can have curve fitting techniques applied to them. The models studied in this report consider the dispersion of tracer while flowing in a fracture between injection and production wells. Two fracture flow models and a porous media model were used on data gathered from two tracer tests in Klamath Falls, Oregon

The initial test was performed on the Klamath Union High School (KUHS) doublet system and the other on the city's district heating doublet system. The KUHS test served two purposes 1) to test different chemical tracers in a geothermal reservoir and 2) to get an indication of reservoir parameters. The district test was carried out in conjunction with an interference test designed to determine the effect of the district doublet system on nearby wells and the reservoir as a whole. 
Data gathered from tracer tests allow information to be obtained pertaining to fluid velocity, thermal breakthrough, effective system volume and the type of flow path encountered between wells. This report focuses on the latter information. By studying the tracer return curve proflle, properties of the reservoir/tracer interaction can be obtained. If a system is successfully modeled mathematically, the model should be able to predict or match the data produced from a tracer test. Although the model may not uniquely match actual data, it can discriminate between those situations where the actual data are produced from a reservoir that is significantly different, such as, porous matrix vs. fractured matrix.

This report tests the applicability of three separate models developed to model tracer return data. By comparing the matches produced by the models both information on the Klamath Falls geothermal resource and the uniqueness of the three models was found. 


\subsection{LTERATURE SURVEY}

Tracer tests can be performed on geothermal reservoirs in an effort to gain better understanding of their characteristics. Information derived from analyzing tracer return curves can be used to predict the flow behavior in a given system and possibly the thermal breakthrough. The aim of any analysis is to use the simplest model that describes the reservoir and see if valid results are obtained. If a model does not work a new model is created and tested.

The geothermal reservoir presents various problems in choosing proper tracers. To assure reliable, accurate data, tracers that can withstand the elevated temperatures and be detected above any natural background in the reservoir fluid must be used. Using tracers for the testing of ground water and aquifer recharge is well known and not unlike geothermal reservoir testing. Smart and Laidlaw (1977) compiled information relevant to fluorescent tracer detection methods, uses, toxicity and physical properties. Potassium iodide, rhodamine WT and fluorescein because of their high detectability, ease of measurement. cost and low toxicity were selected for use as tracers in the Klamath Falls tests.

The energy industry has focused on understanding oil reservoirs which are typically a porous media, but it is known that most geothermal reservoirs are at best a combination of porous and.fractured media and commonly a fractured media with a porous matrix. Sammel (1980) performed a detailed bydrogeologic study on the nature of the Klamath Falls geothermal resource. He showed that the formation which most of the wells penetrate consists of layered lava flows with high angle faults and fracture zones allowing communication between the different permeable beds. Geothermal water is able to flow up the faults from a source thought to be 15,000 feet deep and once near the surface move laterally along the beds. 
The purpose of this report is to test the applicability of various tracer flow models to data obtained from the Klamath Falls geothermal reservoir. By reproducing a tracer return curve profile, a model can demonstrate that the underlying assumptions, at least qualitatively, match the reservoir geometry. Noting the shortcomings of a model give insight to what parameters are not necessary or which effects are negligible in a mathematical model. Three models were investigated in this report: 1) unconfined doublet flow in a porous media, 2) single fracture flow accounting for retention effects, 3) a two fracture flow model with dispersion taken into account.

The homogeneous porous media model The model was presented by Klett et al. (1981). The model is based on streamline potential in an unconfined region for a doublet system. Using this model gives information about dispersion of tracer through the reservoir.

The next level of complexity was to assume only fracture flow. Based on a mathematical model developed by Horne and Rodriques (1983), taking into account the dispersion of tracer during flow through a fracture, Fossum (1982), created a dual flow path model to analyze field data collected in Wairakei, New Zealand, and showed that double flowpath gave much more accurate results than a single flowpath. Another level of complexity was added by Jensen (1983). By adding the effects of retension to the fracture flowpath model, Jensen showed that a single flowpath, with retension accounted for, works as well if not better for matching the Wairakei data.

Both Jensen's and Fossum's models are non specific in that they do not distinguish between different dispersion mechanisms. Any system design that allows for two apparent breakthrough times will match the dual flowpath model whether it is caused by fractures or not. Jensen's model does not discriminate between microfractures, adsorption or permeable matrix as the cause for reten- 
sion of tracer material.

The least squares fit computer program VARPRO (1977) is utilized in Jensen's and Fossum's models. VARPRO fits the data using the equations that define the model. It will match any set of data given if the initial estimates of necessary parameters are close enough to the final values, but does not converge for all sets of data. 


\subsection{GEOTHERMAL RESOURCE OF KI.AMATH FALLS}

The low to moderate temperature geothermal aquifers that exist below the Klamath Falls region have been exploited for more than 40 years, mainly by drilling wells 100 to 3.00 feet below the surface and placing down hole heat exchangers in them or pumping the hot water for direct use. A detailed hydrogeologic study giving a complete description of the area and it resource, Sammel (1981) What follows, relevant information for the understanding of the geology and tracer tests, was extracted from that report.

The area is a typical basin and range geography with high angle (60 $)$ normal faults marking the basin-forming grabens. Figure 3.1 shows the location of the major northwest- southeast oriented faults and their relationship to the Klamath Falls resource known as "Hot well" area. Most of the movement along the faults was in the Pliestocene with present offset being as great as 6000 feet. Little seismic activity is known in historic times for the area. Silicified rocks not in contact with contemporary geothermal water give evidence that the geothermal activity was more widespread in the past. At present the hottest water is found within one mile of a major fault.

Of interest in this study is the Yonna formation which underlies the slopes of upraised blocks and is found at depth in the basins. The Yonna formation is made up of thick massively bedded coarse-grained palagonitic sediments and pyroclastic rocks. The thickness varies from 850 to just a few feet. Underlying the Yonna formation are volcanic rocks mainly vesicular basalts and tuffaceous sediment.

There appear to be two distinct aquifers underneath Klamath Falls: 1) The shallow cold water aquifer and 3 . the deeper geothermal aquifer. The two are not completely separated due to communication via the faults and other frac- 
tures in the Yonna and older formations.

The shallow ground water is a continuous largely unconfined body (some compartmentation due to faults) to depths of more than 1500 feet. The water is restricted to permeable zones between basalt rocks or in granular sediments covered by clay and/or silt. There are some cold water springs which originate from basaltic rocks near the base of fault scarps.

The deeper basaltic aquifers to a large degree seem to be separate from the shallow cold aquifers. Evidence for this comes from not only the different chemical make up of the waters, but from dramatically different static water levels in wells that penetrate one or the other aquifer. Two separate tests have shown that the deeper wells are hydraulically connected not only by fractures, but through permeable basalts.

The ever present faults cause a compartmentation of these aquifers more so in the deeper one than in the cold shallow aquifer. The compartmentation causes varying static levels within the two separate aquifers due to variations in water source, fault location and regional flow. This explains why two apparently close wells penetrating the same aquifer can have different static pressures. From well measurements the deeper aquifer has a lower bydrostatic head than the shallow aquifer leading one to believe that the two aquifers have different recharge systems. Measurements taken indicate that the regional flow for the shallow aquifer is south; the water flows parallel with the regional structure.

The maximum temperature of the geothermal reservoir is established using a geothermometer which uses equilibrium of silica and ratios of isotopes and ions to determine possible temperature ranges for the hot water source. By this technique a value of $150^{\circ} \mathrm{C}$ was derived as a maximum temperature for the geothermal reservoir. Gravity surveys and seismic data indicate the source of heat is most likely not an intrusive silicic mass. From measured thermal gra- 
dients (minimum $30^{\circ} \mathrm{C} / 100 \mathrm{ft}$.) the source rock would have to be 15,000 feet deep which would require some conduit or mechanism to get the water to the surface. The three hottest areas are related to faults which are known to reach depths of at least 15,000 feet suggesting that the faults act as conduits allowing flow along the fractures from reservoir to surface and laterally parallel between beds.

In areas near the principal hot-water bearing faults, thermal waters may move upward, discharging both water and heat to the near-surface environment. In larger areas surrounding the faults, the flow of hot water appears to be predominantly lateral. One example is a region of several square miles bordering the south edge of the city in which warm water from the hot-well area is believed to flow southward in permeable zones of layered basalt.

Most of the heated water rising from the reservoir does not reach land surface, but spreads through permeable zones in basaltic rocks beneath or within the Yonna Formation. In these strata, which occur at depths of a few tens of feet to at least 1,500 feet, the flow is predominantly lateral in response to local gradients in the shallow ground water reservoir. The hot water mixes with local meteoric water in these strata, and within a half mile of the major fault conduits, temperatures may decrease about $60^{\circ} \mathrm{C}$.

The geothermal system at Klamath Falls is best explained as a convection system with deep circulation of meteoric water. Thus, the conceptual model proposed for this system is a fairly simple one. Meteroic water in the Tertiary basaltic rocks of the region is assumed to percolate downward along the vast network of faults and fracture zones that characterize the regional structure. After attaining depths on the order of 15,000 feet the temperatures of at least $150^{\circ} \mathrm{C}$, the water rises to shallow depths through conduits closely associated with major faults. If the two-stage reservoir postulated on the basis of sulfate- 
oxygen isotope data exists, the shallower of the two reservoir zones may occur at depths less than 10,000 feet. This zone may be supplied by slow upward leakage through a few conduits from depths as great as 15,000 to $3 ., 000$ feet.

With the geology as reported by Sammel (1981) it is necessary to find a way of understanding tracer return curves knowing there are permeable beds intersected by faults that do not necessarily break the surface. The geothermal water reaches the surface via the faults mixing with cold shallow aquifers which flow along the terrain. 


\subsection{TRACER FLOW MODEIS}

One way to utilize a geothermal resource is to pump the fluid from a well to the surface, extract energy and then dispose of the spent fluid. Reinjection of spent geothermal fluid can serve two purposes: Pressure maintenance and safe disposal of spent geothermal fluid. Reinjection of spent geothermal fluid may also cause damage to a formation and thus, knowledge of the entire system is necessary. Many well known practices of the petroleum industry, such as, pressure and flow tests, are valuable tools used to interpret geothermal reservoirs. Yet, even more information is desirable. Just as in ground water hydrology, the geothermal engineer is interested in movement of fluids through various formations. For years tracers have been used in ground water hydrology and recently geothermal reservoirs have been the subjects of tracer tests.

\subsection{TRACER TESTING}

The idea behind a tracer test is the following. A tracer is injected into the formation and is measured in fluids produced from an aquifer or reservoir. By understanding the physics and chemistry of the interactions between the tracer and reservoir or formation it is possible to obtain information from the tracer return profile. The information sought has to do with the characteristics and properties of the formation/reservoir, rock matrix, tracer flow path, dispersion, diffusion, retension and carrier fluid. The rock matrix can be porous or fractured, homogeneous or heterogeneous, permeable or impermeable, chemically reactive or inert. The fluid is constrained by the formations it flows through and the tracer is confined by the fluid. Therefore, it is possible, if knowledge is known about the system, to infer properties about the reservoir or aquifer the tracer has passed through. 
When cooler water is injected into a geothermal formation it is heated as it flows between wells, assuming interwell flow. Depending on the velocity and thus, the residence time of injected water before production and the areal sweep the water extracts heat from the reservoir rock. The narrower the flow path the faster the velocity, the less the enthalpy exchange from matrix to fluid. When the injected water is unable to attain its original reservoir temperature after being reinjected the system is said to have experienced thermal breakthrough. Information about thermal breakthrough is the ultimate goal of a tracer test as performed in the Klamath Falls tests. Tracer tests give information about fluid velocity, areal sweep, formation properties and possible communication between wells.

Fluid velocity is derived from the time it takes the tracer to travel from the injection location to the observed well. First arrival of tracer indicates the velocity of the fastest path between wells coupled with information on dispersion of tracer. The occurance of peak tracer concentration gives the mean flow velocity of fluid between the test wells. The equilibrium value of tracer concentration can tell the researcher about the volume swept by the tracer and thus the system volume. Computing a material balance of tracer tells whether the system is isolate or in contact with a larger area than defined by the doublet system being monitored.

The focus of this report is on the shape of the tracer return curve. Different system flow geometries will produce diflerent tracer profiles. By analyzing the shape of the profle information about the reservoir can be gained. Whether the flow is predominately via fractures or through permeable beds can be determined and knowledge about area swept can be found. Of importance in regard to thermal breakthrough is whether or not the flow is along conduits created by faults, fractures or joints. The larger the effective doublet system area the 
slower the thermal breakthrough. If two wells are connected by a large isolated fracture then the heat from the reservoir well not be extracted as efficiently as if the wells were connected by a highly permeable porous sandstone.

The relation of thermal breakthrough to tracer breakthrough is an important concept in evaluating a geothermal resource. The equation:

$$
\frac{\varphi \rho_{w} C_{w}}{\varphi \rho_{w} C_{w}+(1-\varphi) \rho_{r} C_{r}}
$$

relates the energy contained in the reservoir fluid to that contained in the entire reservoir, where

$$
\begin{aligned}
& \varphi=\text { Formation porosity } \\
& \rho_{\boldsymbol{w}}=\text { Water density }\left(\mathrm{kg} / \mathrm{m}^{4}\right) \\
& C_{w}=\text { Water heat capacity }(\mathrm{kJ} / \mathrm{kg} \mathrm{C}) \\
& \rho_{\boldsymbol{r}}=\text { Rock density }\left(\mathrm{kg} / \mathrm{m}^{4}\right) \\
& C_{\boldsymbol{r}}=\text { Rock heat capacity }(\mathrm{kJ} / \mathrm{kg} \mathrm{C}) .
\end{aligned}
$$

By inverting this equation the ratio of tracer breakthrough time to thermal breakthrough is found. The thermal breakthrough time always being larger than the tracer breakthrough time. When the reservoir geometry and apparent fluid flow are understood, development of the geothermal resource can be planned in both an efficient and practical manner.

The final equations (4.19), (4.60), (4.74) presented in this section represent models of tracer flow through a reservoir of different geometries and properties. The result of creating a tracer profle with a model is having something to compare to the profiles actually obtained by running a tracer injection test. The assumption is: If thè test data matches the model data, then the model accurately describes the system tested. The researcher is familiar with the fact that the assumption is not completely valid, but the purpose of having a model is to gain 
the ability to forecast future behavior or predict outcomes of new situations. For this reason the approach becomes: 1) create the simplest model that makes sense, 2) test model against actual system, 3) if necessary refine model, 4) only increase complexity if needed. With this approach it is obvious that the model may not matches reality but it will be an accurate tool for predicting future events.

This technique was used to produce the models tested in this report. The first of these is the porous media model which mathematically describes the tracer profile produced by a doublet system with homogeneous properties. It has been used for years to describe petroleum reservoirs and can be used for geothermal reservoirs as demonstrated in this report. Although a geothermal reservoir may be fractured with no known porous characteristics, on a large enough scale a fractured system will behave as if it were a porous media. To ignore the fact that a reservoir is fractured because it can be matched using a porous model does not allow for specific parameters to be evaluated quantitatively. Fracture width, flow velocity, path length and fluid parameters are defined differently using a porous model as opposed to a fracture model. Porosity thickness $(\varphi h)$ can be equated to fracture width $(\delta)$. Whereas in an appropriate fracture flow model fracture width $\delta$ is solved for directly. Incorporating flow into a tracer return model is not an unnecessary complexity, but a means of quantifying reservoir characteristics using the proper physical understanding at hand. Thus, it is necessary to define and use an appropriate flow model involving fracture flow which brings about the next model. Flow through a fracture (Rodriguez and Horne 1981) which takes into account the obvious fact that most geothermal reservoirs are fractured. The single fracture flow model does not account for many phenomena that are thought to occur in a geothermal reservoir or aquifer. In the third model there is the added complexity of using a 
multiple flow path model (Fossum 1982), which is an extension of the single flow path model. Thinking about what might happen in the reservoir was taken into account. Knowing that a high concentration of tracer is entered into the system creating a large gradient the effects of dispersion into the matrix were added to the fracture flow model giving a one-dimensional representation of tracer movement (Jensen 1983)

The derivations presented in the following sections are condensed versions of derivations presented in the respective papers. Only the material deemed necessary for the clear understanding of where and how the resulting concentration equations come from is given. For more detail or complete mathematics and background the reader is referred to the original reports listed in the references. 


\subsection{POROUS MEDIA DOUBLET MODEL}

The type of flow considered in this section is confined by two impermeable boundaries perpendicular to the wellbores but unconfined in the radial direction. Streamlines and equipotential lines in a plane perpendicular to the wells are shown in Figure 4.1. The basic theory for two-dimensional flow between wells was presented by Muskat (1937). The effect of diffusion and fracture flow was summarized by Klett, Tyner, and Hertel (1981) who reported equations that characterize laminar flow through a fracture for a doublet well geometry. The region can be porous, rubbled, or have fractures running perpendicular to the wells.

The formation characterization equations derived in this section are based on stream and potential functions and the principle of superposition. The reduced test data used in the analyses include volumetric flow rate, temperatures, pressure, well spacing, well diameter, and the time of first arrival of the tracer pulse $t_{F}$ at the detectors after it has traveled throughh the diverging/converging stream tubes shown in Figure 4.1.

Starting with the complex potential for a line sink and using the principle of superposition and conversion to Cartesian coordinates, the velocity potential for a combined line source and sink is

$$
\Phi=\frac{g}{4 \pi} \ln \left[\frac{(x-S)^{2}+y^{2}}{(x+S)^{2}+y^{2}}\right]
$$

where $\mathrm{S}$ is half the distance between the source and the sink. Equipotential lines are defined as constant values of $\frac{4 \pi \Phi}{q}$ or

$$
\frac{(x-S)^{2}+y^{2}}{(x+S)^{2}+y^{2}}=C_{1}
$$

Equation 4.2 can be expressed as 


$$
\left[x-\frac{1+C_{1}}{1-C_{1}} S\right]^{2}+y^{2}=\frac{4 C_{1} S^{2}}{\left(1-C_{1}\right)^{2}}
$$

which is the equation for a family of Apolonious circles with

$$
r=\frac{2 S \sqrt{C_{1}}}{1-C_{1}}
$$

and centers at

$$
x=\frac{S\left(1+C_{1}\right)}{1-C_{1}}, y=0
$$

Using superposition, the stream function is

$$
\Psi=\frac{g}{2 \pi}\left(\tan ^{-1} \frac{y}{x-S}-\tan ^{-1} \frac{y}{x+S}\right) .
$$

Streamlines are defined as constant values of $2 \pi \Psi / q$, so the streamline equation is

$$
x^{2}+\left(y+\frac{S}{C_{2}}\right)^{2}=S^{2}\left(1+\frac{1}{\left(C_{2}\right)^{2}}\right)
$$

which is a family of circles with

$$
r=S \sqrt{1+\left(C_{2}\right)^{-2}}
$$

and centers at

$$
x=0, y=\frac{S}{C_{2}} .
$$

Equations (4.3), (4.4), (4.5), (4.7), (4.8) and (4.9) define the flow paths and potentials in Figure 4.1.

The $\mathrm{x}$ component of velocity $\left(V_{x}\right)$ is the only part of the velocity vector that is needed to compute flow times between wells. $V_{x}$ can be found using

$$
V_{x}=-\frac{d \Phi}{d x}=-\frac{d \Psi}{d y}
$$

Differentiating either Eq (4.1) or (4.6), yields 


$$
V_{x}=\frac{q}{2 \pi}\left[\frac{(x+S)}{(x+S)^{2}+y^{2}}-\frac{(x-S)}{(x-S)^{2}+y^{2}}\right]
$$

Equation (4.11) gives the apparent velocity based on q. If the flow is through a porous medium. the actual velocity is obtained by dividing Eq (4.11) by the effective porosity $(\varphi)$. Void volumes in the effective porosity exclude isolated voids and stagnant regions.

Along the shortest path $(y=0)$ between wells in a porous formation, the actual velocity would be

$$
\left(V_{x}\right)_{y=0}=\frac{q}{\pi \varphi}\left(\frac{S}{S^{2}-x^{2}}\right) .
$$

The variation in velocity with $\mathbf{x}$ is caused be the divergence of streamlines.

Since the well radius a $<S$ for most applications, $V_{x}$ at $x=-(S-a)$ is almost the same as $-V_{x}$ at $x=-(S+a)$. Therefore, the flow is nearly uniform in all directions from the well walls. From Eq (4.12), the time of first arrival of a tracer in the sink well after it is introduced in the source well is

$$
t_{F}=\frac{2 \pi \varphi}{q S} \int_{0}^{S-a}\left(S^{2}-x^{2}\right) d x
$$

After integration,

$$
t_{F}=\frac{2 \pi S^{2} \varphi}{q}\left[\frac{2}{4 .}-\left(\frac{a}{S}\right)^{2}+\frac{1}{4 .}\left(\frac{a}{S}\right)^{4}\right]
$$

\subsubsection{PULSE DECAY AND DISPERSION IN A POROUS MEDIUM}

Transit times for streamlines other than along the shortest path $\left(t_{F}\right)$ are also used to characterize the formation. The relative concentration $[C(t)]$ of a tracer in the recovery well depends on the initial pulse and the streamtubes throughh the formation. A paper by Grove and Beetem (1971) contains a derivation of the relationship which expresses the transit time as a function of stream- 
line angle. The relationship is

$$
\begin{aligned}
& t(\alpha)=t_{F} \quad \alpha=0.2 \pi \\
& t(\alpha)=4 . t_{F} \frac{1-\alpha \cot \alpha}{\sin ^{2} \alpha} \quad 0<\alpha<2 \pi
\end{aligned}
$$

where $\alpha=\beta_{2}-\beta_{1}-\pi$ and $t_{F}$ is the time of first arrival for a negligible well radius. $\beta_{2}$ and $\beta_{1}$ are defined in Figure 4.2.

Hydrodynamic dispersion in porous media can significantly alter the shape of the ideal recovery well pulse. This section mathematically describes dispersion of the tracer pulse. The dispersive media is assumed to be isotropic and homogeneous in the xy plane.

An approximate solution to the convection-dispersion equation for a source-sink configuration is given in Hoopes and Harleman (1967). This solution is for dispersion parallel to the velocity vector; that is, no net flow across streamlines is allowed in this approximation. The concentration for an instantaneous injection of tracer of mass $M$ is

$$
C(\tau, \alpha)=\frac{M}{2 \rho Q \sqrt{\pi \sigma(\alpha)}} \exp \left[\frac{-(a(\alpha)-\tau)^{2}}{4 \sigma(\alpha)}\right]
$$

where

$$
\begin{aligned}
& a(\alpha)=1 \quad \alpha=0,2 \pi \\
& a(\alpha)=4 . \frac{1-\alpha \cot \alpha}{\sin ^{2} \alpha} \quad 0<\alpha<2 \pi
\end{aligned}
$$

and

$$
\begin{aligned}
& \sigma(\alpha)=\frac{4 \beta}{15} \quad \alpha=0,2 \pi \\
& \sigma(\alpha)=\beta \csc ^{4} \alpha[\alpha \sin \alpha-4 . \cos \alpha(1-\alpha \cot \alpha)] .0<\alpha<2 \pi
\end{aligned}
$$

$\beta$ is a dispersion parameter which is directly proportional to the mean grain size 
of the dispersive media and inversely proportional to the well spacing (Lorenz 1973). As $\beta$ approaches 0 , the effects of dispersion become negligible.

Equation (4.16) gives the results for any one streamline identified by angle a. To include the effects of divergence, the solution for dispersion must be integrated over the streamline angle. The full solution becomes

$$
c(\tau)=\frac{M}{2 \rho Q \sqrt{\pi}} \int_{0}^{2 \pi} \frac{\exp \left[\frac{-(\alpha(\alpha)-\tau)^{2}}{4 \sigma(\alpha)}\right]}{\sqrt{\sigma(\alpha)}} d \alpha
$$

with $a(\alpha)$ and $\sigma(\alpha)$ as defined in Eqs (4.17) and (4.18), respectively. The use of $\tau$ (time relative to $t_{F}$ ) makes Eq (4.19) applicable to all geometries. The sitedependent information is contained in $\beta$ and $t_{F}$. 


\subsection{DUAL FLOT PATH MODEA, DERIVATION}

This dual flow path model developed by Fossum (1982) utilizes the fracture flow equations developed by Horne and Rodriguez (1982) by superimposing the effect of two fractures onto a single return curve. In his report Fossum (1982) demonstrates that for laminar molecular diffusion in the direction of flow is negligible compared to the diffusion in the transverse direction. By doing this he was able to start the description of tracer movement in the fracture with the equation describing "Taylor Dispersion". Taylor dispersion is the result of transverse diffusion quickly overcoming the effects of convective dispersion. The net effect being that the tracer will move through the fracture at the mean flow velocity even though the centerline velocity is faster.

The differential equation that applies is:

$$
D \frac{\delta^{2} C}{\delta y^{2}}-u(y) \frac{\delta C}{\delta x}=\frac{\delta C}{\delta t}
$$

This assumes molecular diffusion in the direction perpendicular to flow and convection of tracer in the direction of flow at a distance $x$ from the injector. Figure 4.3 shows idealized fracture flow.

For one-dimensional flow in the $\mathbf{x}$ direction, the momentum equation for flow between parallel plates assuming a boundary is;

$$
\frac{\delta P}{\delta x}=\mu \frac{\delta^{2} u}{\delta y^{2}}
$$

Boundary conditions:

$$
\begin{aligned}
& u=0 \text { if } y=-b \\
& y=b
\end{aligned}
$$

Integrating and applying the above conditions yields:

$$
u(y)=\overline{\frac{4 . u}{2}}\left(1-\frac{y^{2}}{b^{2}}\right)
$$


$-21-$

Substituting this velocity profile into the PDE, gives:

$$
D \frac{\delta^{2} C}{\delta y^{2}}-\frac{\overline{4 . u}}{2}\left(1-\frac{y^{2}}{b^{2}}\right) \frac{\delta C}{\delta x}=\frac{\delta C}{\delta t}
$$

Initial conditions:

$$
C(x, y, 0)=0
$$

Boundary conditions:

$$
\begin{aligned}
& \frac{\delta C}{\delta y}=0 \quad \text { at } y=0 \\
& \frac{\delta C}{\delta y}=0 \quad \text { at } y=1 \\
& C(0, y, t)=C_{0} \text { at } x=1
\end{aligned}
$$

Using the dimensionless parameters:

$$
\begin{aligned}
& y_{d}=\frac{y}{b} \\
& x_{d}=\frac{x}{L}
\end{aligned}
$$

and

$$
u_{d}=\left(\frac{b^{2} u}{D L}\right)^{2}
$$

the equation are written:

$$
\frac{\delta^{2} C_{d}}{\delta y^{2}}-\frac{4 . u_{d}\left(1-y_{d}\right)^{2}}{2} \frac{\delta C_{d}}{\delta x_{d}}=\frac{\delta C_{d}}{\delta t_{d}}
$$

Initial conditions:

$$
C_{d}\left(x_{d}, y_{d}\right)=0
$$

Boundary conditions:

$$
\frac{\delta C_{d}}{\delta y_{d}}=0 \quad \text { at } y_{d}=0
$$




$$
\begin{aligned}
& \frac{\delta C_{d}}{\delta y_{d}}=0 \quad \text { at } y_{d}=1 \\
& C_{d}\left(0, y_{d}, t_{d}\right)=1 \quad \text { at } x_{d}=0
\end{aligned}
$$

To model flow in the $\mathrm{x}$ direction, consider a moving $x_{d}^{\prime}$ coordinate which moves at the average dimensionless velocity $\bar{u}_{d}$ :

$$
x_{d}^{\prime}=x_{d}-\bar{u}_{d} t_{d}
$$

The effective velocity $u_{d}^{\prime}(y)$ related to the moving plane $x_{d}^{\prime}$ at speed $u(y)$ is:

$$
\begin{aligned}
u_{d}^{\prime}(y) & =u_{d}(y)-\bar{u}_{d(y)} \\
& =\frac{{\overline{4 . u_{d}}}_{d}\left(1-y^{2}\right)}{2}-\bar{u}_{d}
\end{aligned}
$$

Thus,

$$
u_{d}^{\prime}(y)=\frac{4 . u_{d}}{2}\left(\frac{1}{4 .-} \frac{y}{b^{2}}\right)
$$

Substituting,

$$
\frac{\delta C_{d}}{\delta y_{d}^{2}}-\frac{\overline{4 . u_{d}}\left(\frac{1}{4 .}-y_{d}^{2}\right)}{2} \frac{\delta C_{d}}{\delta x_{d}^{\prime}}=0
$$

Initial conditions:

$$
C_{d}\left(x_{d}, y_{d}, 0\right)=0
$$

Boundary conditions:

$$
\begin{aligned}
& \frac{\delta C_{d}}{\delta y_{d}}=0 \quad \text { at } y_{d}=0 \\
& \frac{\delta C_{d}}{\delta y_{d}}=0 \quad \text { at } y_{d}=1
\end{aligned}
$$




$$
C\left(-u t_{d}, y_{d}\right)=1
$$

If, on average,

$$
\frac{\delta C_{d}}{\delta x_{d}^{\prime}}=\frac{\delta \bar{C}_{d}}{\delta x_{d}^{\prime}}
$$

where $\bar{C}_{d}$ is the average concentration across the fracture thickness, then $\frac{\delta C_{d}}{\delta x_{d}^{\prime}}$ is only a function of $x^{\prime}{ }_{d}$. Substituting,

$$
\frac{\delta^{2} C_{d}}{\delta y_{d}^{2}}-\frac{\overline{4 . u_{d}}}{2}\left(\frac{1}{4 .}-y_{d}^{2}\right) \frac{\delta C_{d}}{\delta x_{d}^{\prime}}=0
$$

A solution to $\mathrm{Eq}(4.45)$ satisfying the boundary conditions is:

$$
C_{d}\left(x_{d}^{\prime}, y_{d}\right)=\frac{u_{d}}{4} \frac{\delta \bar{C}}{\delta x_{d}^{\prime}}\left(y_{d}^{2}-\frac{y_{d}^{4}}{2}\right)+C_{d_{0}}
$$

Figure 4.4 shows geometry of element considered in mass transfer.

The rate of mass transfer of $C_{d}$ acriss the plane $\mathrm{AB}$ in Figure 4.3 at $x^{\prime}{ }_{d}$ is:

$$
h \int_{0}^{b} u(y) c d y=b h(\overline{u c})=q
$$

where $\mathrm{h}$ is the height of the fracture and $\mathrm{q}$ is the volumetric flow rate. Equations (4.46) and (4.47) can be expressed as:

$$
q_{d}=\int_{0}^{1} u_{d} C_{d} d y_{d}
$$

where

$$
q_{d}=\frac{q b}{C_{0} h D L}
$$

and recalling Eq (4.4.)

$$
u_{d}^{\prime}=\frac{4 . u_{d}}{2}\left(\frac{1}{4 .-} y_{d}^{2}\right)
$$

Substituting Eqg (4.50) and (4.46) into Eq (4.48) yields 


$$
q_{d}=-\frac{2 \bar{u}_{d}^{2}}{105} \frac{\delta \bar{C}_{d}}{\delta x_{d}^{\prime}}
$$

Using a material balance, one can see that the change in volumetric rate out of the system must equal the rate of accumulation $\delta \bar{C}_{d} / \delta t_{d}$. So,

$$
-\frac{\delta q_{d}}{\delta x_{d}^{\prime}}=\frac{\delta \bar{C}_{d}}{\delta t_{d}}
$$

Thus,

$$
\eta_{d} \frac{\delta^{2} C_{d}}{\delta x_{d}^{\prime 2}}=\frac{\delta \bar{C}_{d}}{\delta t_{d}}
$$

where

$$
\eta_{d}=\frac{2}{105} \bar{u}_{d}^{2}
$$

This can also be written in dimensional form giving

$$
\eta=\frac{2}{105}\left(\frac{b^{2} \bar{u}}{D L}\right)^{2}
$$

and then the differential equation becomes

$$
\eta \frac{\delta^{2} C}{\delta x^{2}}=\frac{\delta C}{\delta t}
$$

where $\eta$ is the effective longitudinal dispersion coefficient for the fracture.

As the above derivation by Horne and Rodriquez (1984. shows, the concentration $C$ is dispersed relative to a plane which moves with a mean velocity $\bar{u}$, even though the maximum velocity is at the center of the fracture (at $y=0$ ) and is equal to $4.2 \bar{u}$. Therefore, the longitudinal diffusion process follows the same law as molecular diffusion but with a dispersion coefficient $\eta$.

A solution to Eq (4.56) with a material of mass s, concentrated at a point $\mathrm{x}=$ 0 , at time $t=0$, is

$$
C(t ; \eta, L)=\frac{s x}{2 \sqrt{\pi \eta t}} e^{-\frac{(s-\pi)^{2}}{4 \eta t}}
$$


The exit concentration as a function of time is given by substituting $x=L$ into (4.57).

$$
C(t ; \eta, L)=\frac{s L}{2 \sqrt{\pi \eta t}} e^{-\frac{(L-u t)^{2}}{4 \eta t}}
$$

The above equation can be rewritten in terms of dimensionless time $(\bar{u} / L) t$ and the Peclet number $\bar{u} L / \eta$. This equation then represents the concentration of tracer as it passes the production well recording point.

Thus, the general transfer function for one flow path is

$$
C(t ;(L / \bar{u}), P e)=\frac{s}{2 \sqrt{\pi(\eta / u L)(u / L)}} e^{-\frac{(1-(\bar{L} / L) t)^{2}}{4(\eta / u L)(\pi / L) t}}
$$

and for two flow paths

$$
\begin{aligned}
C\left(t ;(L / u)_{j}, P e_{j}\right) & =\frac{s}{2 \sqrt{\pi(\eta / u L)_{1}(\bar{u} / L)_{1}}} e^{-\frac{\left(1-(\pi / L)_{1} t\right)^{2}}{4(\eta / u L)_{1}(\pi / L)_{1} t}} \\
& +\frac{s}{2 \sqrt{\pi(\eta / \bar{u} L)_{2}(\bar{u} / L)_{2}}} e^{-\frac{\left(1-(\pi / L)_{2^{t}}\right)^{2}}{4(\eta / u L)_{2}(\pi / L)_{2^{t}}}}
\end{aligned}
$$




\subsection{RETENSION MODEL DERIVATION}

Although fractures are the principle paths of groundwater flow and solute transport, Jensen (1984. showed that the matrix adjacent to the fractures plays an important part in the overall solute transport process. The process of solute diffusion from a fracture into the adjacent matrix has been studied and modeled by Grisak and Pickens (1980) and by Neretnieks (1980, 1982). This process is illustrated in Figure 4.5, which schematically depicts a constant solute source of concentration $C_{0}$ transported through a fracture. The effect of matrix diffusion is to provide solute storage, with the rate of change of storage within the matrix related to Fick's second law of diffusion. A one-dimensional form of the diffusion equation into the porous matrix is given by,

$$
\frac{\delta}{\delta y}\left(\varphi D_{a} \frac{\delta C_{p}}{\delta y}\right)=\varphi \frac{\delta C_{p}}{\delta t}
$$

where the porosity $\varphi$ and apparent diffusion coefficient $D_{a}$ are assumed to be constant throughout the matrix contacted by the fluid, so that $\mathrm{Eq}(4.61)$ can be rewritten as,

$$
D_{a} \frac{\delta^{2} C_{p}}{\delta y^{2}}=\frac{\delta C_{p}}{\delta t}
$$

The net effect of matrix diffusion is to retard the arrival of the solute at any point along the fracture. If the source of the solute is discontinued, the effect will be to flush the fracture and reverse the concentration gradient, causing solute to move from the matrix into the fracture.

A general equation describing solute transport in a saturated medium can be written in two dimensions as:

$$
\begin{array}{r}
\rho_{b} \frac{\delta S}{\delta t}+\frac{\delta(\varphi C)}{\delta t}-\frac{\delta}{\delta x}\left(\varphi D_{x x} \frac{\delta C}{\delta x}+\varphi D_{x y} \frac{\delta C}{\delta y}-q_{x} C\right)- \\
\frac{\delta}{\delta y}\left(\varphi D_{y x} \frac{\delta C}{\delta x}+\varphi D_{y y} \frac{\delta C}{\delta y}-q_{y} C\right)=0
\end{array}
$$


where.

$\rho_{b}=$ bulk density of the medium, $M / L^{3}$

$S=$ amount of solute in the sorbed phase, $M / M$

$\mathbf{x}, \mathbf{y}=$ Cartesian directions, $\mathrm{L}$

$\mathrm{D}=$ hydrodynamic dispersion coefficients in the corresponding $\mathbf{x}, \mathbf{y}-$ directions, $L^{2} / T$.

$q_{x}, q_{y}=$ Darcy velocities, $\mathrm{L} / \mathrm{T}$.

This form of the equation includes the effects of adsorption by the medium, hydrodynamic dispersion, and advection. A linear equilibrium relationship between the dissolved and sorbed phases of the solute has been assumed and is written $\mathbf{S}=\mathbf{k C}$, where $\mathbf{k}$ is referred to as the adsorption distribution coefficient. Linear adsorption assumes that once the tracer and rock are brought sufficiently close together, adsorption will be an instantaneous process.

Simplifying Eq (4.63) to model a unidirectional flow field in a fractured porous medium gives,

$$
\left(\varphi+\rho_{b} k\right) \frac{\delta C}{\delta t}-\frac{\delta}{\delta x}\left(\varphi D_{x x} \frac{\delta C}{\delta x}\right)+q_{x} \frac{\delta C}{\delta x}-\frac{\delta}{\delta y}\left(\varphi D_{y y} \frac{\delta C}{\delta y}\right)=0
$$

where $\mathrm{x}$ is the direction of flow and $\mathrm{y}$ is normal to this direction. If it is assumed that the porosity $\varphi$, adsorption distribution coefficient $k$, bulk density $\rho_{b}$, hydrodynamic dispersion coefficients $D$, and the Darcy velocity $q_{x}$ are constant in the region of interest, then $\mathrm{Eq}(4.64)$ becomes,

$$
\left(1+\frac{\rho_{b} k}{\varphi}\right) \frac{\delta C}{\delta t}-D_{x x} \frac{\delta^{2} C}{\delta x^{2}}+U_{f} \frac{\delta C}{\delta x}-D_{v y} \frac{\delta^{2} C}{\delta y^{2}}=0
$$

This equation can be simplified further by neglecting hydrodynamic dispersion in the fracture so that the second term drops out. In its place, however, a 
term describing the loss of tracer from the fluid flowing in the fracture due to diffusion into the porous matrix of the wall is included. This new term is represented by,

$$
\frac{2 D_{e}}{\delta} \frac{\delta C_{p}}{\delta y} l_{y=0}
$$

Two different diffusion coefficients have been presented up to this point, $D_{a}$ and $D_{a}$. The apparent and effective diffusion coefficients are related as follows:

$$
D_{a}=\frac{D_{e}}{K_{d} \rho_{b}}
$$

The effective diffusion coefficient $D_{\theta}$ is dependent on temperature, porosity, molecular diffusivity, and the geometry of the rock. $K_{d} \rho_{b}$ is a volumetric sorption equilibrium constant and is related to porosity $\varphi$. The solid rock density $\rho_{s}$ and the adsorption distribution coefficient $\mathbf{k}$ by the equation.

$$
K_{d} \rho_{b}=\varphi+(1-\varphi) k \rho_{s}
$$

Notice that if the solids are inert, i.e., $k=0$, the porous rock matrix still has a volumetric sorption equilibrium constant equal to its porosity $\varphi$. Rearrangement of Eq (4.67) gives,

$$
\frac{K_{d} \rho_{b}}{\varphi}=1+\frac{(1-\varphi)}{\varphi} k \rho_{s}
$$

And since $\rho_{s}(1-\varphi)=\rho_{b} . \mathrm{Eq}(4.68)$ becomes

$$
R=\frac{K_{d} \rho_{b}}{\varphi}=1+\frac{k \rho_{b}}{\varphi}
$$

where $\mathrm{R}$ is referred to as the retardation factor. Using this above relation further simplifies Eq (4.65).

The retardation factor defines the mean velocity of the moving liquid relative to the mean velocity at which the tracer itself moves through the rock. This 
factor accounts for the slowing down of a tracer moving with the fluid due to the interaction with the solid. If there is no interaction between the tracer and the solid phase, $\mathbf{k}$ becomes zero and $\mathrm{R}$ reduces to one.

The last term in $\mathrm{Eq}(4.65)$ describes a diffusive flux int or out of the matrix adjacent to the fracture. This term is also represented by Eq (4.62) which can be decoupled to form two equations describing the physical situation of onedimensional advective flow through a fracture with simultaneous tracer adsorption and diffusion into the surrounding porous matrix. The two equations describing this condition are as follows:

$$
\begin{aligned}
& R \frac{\delta C_{f}}{\delta t}-\frac{2 D_{a}}{\delta} \frac{\delta C_{p}}{\delta y} l_{y=0}+U_{f} \frac{\delta C_{f}}{\delta x}=0 \\
& D_{a} \frac{\delta^{2} C_{p}}{\delta y^{2}}=\frac{\delta C_{p}}{\delta t}
\end{aligned}
$$

where,

$C_{f}=$ concentration of tracer in the fracture fluid

$C_{p}=$ concentration of tracer in the porous matrix fluid

$D_{\alpha}=$ apparent diffusion coefficient, $L^{2} / T$

$D_{a}=$ apparent diffusion coefficient, equal to $D_{a} \rho_{b} K_{d}, L^{2} / T$

$\delta=$ fracture width, $\mathrm{L}$

$U_{f}=$ Auid velocity in the fracture, equal to $x_{0} / t_{w} \mathrm{~L} / \mathrm{T}$

$t_{w}=$ residence time of water, $T$

$x_{0}=$ fracture path length from injection well to production well, $\mathrm{L}$

The initial and boundary conditions are a finite rectangular pulse of tracer with duration $\Delta t$ introduced at the inlet of the fracture at time $t=0$, and the 
fracture and rock are originally free of tracer. These conditions can be expressed as follows:

Initial conditions,

$$
C_{p}=C_{\rho}=0 \quad t<0 \text { for all } x \text { and } y
$$

Boundary conditions,

$$
\begin{aligned}
& C_{p}=0 \quad t>0 \text { as } y \rightarrow \infty \\
& C_{f}=C_{0}=\text { initial tracer concentration in the fluid at } x=0 \text { during finite }
\end{aligned}
$$
input of tracer of duration $\Delta t$.

The solution to Eqs (4.70) and (4.71) subject to the given initial and boundary conditions is, according to Carslaw and Jaeger (1959, p.4.6),

$$
C_{f}=0 \text { for } t<t_{w} R
$$

and,

$$
C_{f} / C_{0}=f(t+\Delta t)-f(t) \text { for } t>t_{w} R
$$

where,

$$
\begin{aligned}
f(t) & =\operatorname{erfc} \frac{D_{e} t_{w}}{\delta\left[D_{a}\left(t-t_{w} R\right)\right]^{0.5}} \\
t_{w} & =\text { water residence time } \\
t_{w} R & =\text { first tracer arrival time }
\end{aligned}
$$

Since $C_{0}$ equals the total mass input over time $\Delta t$ divided by the total volume flow rate times $\Delta t, M /(Q \Delta t)$, and the input pulse duration is very small, the solution can be rewritten as follows:

$$
\begin{aligned}
C_{f} & =\frac{M}{Q \Delta t}[f(t+\Delta t)-f(t)) \\
& =\frac{M}{Q} \lim _{\Delta t \rightarrow 0}\left(\frac{f(t+\Delta t)-f(t)}{\Delta t}\right)
\end{aligned}
$$




$$
=\frac{M}{Q} \frac{\delta f}{\delta t}
$$

Because $\frac{d\{\operatorname{erfc}(x)\}}{d t}=-\frac{2}{\sqrt{\pi}} e^{-x^{2}} \frac{d x}{d t}$, we have

$$
\begin{aligned}
& c_{\rho}=
\end{aligned}
$$

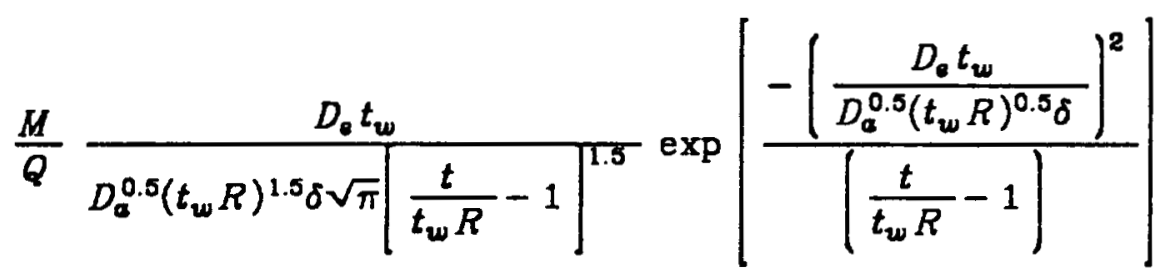

If $\alpha=\frac{D_{e}}{D_{a}^{0.5}} \frac{t_{w}}{\left(t_{w} R\right)^{0.5}}, \frac{1}{\delta}=\frac{\left(D_{e} \varphi t_{w}\right)^{0.5}}{\delta}$ and $\beta=\frac{1}{t_{w} R}$ are substituted into $\mathrm{Eq}$ (4.72), the following simplified solution is obtained:

$$
c_{f}=C(t ; \alpha, \beta)=\frac{M}{Q}\left[\frac{\alpha \beta}{\sqrt{\pi}(\beta t-1)^{1.5}} \exp \left(-\frac{\alpha^{2}}{(\beta t-1)}\right)\right]
$$

Rewriting the nonlinear parameters in terms of $\alpha_{j}$ and $E$ (a linear scaling parameter) yields,

$$
C=C_{f} \frac{Q}{M}=\frac{E \alpha_{1} \alpha_{2}}{\sqrt{\pi}\left(\alpha_{2} t-1\right)^{1.5}} \exp \left[-\frac{\alpha_{1}^{2}}{\left(\alpha_{2} t-1\right)}\right]
$$

where $\alpha_{1}=\alpha$ and $\alpha_{2}=\beta$.

The linear parameter $\mathrm{E}$ normalizes the flow fraction to one. This normalization is needed because precise information on the initial concentration injected into the fracture system connected with the producing well is not available. This does not affect the shape of the calculated tracer profle, but merely the size. 


\section{0: DESCRIPTION OF PRELIMINARY TEST}

Two tracer tests were performed in an effort to better understand the behavior of geothermal reserviors and chemical tracers. The first test, carried out in May and June of 1983, was designed to be a small scale trial test to see if the apparatus and chemicals to be used would work as planned. The second test performed in July through August was in conjunction with a flow test to measure various parameters of the geothermal reservior.

\subsection{TEST PREPARATION}

The goal of the test was to obtain tracer return data which would yield information about the reservior. In order to accomplish this a suitable system had to be found. To find a doublet system with a fairly constant high flow rate, separated by a moderate distance, that could be monitored by the apparatus limited the possible sites down to the KUHS doublet. The major problem with other doublet systems in Klamath Falls was insufficient flow rate, non-adaptable for monitoring, too far away from area of interest and/or wells were not flowed continually.

For a chemical to be useful as a geothermal tracer it must not degrade when exposed to elevated temperatures, not interact with the reservior rock or test equipment, not be toxic to the environment and be easily detectable in the sample water. Iodide in the form potassium iodide has been used successfully in Japan and elsewhere (Horne 1981). In most geothermal waters iodide has a low background concentration and is stable at high temperatures. The chemical interaction of potassium iodide with reservior rock is small and its detectability is high. The cost of potassium iodide can make a test uneconomical. Potassium iodide is a white crystalline powder which is extremely soluble in water $(127.5 \mathrm{~g}$ in $100 \mathrm{cc}$ water at $0^{\circ} \mathrm{C}$ ). For these reasons potassium iodide was chosen as one 
of the tracers to be used.

Fluorescent dyes present many positive characteristics for geothermal testing and are commonly used in groundwater hydrology. Fluorescent dyes are very detectable $(0.1-0.01 \mu \mathrm{g} / \mathrm{kg})$, have little to no background contamination and are environmentally safe (Smart and Laidlaw 1977). The small amounts and minor cost make them attractive candidates for tracer tests, but the major drawback is that they are sensitive to light and heat. When exposed to heat the fuorescence decreases, although this effect is reversible (when cooled fluorescence returns), the longer effect of exposure to light causes the molecules to decay, permanently destroying the fluorescent properties. The two dyes used for the test were rhodamine WT and fluorescein (Uranine). Rhodamine WT is a dark red liquid which comes in $20 \%$ by weight solution. The detectability limit is $0.013 \mu g / k g$ (13 ppb) (Smart and Laidlaw 1977). Fluorescein is available in powder form and known as Uranine concentrate, when added to water it takes on a characteristic green color, detectability limit $0.29 \mu \mathrm{g} / \mathrm{kg}$ (290 ppb) (Smart and Laidlaw 1977).

\subsection{SYSTEM DESCRIPTION}

The KUHS system is composed of an injector and a producer $250 \mathrm{ft}$. apart. The injection well is $247 \mathrm{ft}$ deep and cased to $120 \mathrm{ft}$., the production well is perforated for the last $25 \mathrm{ft}$ of its $250 \mathrm{ft}$ depth. The doublet system has been used since 1960 and is on the fringe of the hot well area (Figure 4.1). The system operates continually during the school year from fall to spring. The production well flows at an estimated $320 \mathrm{gpm}$ at a temperature of $72^{\circ} \mathrm{C}$. The flowing temperature is said to fall $2^{\circ} \mathrm{C}$ within 3-10 days of starting the heating system in the fall. The water reaches the schools heat exchangers at $71^{\circ} \mathrm{C}$ and exits at $67^{\circ} \mathrm{C}$. Besides the main school building the wells also heat a nearby storage shed and 
the school's pool. A schematic diagram of the system is shown in Figure 4.2.

Surrounding the KUHS doublet wells are five other wells of different design and use (Figure 4.3). The Medo-Bel Creamery has a well, formerly used as its source of hot water for cleaning and pasteurizing processes, having an approximate flow of $75 \mathrm{gpm}$. The Creamery well is 600 feet away from the KUHS injection well and is approximately 765 feet deep. Both the Eccles and Garrison wells are used for space heating. The Garrison well pumps the water from a depth of $240 \mathrm{ft}$ into the building for direct use and is controlled by a thermostat. By using a low volume pump to circulate geothermal water through the well bore, it has been possible to increase the temperature of the down hole heat exchanger. The water pumped out of the $787 \mathrm{ft}$. well is dumped into a sump. The Balsinger well, 260 feet deep, is pumped into an underground wooden channel and flows under gravity 1000 feet where it is used for space heating. Bob's laundry is the location of the Friesen well (563 ft) which is the hot water supply for the laundry. The flow rate of the five wells is not known accurately but estimates are: Creamery $75 \mathrm{gpm}$, Balsinger $30 \mathrm{gpm}$, Eccles, Friesen and Garrison are all used on and off with varying rates probably less than $20 \mathrm{gpm}$. However, during the district test the Friesen well was pumped continuosly.

The location of the five wells does not interfere with the approximation of the Klamath Union High School system being a doublet, because the cumulative flow rate in insignificant and the wells are not continually flowing.

\subsection{SAMPLING AND TEST DESCRIPTION}

Several wells in the area were sampled manually, only the production well was equipped with a sampling device. The automatic sampling device used consisted of a programmable clock connected to 16 double acting solenoid valves designed to fill fifteen 500 millilitre bottles, one every half hour (Jackson 1983). 
In order to use the sampling apparatus it was necessary to connect it to the production well. Once the sampler was connected and working all one had to do was change the bottles every seven and one half hours. Depending on the well and pump type sampling varied from turning a valve to holding the bottle under a sump inlet. In all, six wells were sampled; KUHS production well, Creamery well, Garrison well, Friesen well and the Eccles well. All the wells produced at different rates, temperatures, frequencies and were completed to different depths. Samples from the five wells in the vicinity to KUHS were sampled every hour for several days after the tracer injection began.

The injection of chemicals was done in two steps. First, one pound of rhodamine liquid and one pound of uranine concentrate were mixed with 100 gallons of reservior water taken from the Creamery well. Second, 500 pounds of potassium iodide were dissolved in 150 gallons of reservior water. These amounts were based on the environmental limits and the detectability anticipated using a porous media radial flow model. The injection of tracer took about 20 minutes each time and was injected using a rented pesticide tank sprayer to pump the tracers through a garden hose into the KUHS injection well.

\subsection{MEASUREMENT TECHNIQUE}

To measure potassium iodide a specific ion electrode is used. The detectability limit of iodide by this method is approximately $1 \mathrm{mg} / \mathrm{kg}$. Each sample measurement took approximately 10 minutes. The measurements are based on the activity of the ion in solution and the approximation that activity is equal to concentration at low ion concentrations is used.

Fluorescein and rhodamine WT are easily measured using a fluorometer. Fluorometers measure the amount of re-emitted light given off by a sample while it is being exposed to light of selected wave length. Care must be taken 
when measuring the fluorescence of a specific compound because many materials are slightly fluorescent which can cause error in measurement. When using a fluorometer materials being used should always be "zeroed", this is simply measuring them in the fluorometer and recording their value. To get absolute concentrations it is necessary to make up standard solutions, measure them and make a correlation between fluorometer readings and true concentrations. Taking measurements with a fluorometer requires only five $\mathrm{ml}$ of sample and approximately 60 seconds.

\subsection{RESULTS FROM KIAMATH UNION TRACER TEST}

Of the wells monitored, only two, the KUHS and Creamery, Showed tracer breakthrough. The data collected from both KUHS and the Creamery wells was sufficient to utilize and compare current models which was the goal of this report. The tracer return curve for the KUHS well, Figure 4.4, showed a chemical breakthrough in 2.5 hours and a peak arrival time of 6.0 hours with maximum iodide concentration of $60 \mathrm{ppm}$. The tracer concentration never returned to the background level during the duration of the test (500 hours). The three different tracers had identical return profiles. Shown in Figure 4.5 are those for fuorescein and potassium iodide. In the Creamery well the potassium iodide concentrations were significantly lower causing measurements to be scattered. This was due to the concentrations being near the limits of the ion electrode's detectability. The Creamery well had a tracer breakthrough at 26 hours tracer injection and a peak arrival time of $180-200$ hours with maximum concentration of $1.5 \mathrm{ppm}$ (Figure 4.6). After reaching maximum the tracer concentration decreased slowly never reaching background levels by the end of the test.

Of concern in the test was the possibility of recirculation of tracer as it was produced and reinjected during the length of the test. Calculations show that 
500 pounds of potassium iodide pumped into the system over the injection period is equivalent to a concentration of $9820 \mathrm{ppm}$ injected and the maximum first produced tracer concentration was $60 \mathrm{ppm}$ (Gudmundsson 1984). This shows that any reinjected tracer would not significantly affect the test results due to the two orders of magnitude reduction in concentration (limit of detectability for iodide with method used is $1 \mathrm{ppm}$ ). 


\subsection{DISCUSSION OF DISTRICT TEST}

The second tracer test was performed in conjunction with an aquifer test of the Klamath Falls resource. The primary purpose of the test was to gather information about the long term effects on the Klamath Falls reservior due to operating the District Heating System doublet.

\subsection{TEST DESCRIPTION}

The doublet system used was the Klamath Falls District Heating System. The two wells are separated by 3000 feet and have several wells between them. The production well flowed at $740 \mathrm{gpm}$ with the Museum well acting as injector. The production well, called City well \#1 (CW 1) was completed to 900 feet in January of 1980 and because of low productivity the well was perforated from 195 to 290 feet. The production well was sampled using the automatic device described earlier. Other wells in the area were sampled by hand. The tracer used for the second test was rhodamine WT ( 50 pounds, $20 \%$ by weight for a total of $10 \mathrm{lbs}$, $4.55 \mathrm{~kg}$ ). The district pumping test began on July 5, 1983 at $15: 10$. Initially the pumped water was discharged into an irrigation canal at a rate of $720 \mathrm{gpm}$ and $100^{\circ} \mathrm{C}$. Three weeks later on July 26, at $10: 11$ the water was sent to the injection well (Museum). Injection lasted for four weeks at a rate of $634 \mathrm{gpm}$ ending on August 24, at 17:35. The rhodamine WT was injected on July 27 from 10:14 to 10:19. The Museum well was drilled to 1,235 feet and completed with casing from surface to a depth of 450.5 feet. At time of completion the well was artesian, ca-

pable of flowing 188 gallons of water per minute (Benson et al. 1984)

Sampling and measurements were the same as in the preliminary test described in section 4 . 


\subsection{TEST RESULTS}

Of the wells sampled that showed tracer breakthroughs, only the Creamery well and the Friesen well were used in this report for model testing. The Creamery well was not sampled in the early part of the test and breakthrough times can only be inferred from the curve matches to be discussed later in this paper. Located 600 feet to the northwest, the same orientation of the major faults in the area, the Creamery Figure (6.17) well showed breakthrough in 1-2 days and occurence of peak concentration in 8-10 days. To the east of the City well at a distance of 1000 feet is the Friesen well, flowing at an estimated $20 \mathrm{gpm}$ and $\left(78^{\circ}\right) \mathrm{C}$, in which breakthrough occurred in 15 days with peak concentration in 40 days (Figure 6.15). Tracer breakthrough in the production well was not observed during the test.

Accurate values of concentration are not given because the correlation between fluorometer readings and absolute tracer concentrations are not available at present. Also due to the fact that The flow rates of both the Creamery and Friesen wells are not known precisely a material balance is unavailable. 


\subsection{RESULTS AND ANALYSIS}

In this section the techniques for analyzing the data and the results of the analysis are presented. The analysis is concentrated on the information the tracer profile contains and how the different models reveal that information. By looking at the curve fit in three areas 1) the breakthrough, 2) peak concentration and 3) the tail profile, the match of the flow model can be evaluated quite well. Breakthrough time and its relationship to peak concentration give information about the dispersion of tracer and both mean and tracer front velocities. The tracer front velocity is the distance between wells divided by the breakthrough time $\left(L / t_{F}\right)$. The mean tracer velocity, and thus the average velocity of the reservoir fluid is simply the distance between wells divided by the time from injection to peak arrival of tracer $\left(L / t_{p}\right)$. The slope between the breakthrough and the peak corresponds to the dispersion of the tracer while flowing between wells. The greater the slope the lesser the dispersion and vise-a-verse. The tail of the tracer profle is most critical in analyzing the flow model. The information about retention effects, recirculation, and equilibrium concentrations are all contained in the 'after peak' profile. The term retention in this case refers to adsorbtion, absorption and diffusion of tracer into the reservoir matrix or any combination.

It should be understood that the models presented will match any flow geometry that produces similar tracer return curves. The double fracture flow model cannot discriminate between a profile produced from a two fracture system and one produced from a two layered porous media system if the porous media doublet system happens to have an effective dispersion similar to a fractured flow system. The retention model matches a tracer return the same if the effects are caused by matrix diffusion instead of absorption. One must be careful not to get caught up in thinking the model is correct simply because it 
matches the data. It is also important to realize that even though the model may be incorrect, valuable information can still be obtained so that qualitative comparisons can be made between different reservoirs or areas within the same reservoir.

\section{'7.1 CURVE MATCHING}

To analyze the data gathered, two different methods were used. For the fracture flow models a curve fitting technique was used where the model was presented as an equation with a set form. The data were fitted using a least square fit and the desired parameters output of the computer program. Once a satisfactory fit was obtained, specific values of reservoir characteristics can be calculated. The more traditional method was used for fltting the porous media model to the data; a trail and error method.

\subsubsection{CURVE FTTTING METHOD}

To curve fit the Klamath Falls data a computer program written by Stanford University Department of Computer Science was used. The program is based on a paper by Golub and Pereya (1973). The program incorporates a subroutine (VARPRO) which optimizes the linear and nonlinear parameter of a curve fitting function with the form:

$$
C(t ; \varepsilon, \alpha)=\sum_{j=1}^{M} \varepsilon_{j} C_{j}\left(t ; \alpha_{i j}\right) \quad i=1, \ldots N
$$

where,

$$
\begin{aligned}
& \mathrm{M}=\text { number of proposed paths } \\
& \mathrm{t}=\text { independent variable } \\
& C_{j}=\text { observed dependent variable }
\end{aligned}
$$




$$
\varepsilon_{j}=\text { linear parameter }
$$

$\alpha_{i j}=$ nonlinear parameters

Least-squares fitting can be performed by separately optimizing the linear parameters $\varepsilon_{j}$, and the nonlinear parameters $\alpha_{i j}$ using the objective function,

$$
F\left(\varepsilon_{j}, \alpha_{j}\right)=\sum_{i=1}^{N}\left(c_{i}-c\left(t ; \varepsilon_{j}, \alpha_{j}\right)\right)^{2}
$$

by substituting the first estimates of the nonlinear parameters $\alpha_{j}$. The program iterates to determin the nonlinear parameters after which the linear parameters are calculated.

The numerical nonlinear least-squares routine utilizes a Taylor expansion of the transfer function $\mathrm{C}$ by expanding with respect to the nonlinear parameters $\alpha_{j}$. Linear least-squares is then used to determine the optimum values for the parameter increments, $\delta \alpha_{j}$. Mathematically this is shown as:

$$
C\left(t_{i} ; \alpha_{j}, \varepsilon_{j}\right)-C_{0}=\sum_{j=1}^{M}\left(\frac{\delta C_{0 j}}{\delta \alpha_{j}} \delta \alpha_{j}\right) \quad i=1,2, \ldots N
$$

the derivatives are evaluated at the starting point $C_{l}$. The residual $\mathrm{R}$ can then be expressed as:

$$
R\left(\varepsilon_{j}, \alpha_{j}\right)=\sum\left[\left(C_{i}-C_{0}\right)-\sum_{i=1}^{N} \frac{\delta C_{0}}{\delta \alpha_{j}} \delta \alpha_{j}\right]^{2}
$$

Applying least-squares then yields a set of normal equations.

A gradient expansion method is used to search for those parameters $\alpha_{j}$ that minimize the objective function $F\left(\varepsilon_{j}, \alpha_{j}\right)$. All parameters are incremented simultaneously so that the maximum variation of $F$ is attained. The gradient of $F$ determines the magnitude of the largest change, and giving it the opposite direction indicates the path of steepest descent. The objective is to change $\delta \alpha_{j}$ so that $F\left(\varepsilon_{j}, \alpha+\delta \alpha_{j}\right) \leq F\left(\varepsilon_{j}, \alpha_{j}\right)$. Both Jensen (1983) and Fossum (1982) describe the use of VARPRO in their reports listed in the references. 
Although curve matching is a useful tool in analyzing data, skepticism is a valuable resource in understanding the results of any curve fitting. Figure 6.1 points out the limits of the VARPRO subroutine. Even though a near perfect match is made, the unrealistic negative concentration of tracer from the second fracture nullifies the reliability of the program output. The non-uniqueness of the results obtained from the computer program and the possibility of it being completely inaccurate must be remembered at all times. The output is limited by the constraints of the equations and only give one possible result; that of the least-squares fit.

\subsection{POROUS MEDIA MODEI, FTTTING}

Equation (3.74) was incorporated into a computer program (listed in Appendix A) so that by varying the dispersion parameter $\beta$ a fit could be made to the return proflles of the Klamath Falls tests. By using a porous media model it is possible to see similarities and differences in the flow models and understand the applicability of the models to reservoirs known to be different from what the model is suppose to match. In a typical porous doublet system some dispersion is expected allowing for uniform radial divergence from the injection well. In the fractured system each fracture is equivalent to a single streamline in the porous system and thus has a different return profle. As the number of fractures in-

crease, becoming homogeneous on the large scale, the tracer profile tends to look like that of a porous system. Essentially a porous system is made up of an infinite number of fractures all having different lengths corresponding to the length of a radial streamline.

Using a similar derivation and different parameters similar in style to $\beta$, to describe the tracer flow it would be possible to fit a return curve by changing a variable that contains relevant unknowns to the system. Where $\beta$ contains cer- 
tain variables a different factor could contain variables relevant to a particular test. In this way it would be possible to extract information using a trial and error technique on any system.

\subsection{POROUS MEDIA MODEL ANALYSIS}

The main difference between the porous model and the fracture flow models is that the fracture flow models represent flow along only one or two of the infinite number of streamlines contained in the porous model. As more fractures are added the solution approaches that of the porous media model. Stated differently, the porous media model represents a flow model with an infinite number of fractures. Thus, the fracture models are a limited case of the porous model. In Figure 6.3 a family of profiles for the porous media model are shown demonstrating the effect that the dispersion term $\beta$ has on the return curves. As $\beta$ goes to zero the peak reaches a relative concentration of unity and the breakthrough time $t_{F}$ corresponds to the peak concentration of tracer. With a dispersion constant $(\beta)$ of 0.1 it is seen that the peak concentration varies from the value expected when using mean flow velocity and the time for first arrival of tracer is reduced. For the model used $t_{F}$ is defined as the tracer arrival time if there are no dispersion effects $(\beta=0.0)$.

Figures 6.3 and 6.4 show how well the porous media doublet flow model fits the KUHS well data. Fitting the data in all areas of the profile proved to be impossible. If the maximum concentration matched then the trailing profle was low and the curve did not encompass the early rise from breakthrough to peak. By increasing the dispersion coefficient to catch both the rise and fall of the curve caused the breakthrough time to be out of line. An example of this is seen in the graph of the Creamery well, (Figure 6.5). Figure 6.4 displays the effects of allowing the concentration to be exceedingly large, the breakthrough time is ac- 
ceptable, but the peak and tail concentrations bare no resemblance to the actual data.

By changing the parameters in the porous media model to achive the best fit possible yielded the graphs presented. Any other combinations particularly $\beta$ caused the model curve to be a worse match. Even though the district test was over larger distances and longer times Figures 6.5 and 6.6 reinforce the idea that the porous model does not adequately describe the reservoir. This is due to the fact that the porous model does not match the data adequately. The same problems are apparent for both the KUHS and the district test performed in the Klamath Falls aquifer.

In looking at the porous model it is obvious that the single layer porous model does not describe the return profiles with the largest error being in the tail region. The porous model drops off to near background levels within two peak arrival times.

\subsection{FRACTURED MEDIA FLOW MODELS}

The following two models were designed to model known fractured geothermal reservoir tracer return data. The simplest model being the single fracture flow model incorporating only the dispersion of tracer while in transit between wells. The models studied in the following section are 1) the dual flow path model and 2) the single flow path model allowing for retention effects. The dual flow path model was used to evaluate both the one and two fracture flow case. The retention model was only carried out for the single flow path case.

SINGLE FRACTURE RETENTION MODEL

Figure 6.7, showing the single fracture retention model match to the KUHS 
well data demonstrates the shortcomings of this model. At late times the model fails to show sufficient concentration of tracer and at times immediately following the peak concentration the model predicts much higher concentrations. More easily seen in Figure 6.8 is how well the peak arrival time is matched and how the actual data are lower than the model for short times after the peak. This leads one to think that the retention term is effective for short times only.

The fit of the retention model to data gathered at the Creamery well during the KUHS test shows a fair match; the breakthrough time is a little late and the slope from breakthrough to peak is steeper than the data (Figure 6.9). Following the peak the model predicts a concentration which appears to be higher than the observed values. Due to the scatter in the late time points it is difficult to critique the late time correlation.

The limited data for the district test represented in samples from the Creamery well match the retention model the best of the data sets (Figure 6.10). The only weakness being the low peak concentration. In this case it appears that the retention model accurately models the system. Remembering that the injection well and the production well (Creamery) are at an orientation such that they are aligned with the major fault directions witch might explain the correlation and apparent fast tracer breakthrough. See Table 6.3 for tracer velocities between wells.

Keeping in mind the geology of the area would lead one to expect noticeable differences in the profiles and model fits for the Laundry and Creamery well during the district test. As shown with the porous model (which nearly matched the Friesen well, Figure 6.6) the tracer return profle for the Friesen well is significantly different from that of the Creamery well for the same test. The orientation of the Friesen well in relation to the Museum well is perpendicular to to fault trend requiring flow to be through fractures perpendicular to the 
northwest-southeast trend or through the permeable lava beds (which are the porous matrix of the aquifer). If the fracture model is to fail it would most likely be for the Friesen well case, but as is seen in Figure 6.9 the model accurately predicts the breakthrough and slope of concentration to peak values. The retention model for both the Creamery and Friesen wells are low in relation to the peak concentrations. Whereas the Creamery data is matched quite well after the peak the Friesen data is correlated rather poorly, showing that the retention term has too great an effect at late times for the Friesen well case (Figures 6.7, $6.8,6.9,6.10)$. In comparison to the porous media model, the retention model fits the Friesen data much better in all respects.

\section{SINGLE AND DUAL FLOW PATH MODEL}

Figures 6.10 through 6.17 show the near perfect fits that the fracture flow path models make. Where only one flow path is needed, as in, the Creamery (KUHS test) and the Friesen well (district test) the fits are superior to both the porous media model and the retention model. Where the two flow path model matches best the single fracture flow model is lacking, the KUHS well demonstrates this the best. In Figure 6.10 it can be seen that the single flow path inadequately models the data in all catagories except breakthrough time. The peak is low and the tail only approximates the data at late time. In every case the dual flow path model matches the breakthrough times, peak concentrations and tail profle (this takes into account the cases where the double flow path model is not used, because the single flow path is a sub-case of the dual flow path model).

In the case of the Creamery well (KUHS test) and the Friesen well (district test) the dual flow path model does not give an answer. As shown in fig 6.1 the computer program converges to an answer which fits almost perfectly with the 
only drawback being that the second flow path represents negative concentrations, which is impossible. In this instance information can be drawn from the programs inability to converge 'correctly'. In analyzing the output it can be seen that the superposition of the flow paths are nearly the same showing that the data is just as well matched using a single flow path. Or if desired, two equal flow paths, each of one half concentration, which the program is not able to distinguish and is a trivial solution.

In looking at the dual flow path model it appears that the first fracture is similar in shape to a porous media model contributing mostly to the peak profile. Whereas, the second fracture defines the later points having a much larger effective dispersion. The structure of the model does not uniquely define the geometry of the system matched. In other words the solution is not difinitive. In the case of the two fracture flow model it is just as easily modeled using pipe flow with the correct dispersion constants and flow properties. Or a multi-layered porous system with each layer acting as a separate flow path having its own dispersion effects just as the fracture paths. The second flow path could also be explained as being the effect of recirculation of tracer in a isolated system. Even if the recirculation scenario is unacceptable, a qualitative difference can be observed between the data sets that do not converge using the programmed equations of the model. This allows one to separate the cases where a two flow path model cannot be matched from those that can. 


\section{B.0 DISCUSSION}

It is evident from both the KUHS and district tracer tests that the dual flow path model fits the observed data best with the retention model lacking in certain areas and the porous media model being an inadequate representation of the actual information obtained. Tables $6.1,6.2,6.3,6.4,6.5,6.6$ list data produced or calculated from the program output. The porous media model was the only one that did not match the data throughout the entire profle. If the peak concentration matched the breakthrough time was grossly in error. The porous media model also did not display the late time concentrations accurately. Even though the models are 'blindly' fitted to the data without regard to the actual system other than the underlying assumptions of the mathematics involved in the model formulation, extraction of information is possible from the programs output. Failure of the program can actually aid in the understanding of the information contained in a tracer return profle as was seen in the dual flow path model. Although the models do not provide unique solutions, they do give the researcher insight into the behavior of the tracer while in transport and at least produce numbers that can be use for qualitative if not quantitative evaluation of a reservoir or aquifer.

The dual flow path model predicts the flow of tracers quite well in the tests studied and there is no evidence to suggest that it is simply coincidence that the model works for this system. The aquifer is known to be fractured and pump tests have shown communication between wells in the area around the test sites.

There are many characteristics that none of the models take into account. The three most important factors being: 1) Convection of fluid near well bores, 2) vertical permeability and 3) regional fluid flow. It has been observed through temperature surveys of several wells that convection dominates flow around and in the well bore. This also implies vertical permeability as does the fact that 
wells which display tracer returns, such as, the KUHS and Creamery, are open to the aquifer at significantly different depths $(240 \mathrm{ft}$ vs. $765 \mathrm{ft}$ ). The present understanding of the aquifer includes the effect of a hydrostatic head caused by the upwelling geothermal water along the faults in the region. Resulting from the hydrostatic head is a regional flow in the southerly direction mixing geothermal water with cooler meteoric water. The effects of this regional flow has been considered negligible over the duration of the two tracer tests.

If vertical permeability is great enough then convection could act as a mechanism for dispersing tracer as well as cooled, reinjected water throughout the aquifer. This would account for the apparent absence of thermal breakthrough in the KUHS doublet system over the years. Although the tracer breakthrough times indicate rapid breakthrough, the low concentration (as compared to a homogeneously mixed radial system) indicate a large mixing volume. When the concentration of observed tracer is compared to that expected in an ideal doublet or radial system with comparable breakthrough times the concentrations are anonymously low:

The fact that tracer is observed in wells hundreds of feet deeper within several hours indicates that the vertical permeability is sufficient to allow vertical mixing of cooler water in a relatively short time. The evidense that the flow models provide for fracture flow gives reason to believe that vertical fractures are the major channels of flow in both the horizontal and vertical directions and that absorption, adsorbtion and/or diffusion into the rock matrix is not of major importance in the Klamath Falls system. 


\subsection{CONCLUSIONS}

1. A double flow path model provides an accurate data match for the Klamath Falls tests. Both the Klamath Union High School test and the district flow test results show very good curve fits to the no retention fracture flow model. In the cases where a dual flow path convergence was a problem for the least-square program, a single flow path match was adequate.

2. The effective tracer retention of the Klamath Falls geothermal resource appears to be negligible. The model used showed that the retention effect applied for short time only and did not change the late time tracer profile.

3. A porous media model of the system fails to match the actual data gathered. Flow between wells in the Klamath Falls area is dominated by the effects of fracture flow.

4. Analyzing a tracer return curve's profile can provide information on the reservoir/aquifer of interest and qualitatively distinguish flow behavior in varying geometries. A distinction can be made between porous and fractured systems, and characteristics of tracer flow (ie. retentions) can be identifled.

5. Fluorescent dyes are useful tracers for low temperature geothermal systems. Xanthene dyes are environmentally safe, inexpensive, able to withstand elevated temperatures and are easily detectable, making them ideal for geothermal tracer tests. 


\section{REFTERENCES}

1. Benson, S. M., et al., "Data From Pumping and Injection Test and Chemical Sampling in the Geothermal Aquifer at Klamath Falls, Oregon," Open-File Report 84-146, United States Department of the Interior Geological Survey, Menlo Park, CA., 1984.

2. Carslaw, H. S. and Jaeger, J. E., Conduction of Heat in Solids, 2nd ed., Oxford University Press, New York, 1959.

3. Fossum, M. P., Tracer Analysis in a Fractured Geothermal Reservoir: Field Results from Wairakei, New Zealand, Stanford Geothermal Program, SGP-TR-56, Stanford CA, June 1982.

4. Golub, G., and Pereya, V., "The Differentiation of Pseudo-Inverses and Nonlinear Least-Squares Problem Whose Variables Separate," Technical Report STAN-CS-72-261, Stanford University, Stanford, CA, 1972.

5. Grisak, G. E. and Pickens, J. F., "Solute Transport Through Fractured Media," Water Resources Research. Vol. 16, No. 4, 719-739, 1980.

B. Grove, D. B., Beetem, W. A., "Porosity and Dispersion Calculations for a Fractured Carbonate Aquifer Using the Two-Well Tracer Method," Water Resources Research, Vol. 7, No. 1, 128-134, Feb. 1971.

7. Gudmundsson, J. S., Johnson, S. E., Horne, R. N., Jackson, P. B., and Culver, G. G., "Doublet Tracer Testing in Klamath Falls, Oregon," Proceedings Ninth Workshop Geothermal Reservoir Engineering, SGP-TR-74 Stanford University, Stanford, CA., 1983.

8. Hoopes, J. A., and Harleman, D. R. F., Wastewater Recharge and Dispersion in Porous Media Report No. 75 Cambridge: Hydrodynamics Laboratory, MIT, June 1965

9. Hoopes, J. A., and Harleman, D. R. F., "Wastewater Recharge and Dispersion in Porous Media," Journal of the Hydraulics Division, ASCE, Vol. 93, No. HY5, 51-71, Sept. 1967.

10. Horne, R. N., "Geothermal Reinjection Experience in Japan," Journal of Petroleum Technology., 34, 495, 1982.

11. Horne, R. N., "Effects of Water Injection into Fractured Geothermal Reservoirs - A Summary of Experience . Worldwide," in Fractures in Geothermal Reservoirs, Geothermal Resources Council, Davis, CA., 1982.

12. Horne, R. N. and Rodriguez, F., "Dispersion in Tracer Flow in fractured Geothermal Systems," Geophysical Research Letters, Vol. 10 No. 10, 289292, 1983. 
13. Jackson, P. B., Method for Collection and Analysis of Sample Fluids During a Tracer Test, Petroleum Engineering Department, Stanford University, Stanford CA, 1982

14. Jensen, C.L., Matrix Diffusion and its Effects on the Modeling of Tracer Returns from the Fractured Geothermal Reservoir at Wairakei, New Zealand, Stanford Geothermal Program, SGP-TR-XX, Stanford CA, Dec. 1983.

15. Klett, R. D., Tyner, C. E., and Hertel, E. S. Jr., "Geologic Flow characterization Using Tracer Techniques," Technical Report SAND80-0454, Sandia National Laboratories Albuquerque, NM, 1981.

16. Lorenz, R. D., ed, "Radioactive Tracer Pulse Method of Evaluating Fracturing of Underground Oil Shale Formations," Bartlesville Energy Research Center. Report of Investigations 7791, 1973.

17. Muskat, M., The Flow of Homogeneous Fluids Through Porous Media, (New York: McGraw-Hill Book Co., 1937).

18. Neretnieks, 1., "Diffusion in the Rock Matrix: An Important Factor in Radionuclide Retardation?," Journal of Geophysical Research, Vol. 85 No. B8, 4379-4397, 1980.

19. Neretneiks, I., Eriksen, T. and Tahtinen, P.. "Tracer Movement in a Single Fissure in Granitic Rock: Some Experimental Results and Their Interpretation," Water Resources Research, Vol. 18, No. 4, 849-858, 1982.

20. Sammel, E. A., "Hydrogeologic Appraisal of the Klamath Falls Geothermal Area, Oregon," Geohydrology of Geothermal Systems, Geological Survey Professional Paper 1044-G, United States Government Printing Office, 1980.

21. Smart. P. L., and Laidlaw, I. M. S., "An Evaluation of some Fluorescent Dyes for Water Tracing," Water Resources Research, Feb. 1977.

22. Tester, J. N., Bivens, R. L. and Potter, R. M., "Interwell Tracer Analysis of a Hydraulically Fractured Granitic Geothermal Reservoir," Society of Petroleum Engineers Journal, Vol. 22, 537-545, 1982. 


\section{NOMENCLATURE}

Symbol

\begin{tabular}{|c|c|}
\hline a & radius of well \\
\hline$a(a)$ & relative transit time as a function of $\alpha$ \\
\hline$\alpha$ & streamline geometry (see Figure 3.2) \\
\hline $\mathbf{b}$ & $1 / 2$ fracture width \\
\hline$b_{d}$ & dimensionless time (fracture model) \\
\hline$\beta$ & dispersion constant (for porous media model) \\
\hline$\alpha, \beta$ & nonlinear parameters (retention model) \\
\hline$C_{\rho}$ & concentration of tracer in fracture \\
\hline$C_{0}$ & initial concentration (fracture model) \\
\hline$C_{0}$ & relative concentration constant for pulse spreading \\
\hline$c_{p}$ & concentration of tracer in porous matrix \\
\hline$C(t)$ & relative concentration of tracer in discharge well \\
\hline $\bar{C}_{d}$ & average concentration across fracture \\
\hline D & hydrodynamic dispersion coefficient \\
\hline$D_{a}$ & apparent diffusion coefficient \\
\hline$D_{6}$ & effective diffusion coefficient \\
\hline$\delta$ & fracture width (retention model) \\
\hline $\mathbf{E}$ & linear scaling factor \\
\hline$\varepsilon$ & fraction of flow \\
\hline$\eta$ & effective longitudinal dispersion coefficient \\
\hline $\mathbf{F}$ & objective function \\
\hline h & thickness of fracture (porous media model) \\
\hline $\mathbf{k}$ & adsorption distribution coefficient \\
\hline
\end{tabular}

Definition 


\section{NOMENCLATURE}

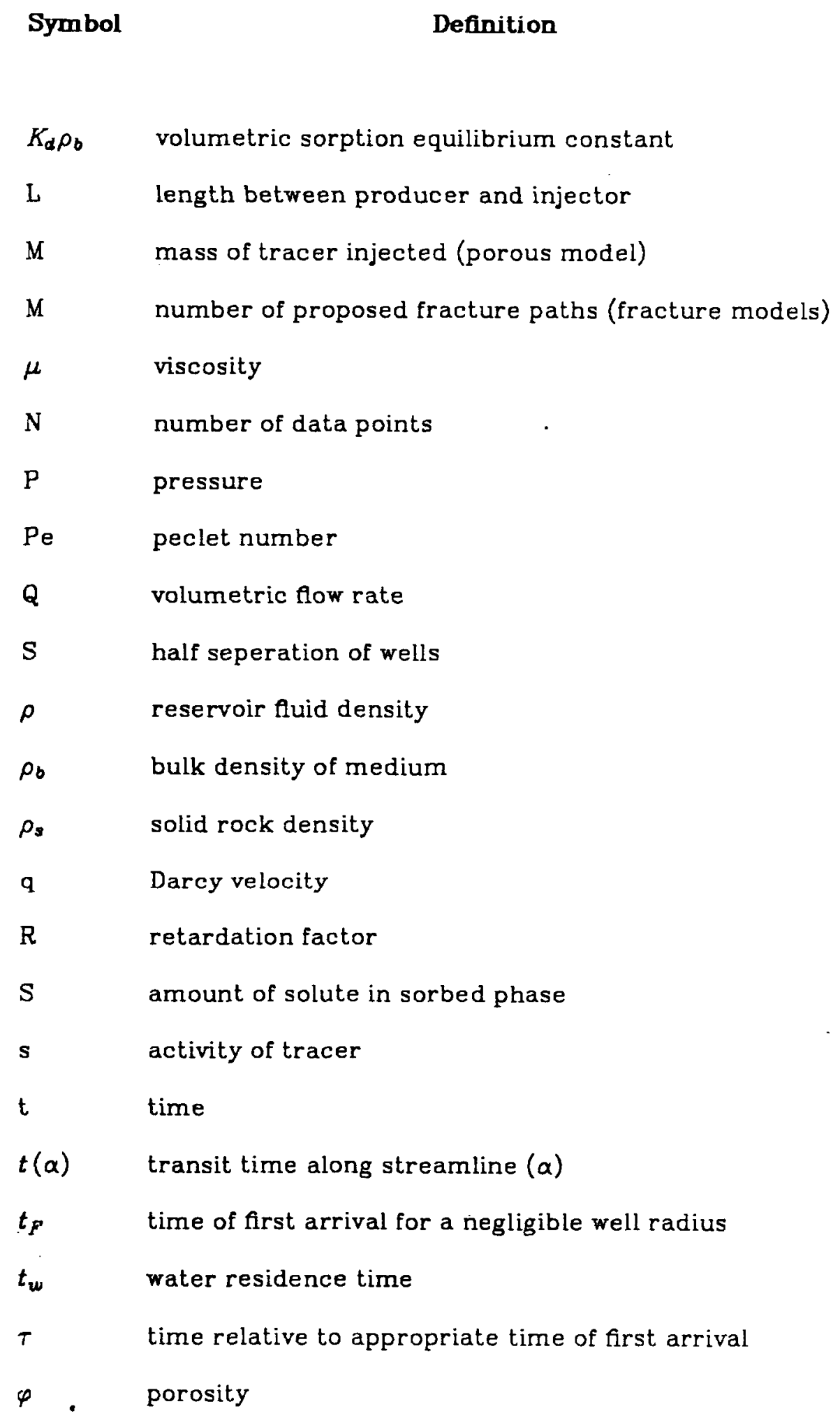




\section{NOMFNCLATURE}

Symbol

Definition

$\begin{array}{ll}U_{f} & \text { fluid velocity in fracture } \\ V_{x} & \text { velocity in } \mathrm{x} \text { direction } \\ V_{y} & \text { velocity in y direction } \\ x_{d} & \text { dimensionless distance } \\ x_{0} & \text { fracutre pathlength from injection to production well } \\ \mathbf{x}_{1} \mathrm{y} & \text { Catesian directions } \\ y_{d} & \text { dimensionless fracture width } \\ \Phi & \text { velocity potentisl } \\ \Psi & \text { stream function }\end{array}$




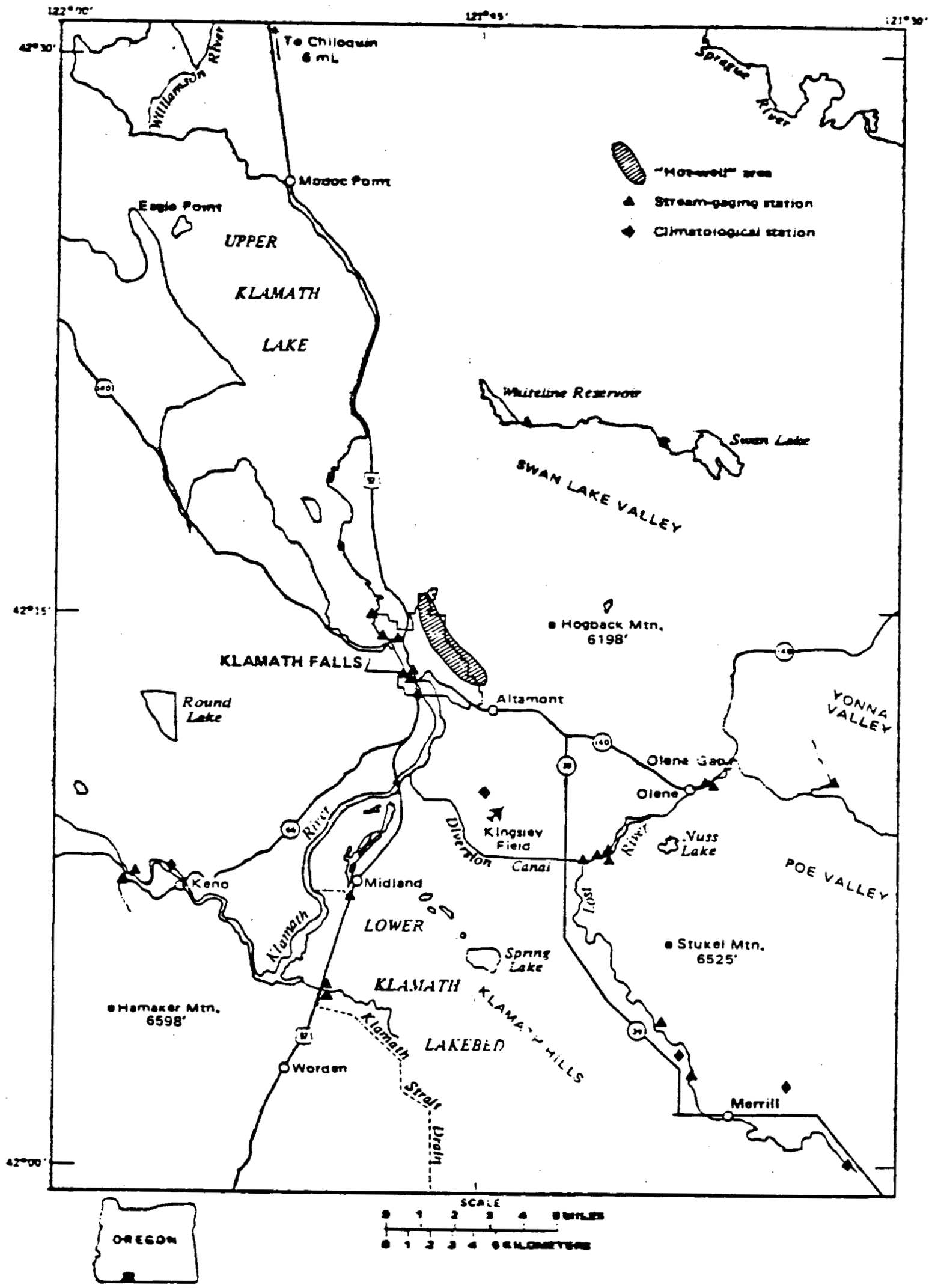

Figure 2.1:

Location of Klamath Falls 


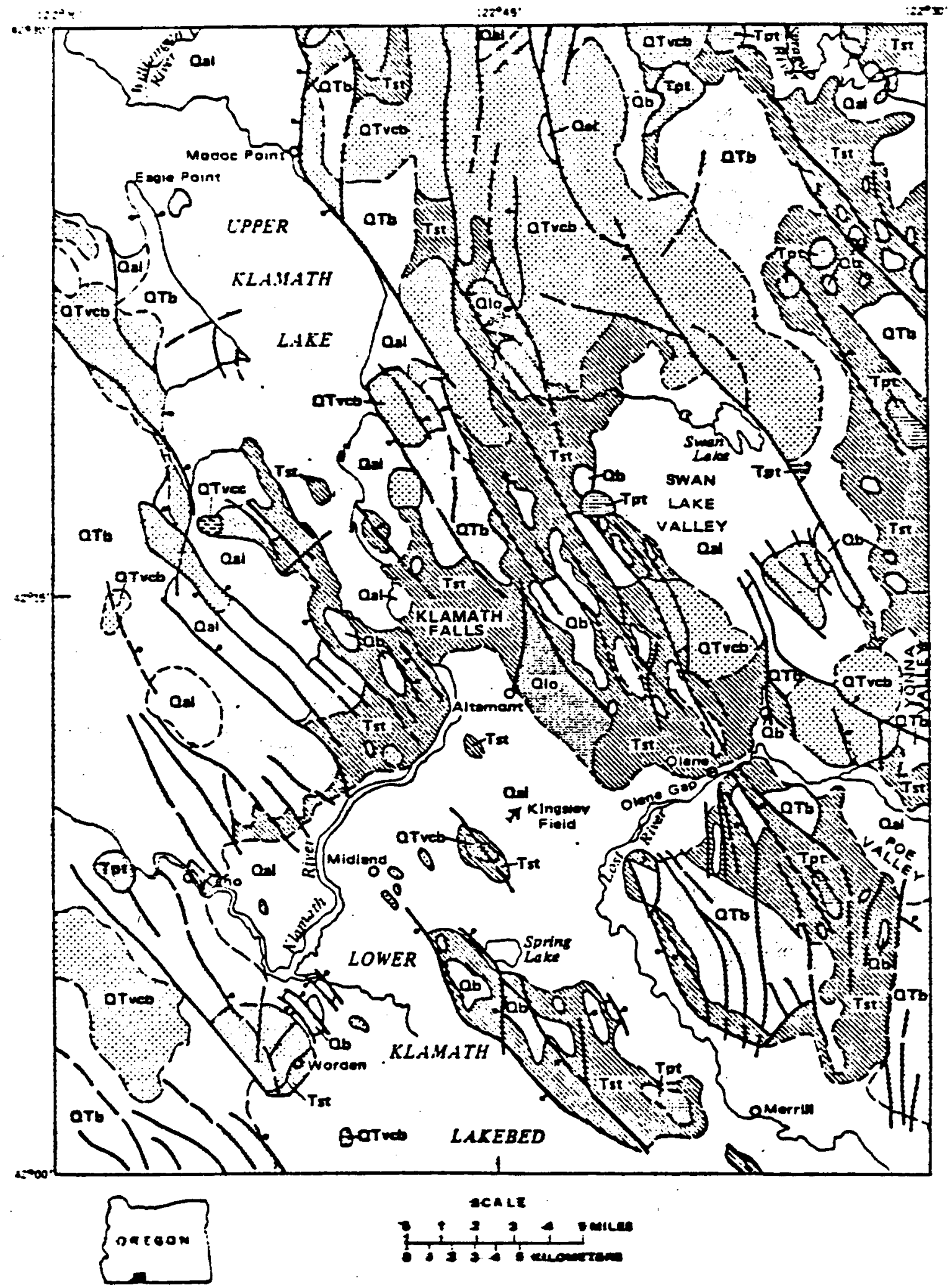

Figure 2.2:

Areal geology of Klamath Falls area 


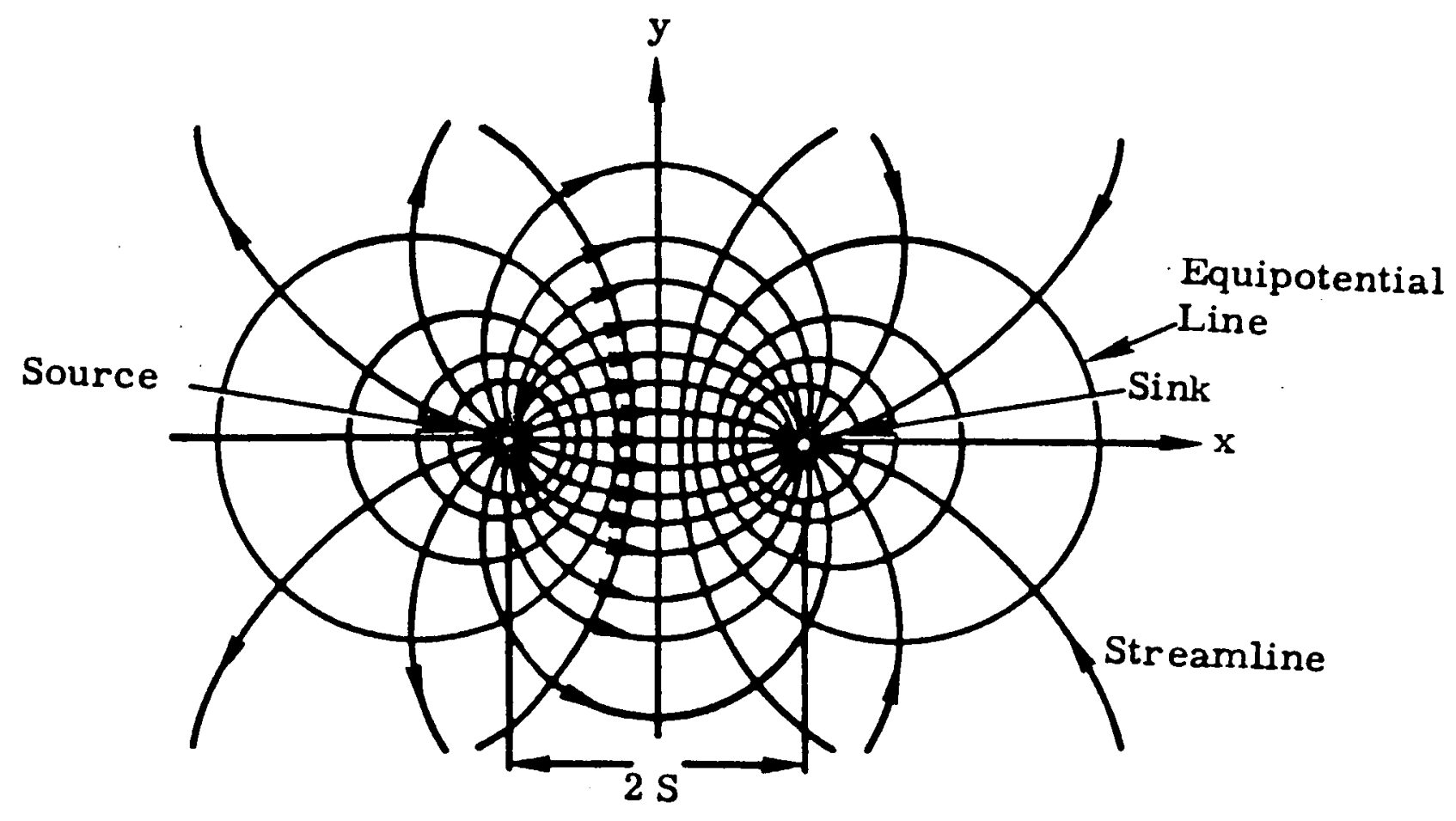

Figure 3.1:

Equipotential and Streamlines for Flow between wells 


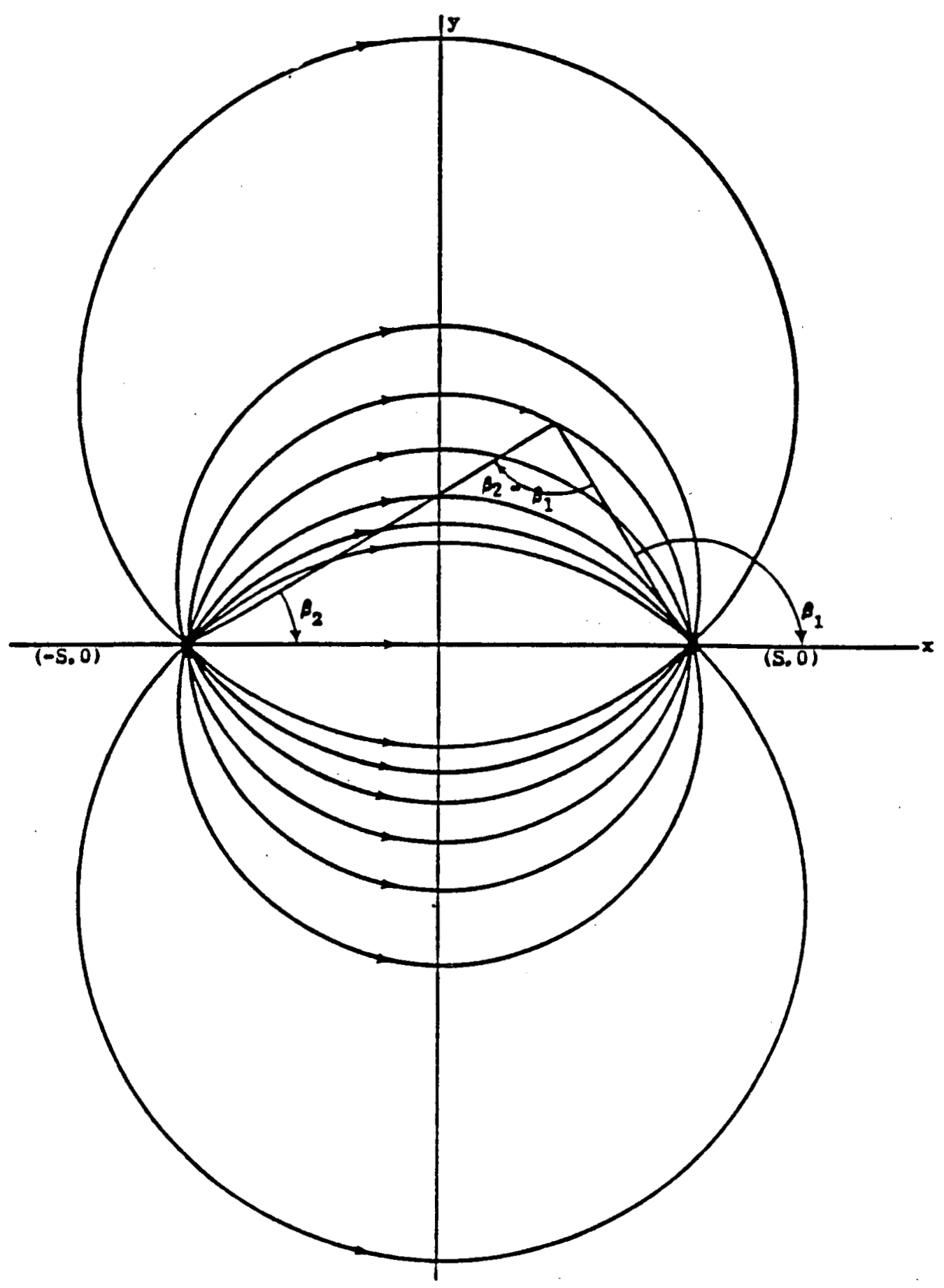

Figure 3.2:

Streamline Layout and Definition of Streamline Angle $\alpha$ for and Infinite Line Source and Sink $\left(\alpha=\beta_{2}-\beta_{1}-\pi\right)$ 


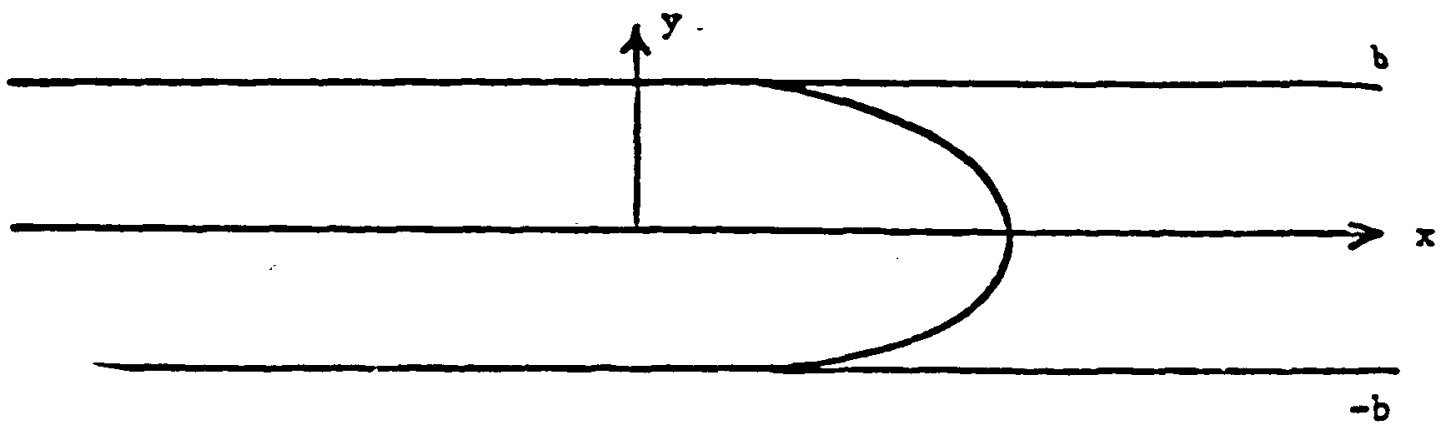

Figure 3.3:

Fracture flow geometry 

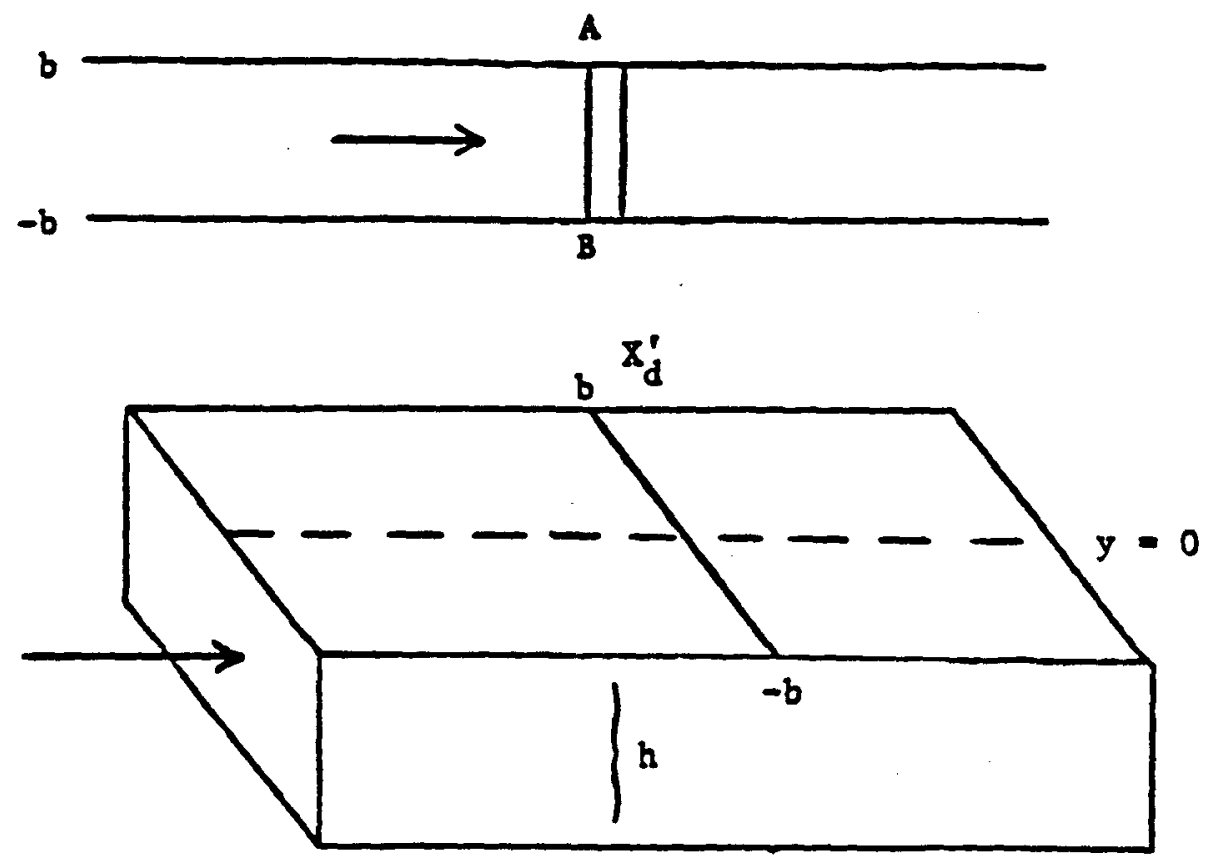

Figure 3.4:

Fracture geometry 


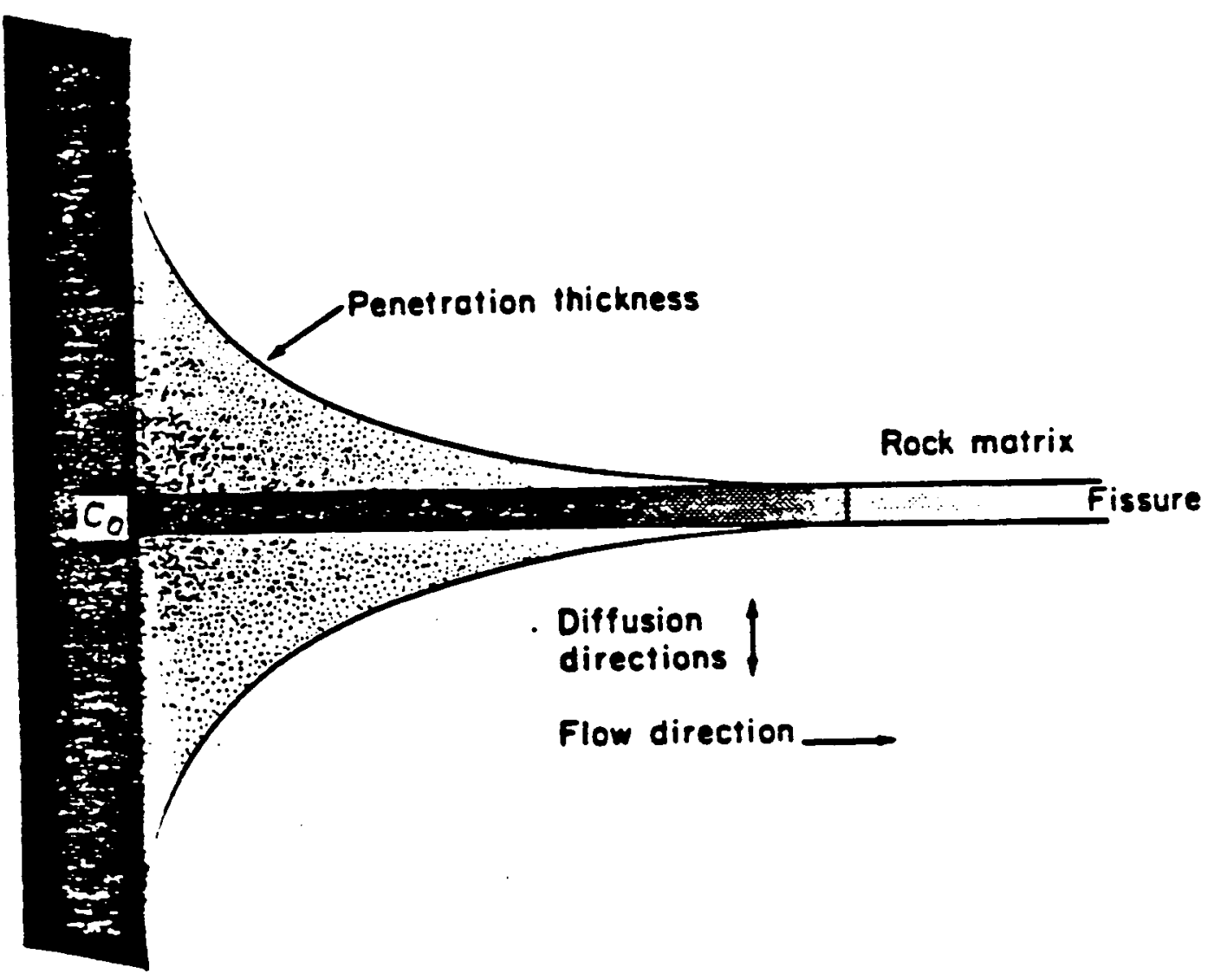

Figure 3.5:

Fissure flow and sorption by diffusion into the rock matrix 


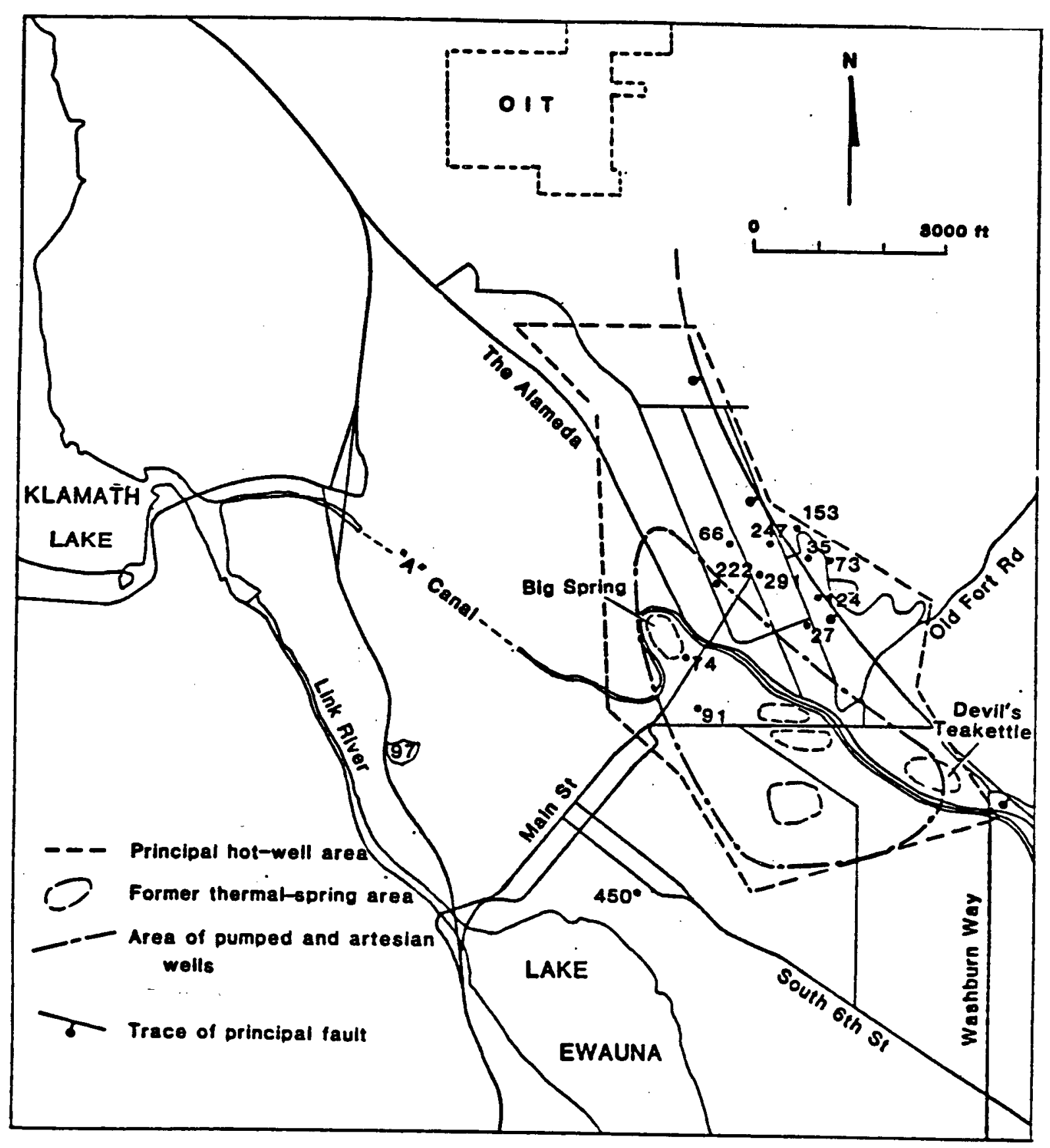

Figure 4.1:

Hot well area of Klamath Falls 


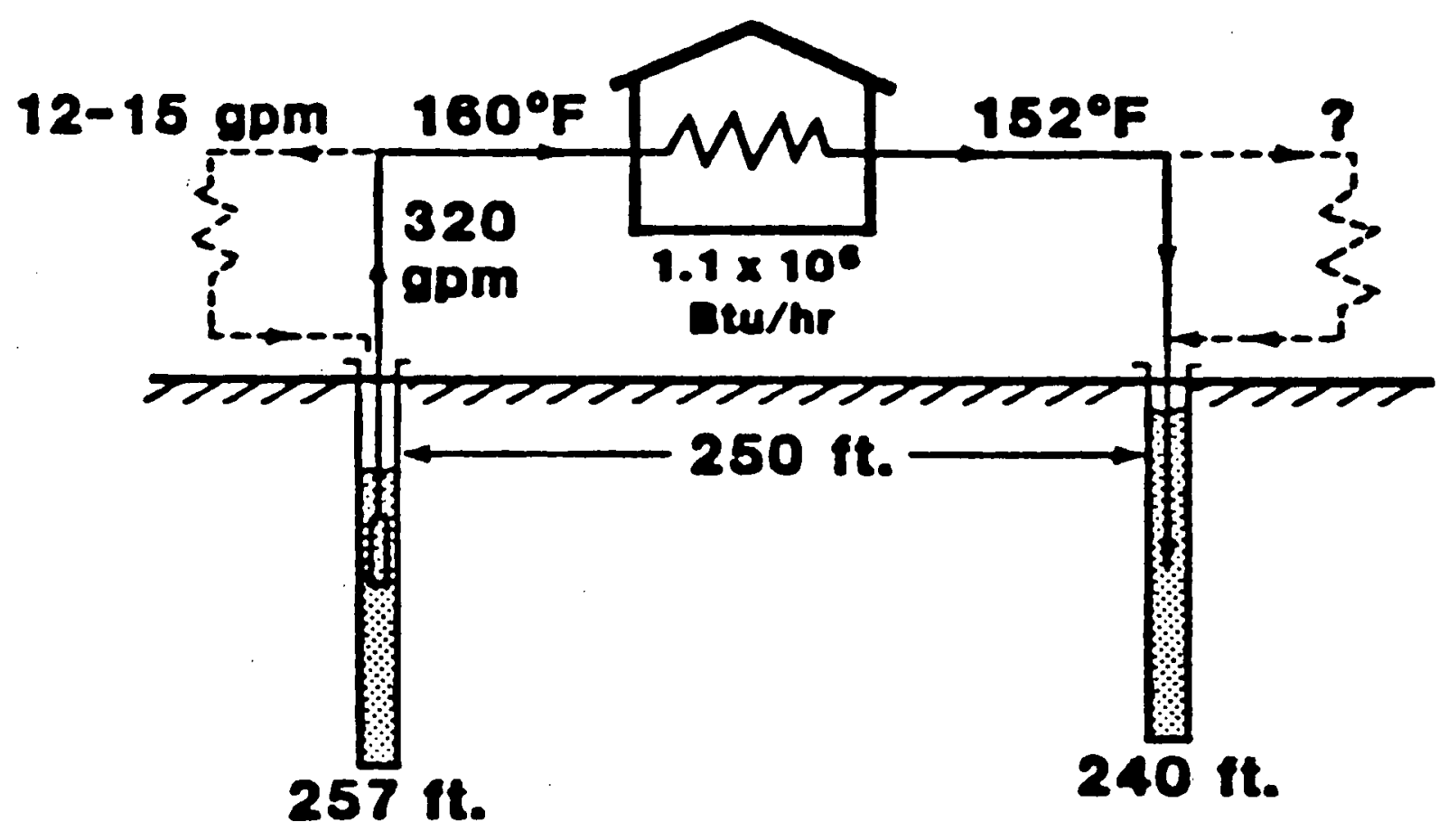




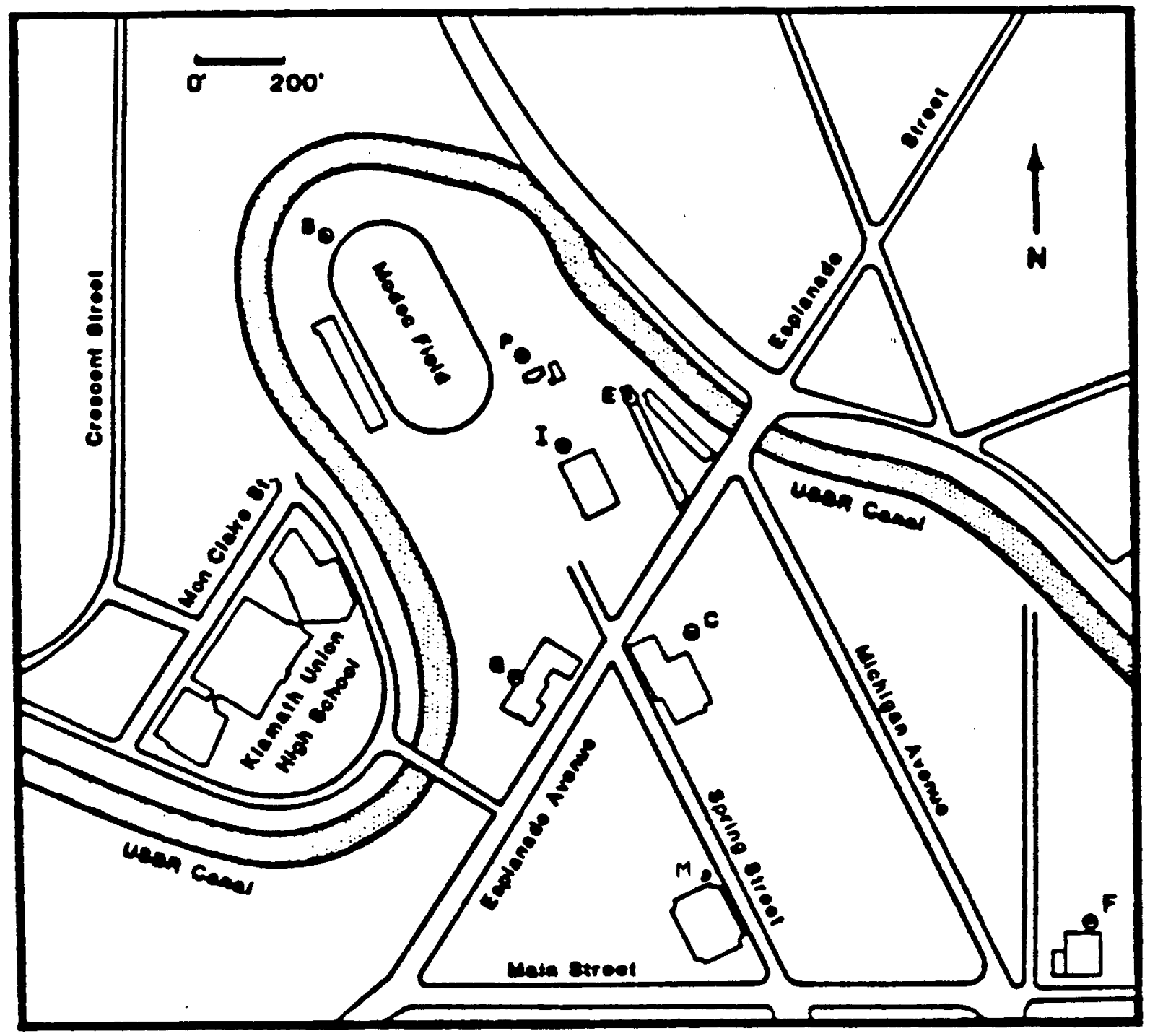

Figure 4.3:

Location of wells for KUHS tracer test

I) injection well, P) production well, C) creamery well,

E) eccles well, G) garrison well, F) friesen well 


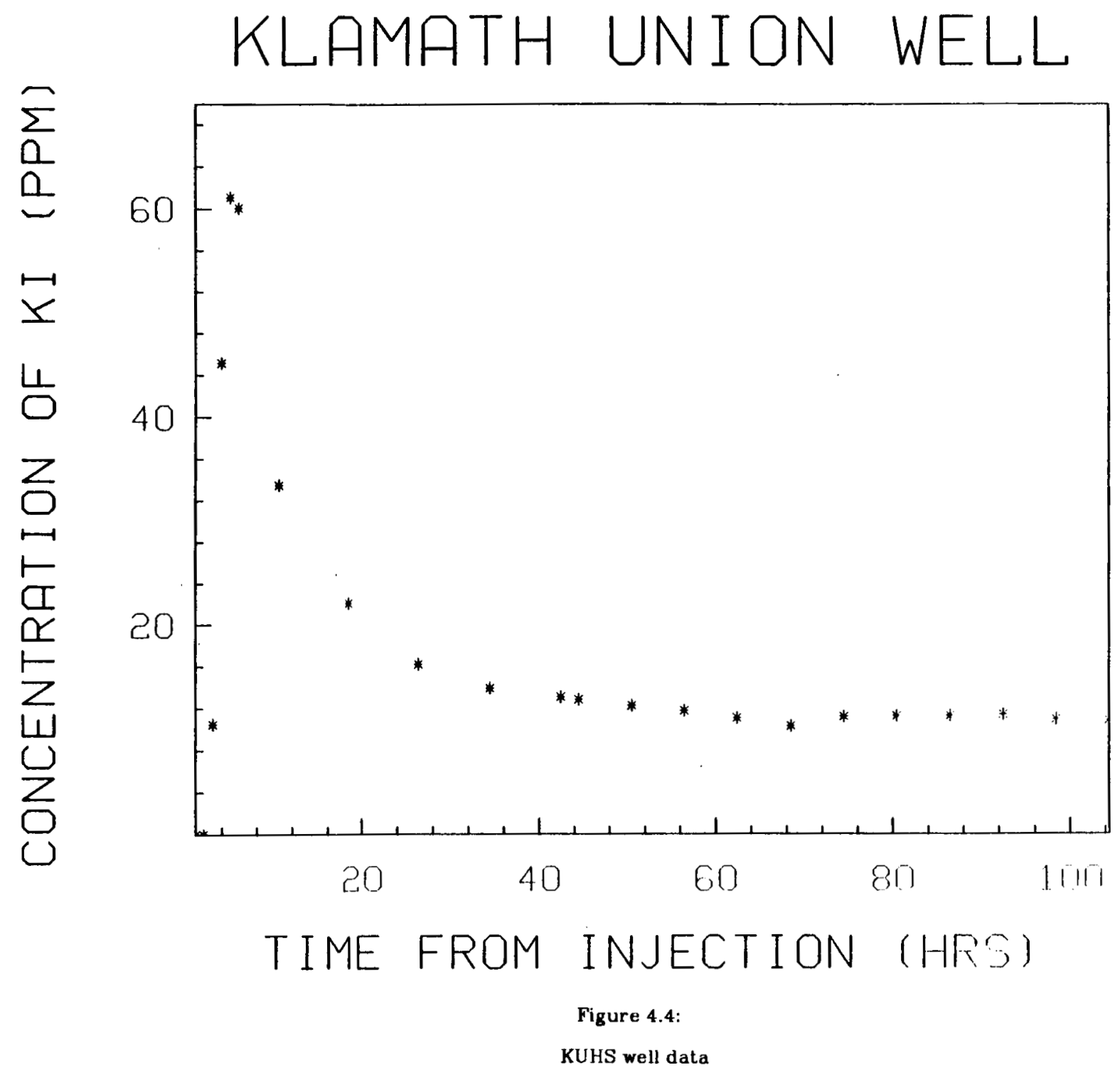




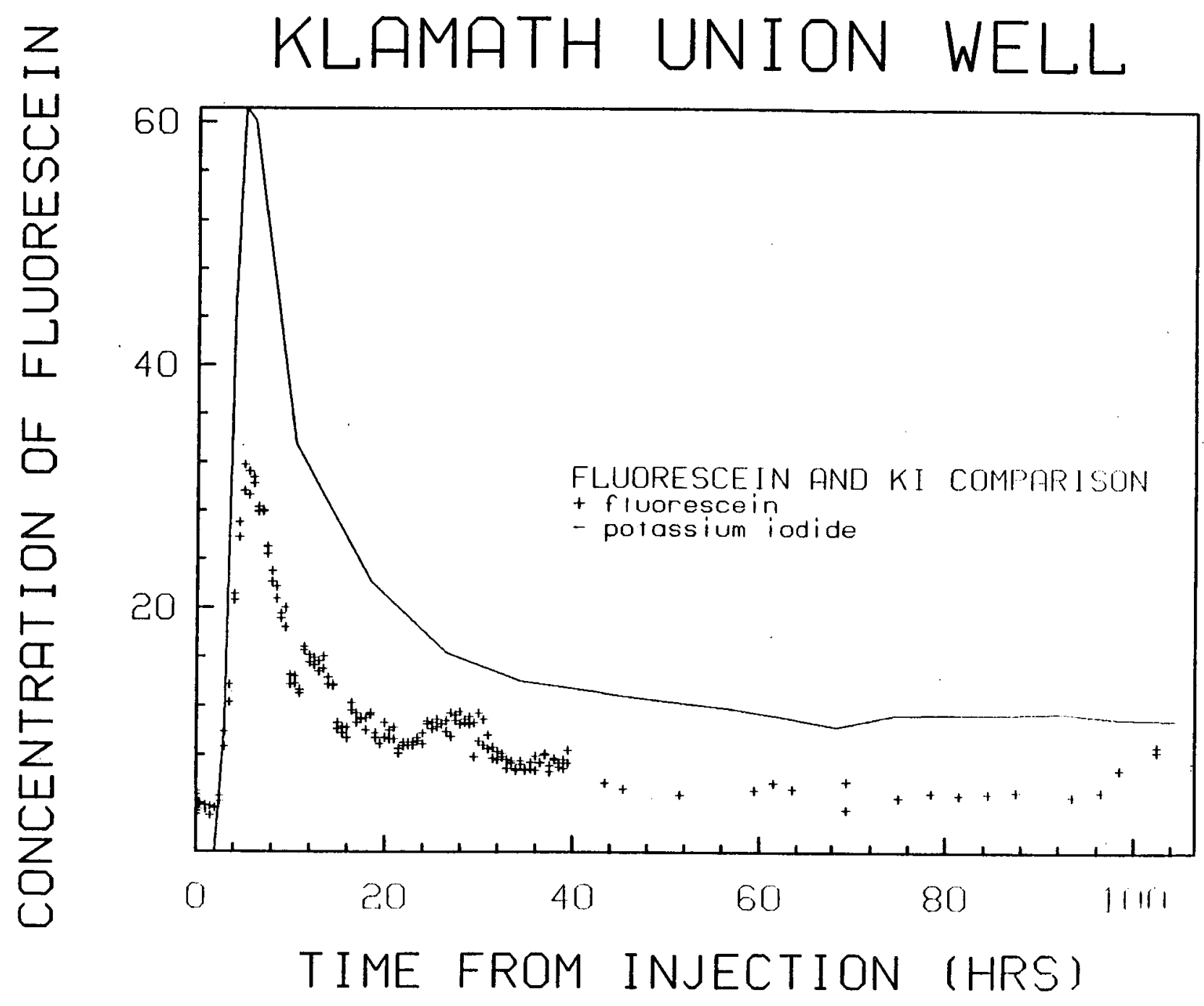




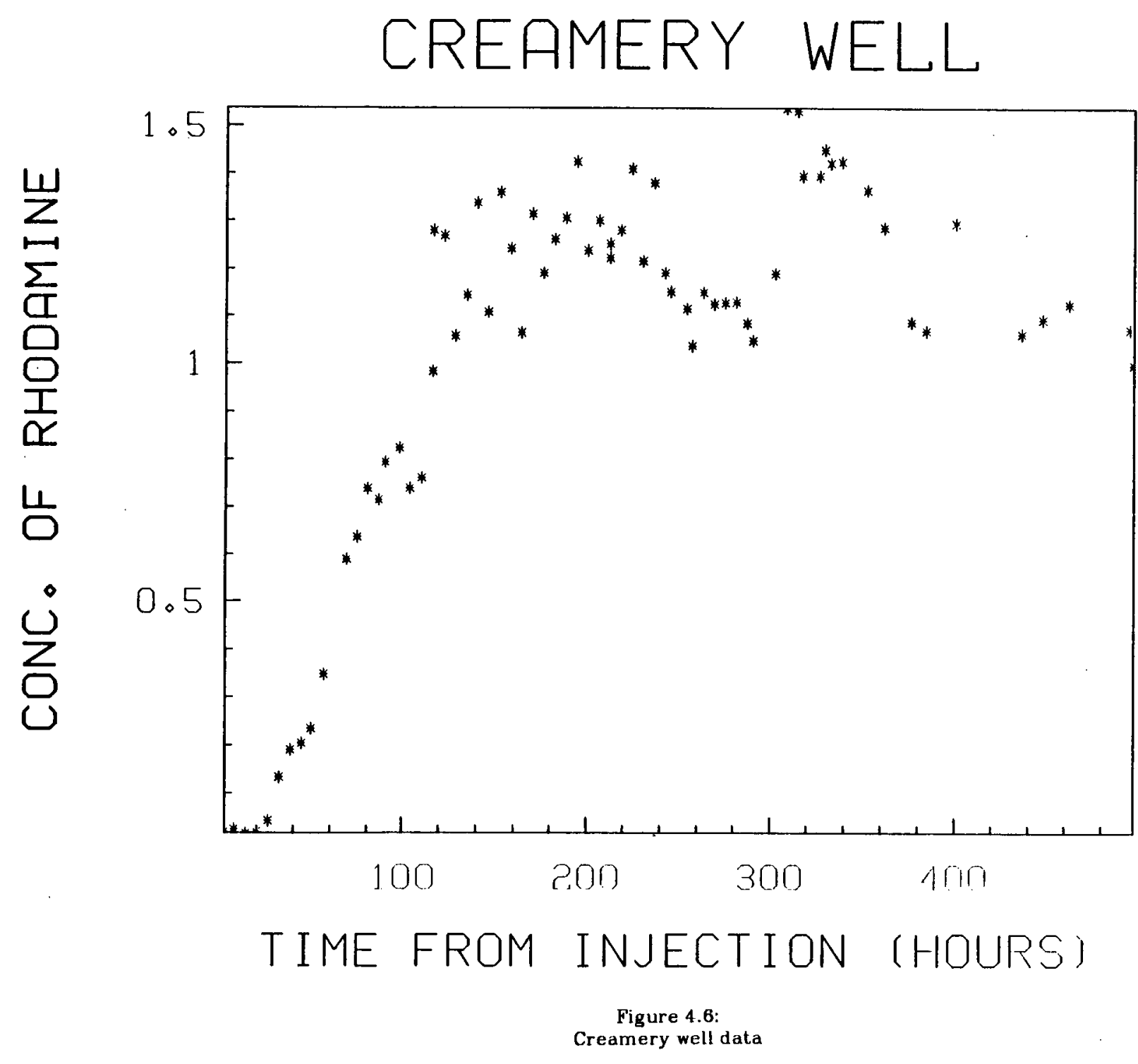




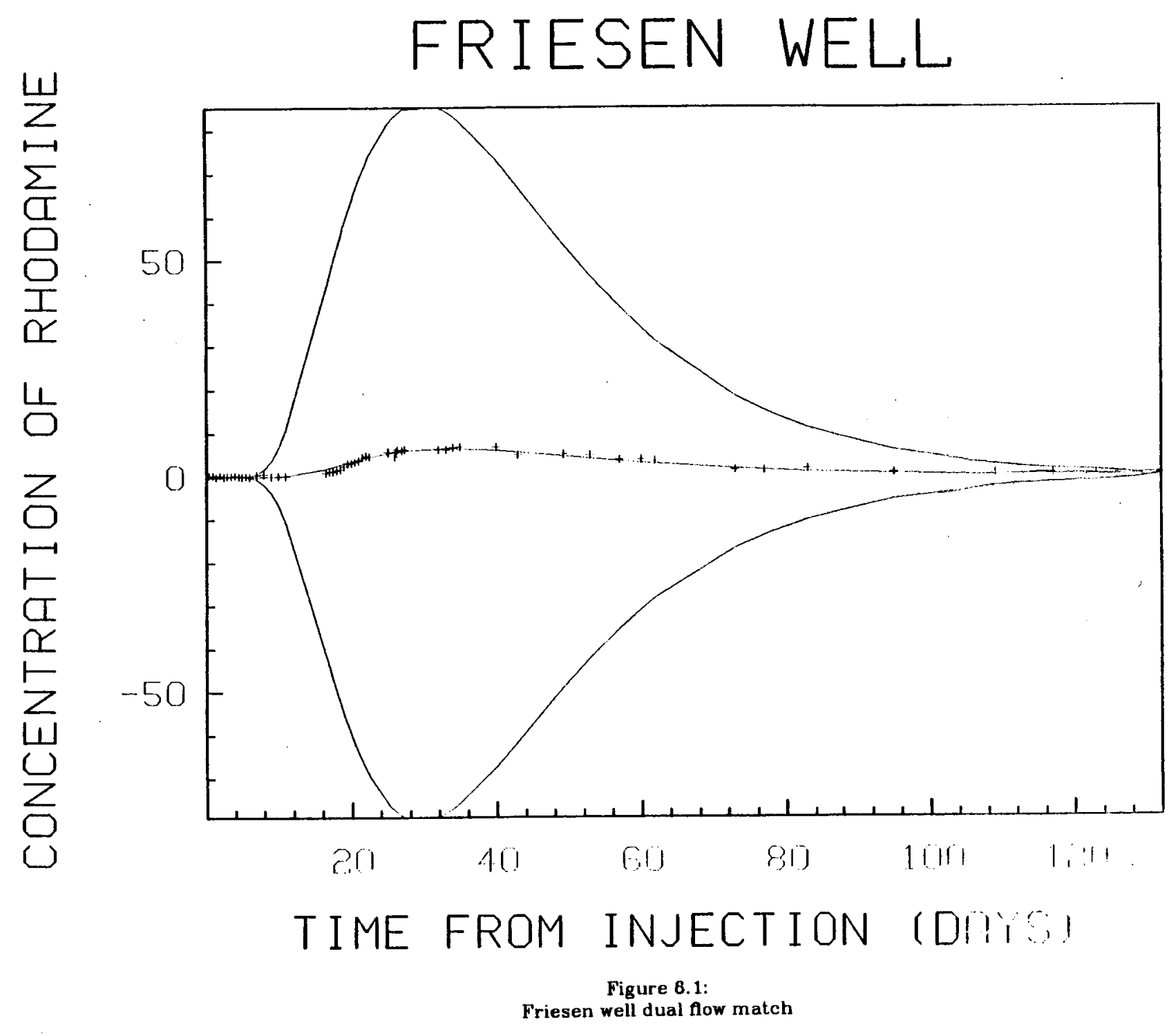




\section{POROUS MEDIA MODEL}

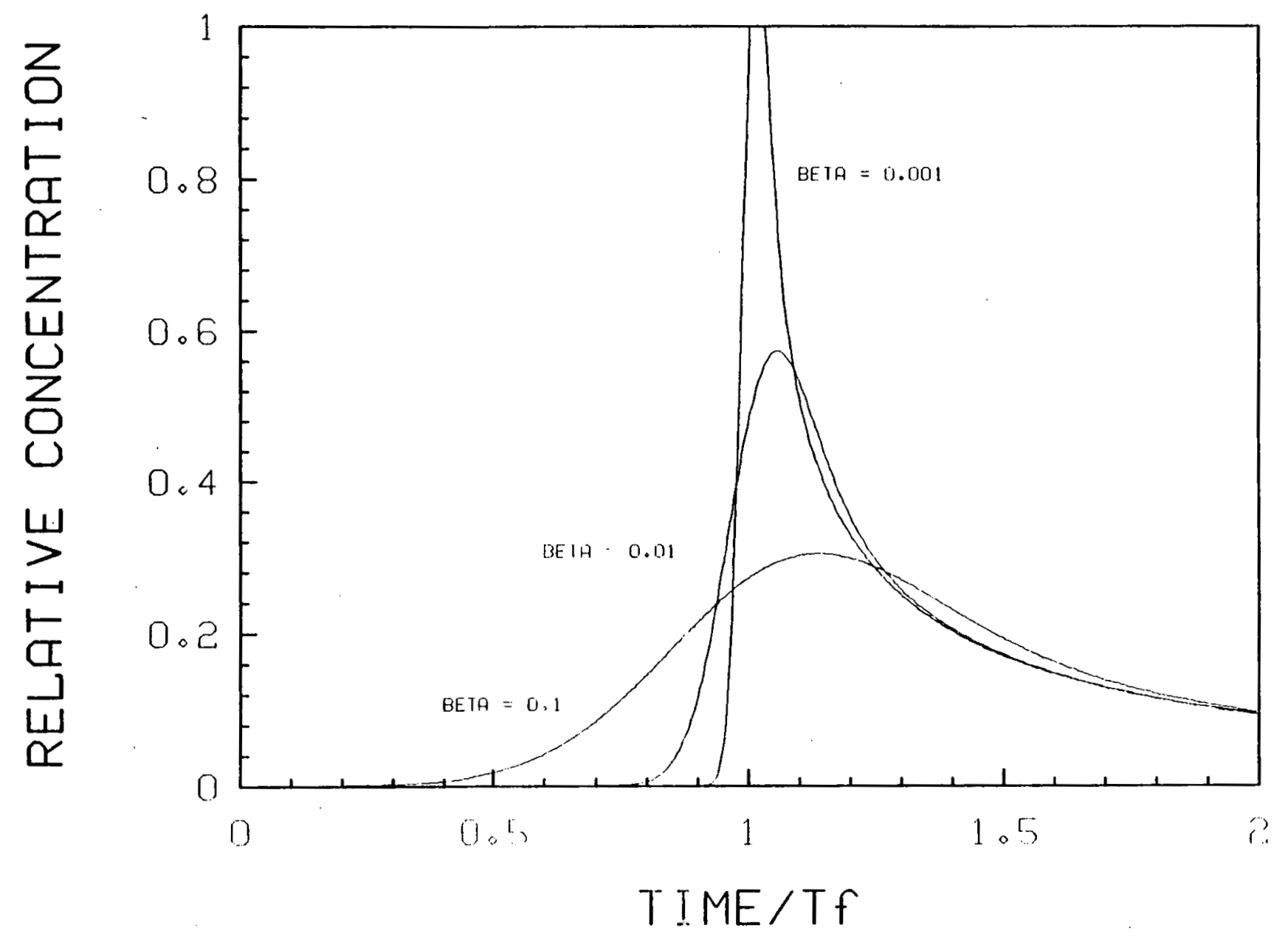




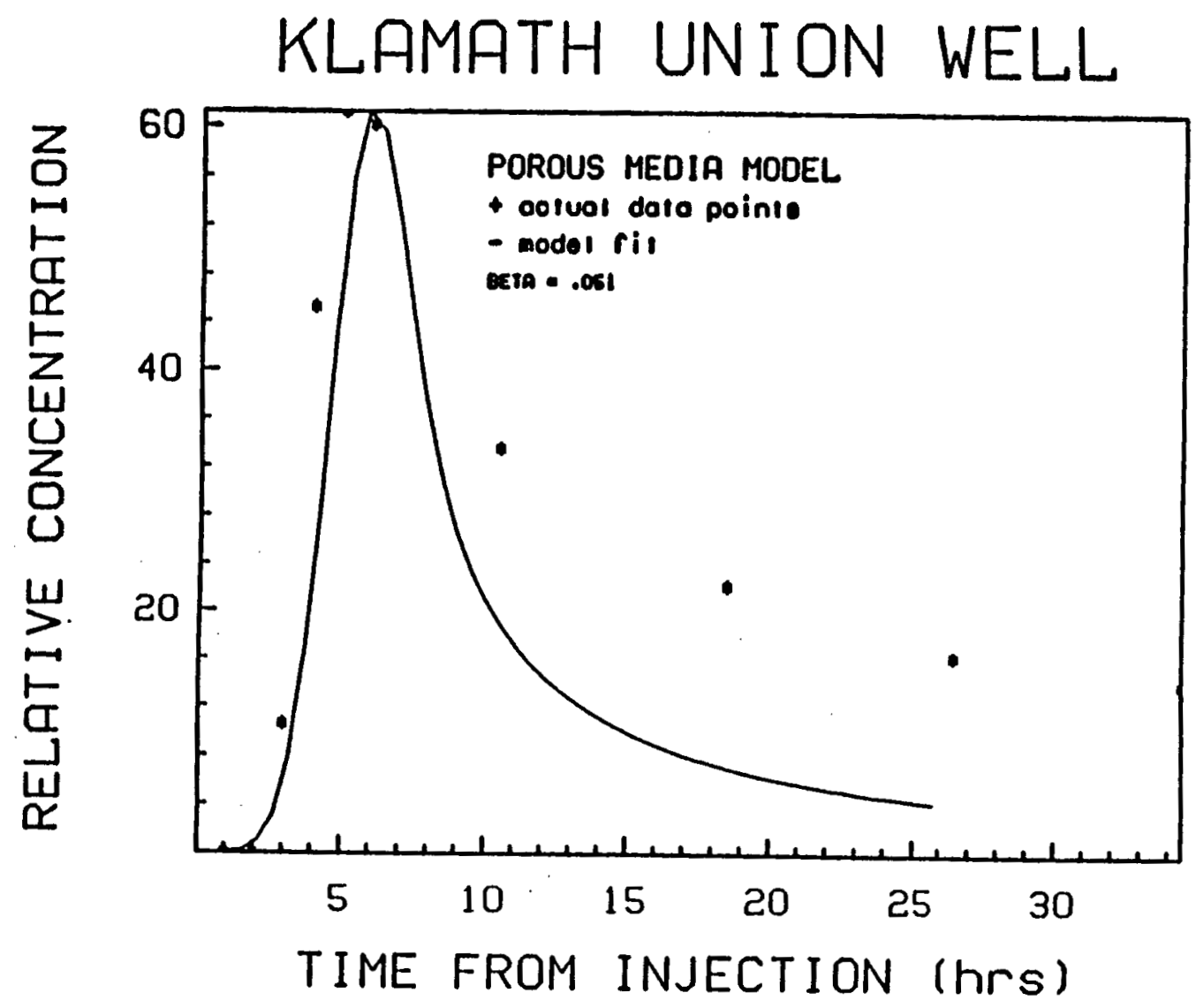

KUHS porous model match 


\section{KLAMATH UNION WELL}

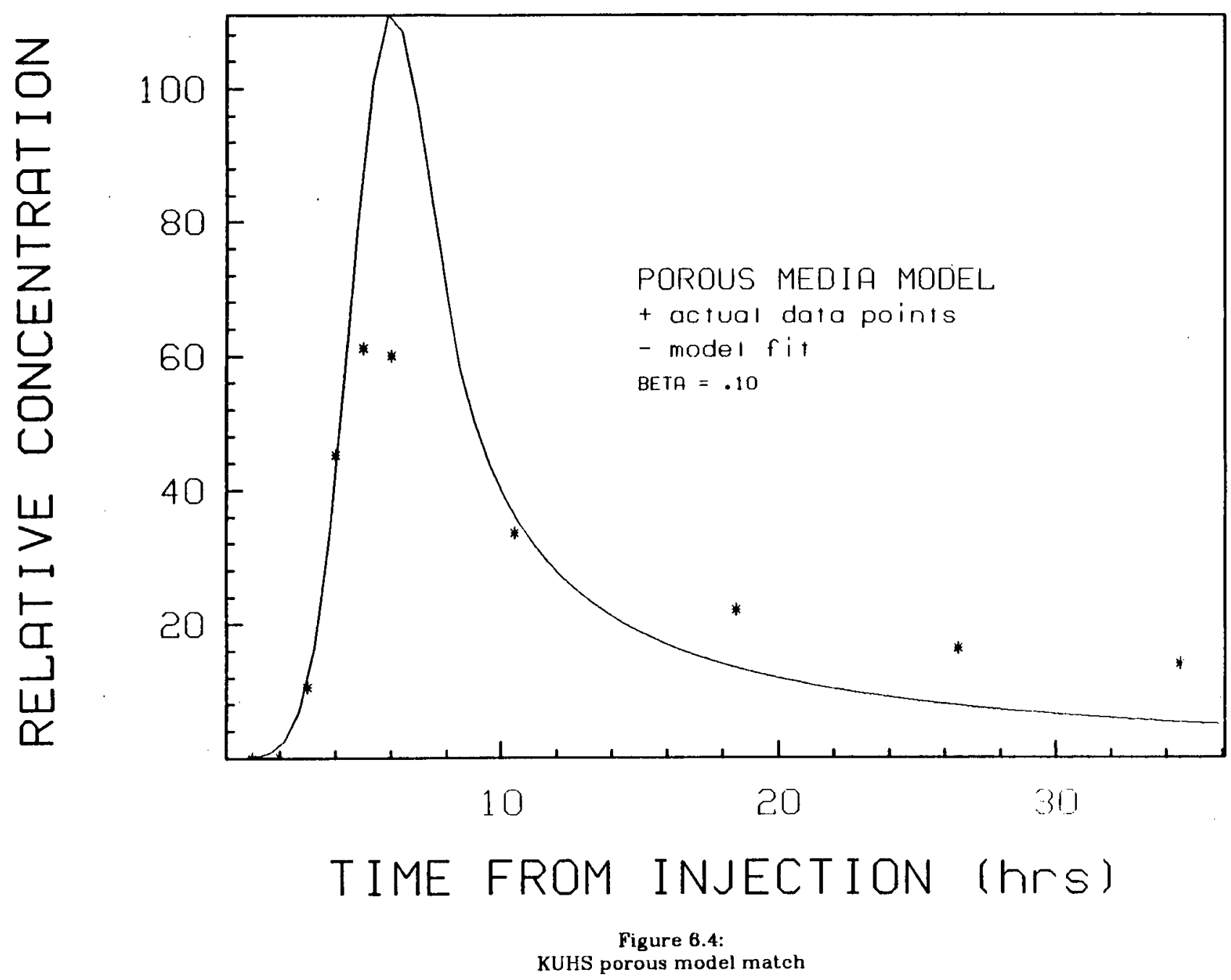




\section{CREAMERY WELL}

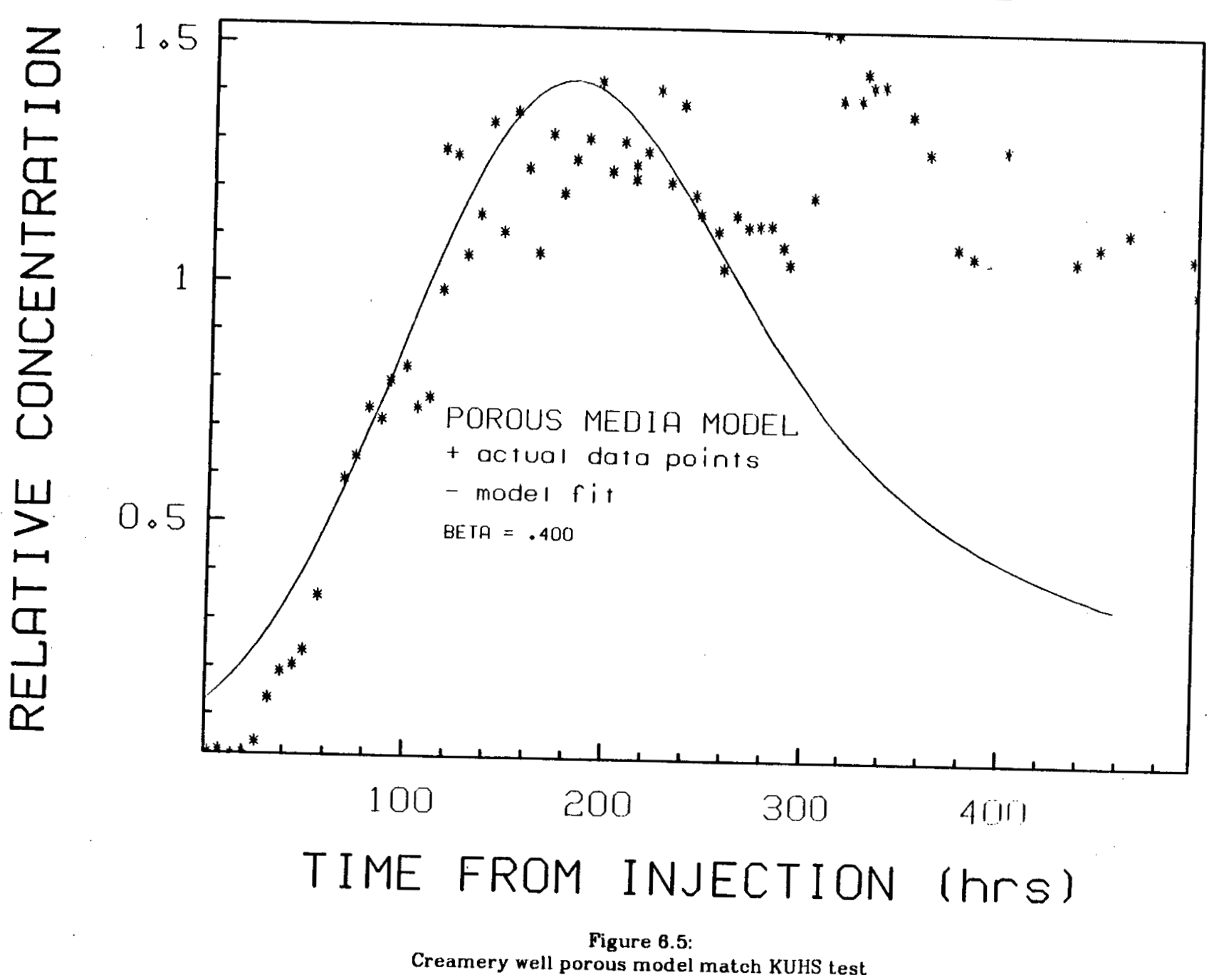




\section{FRIESEN WELL}

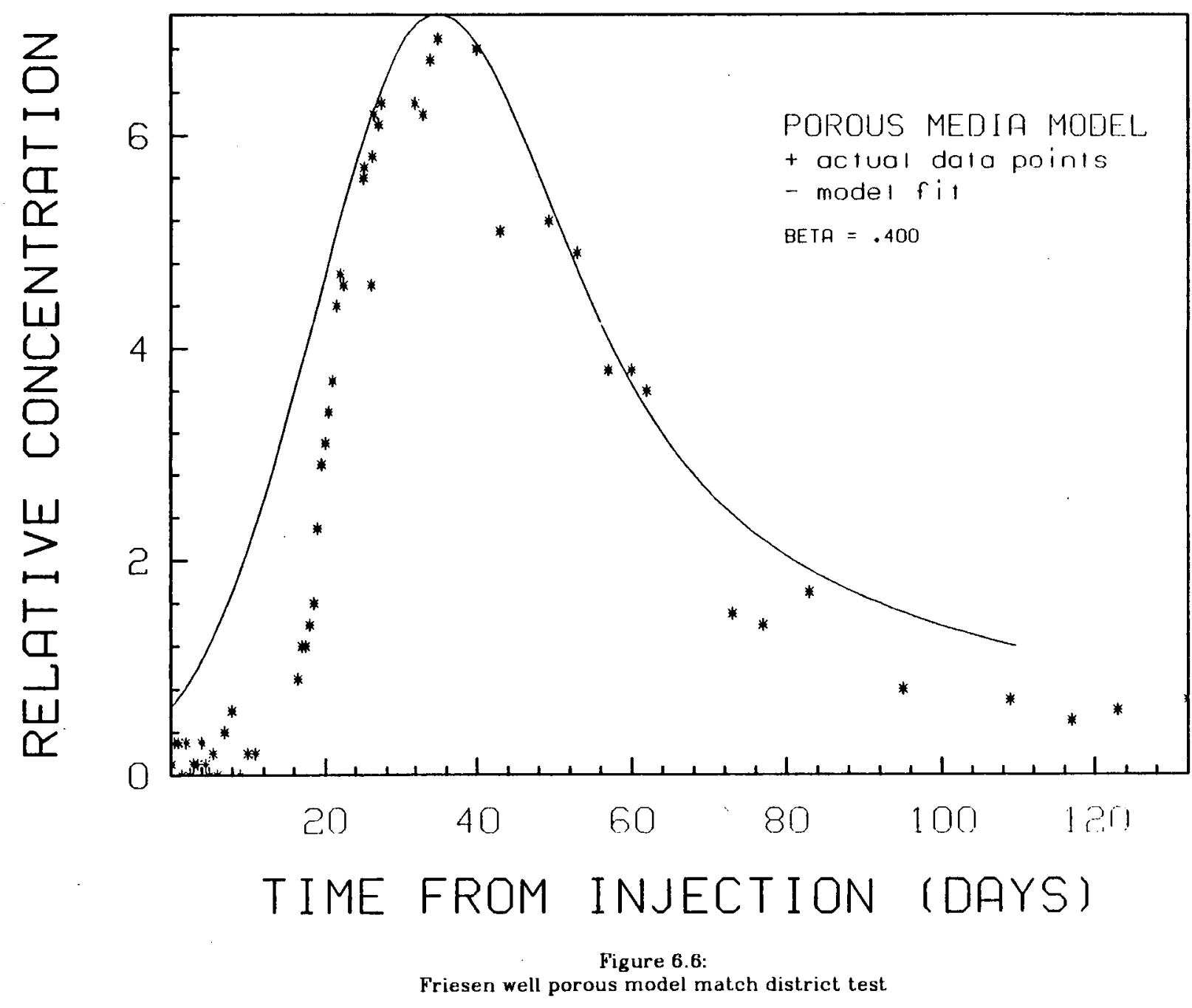




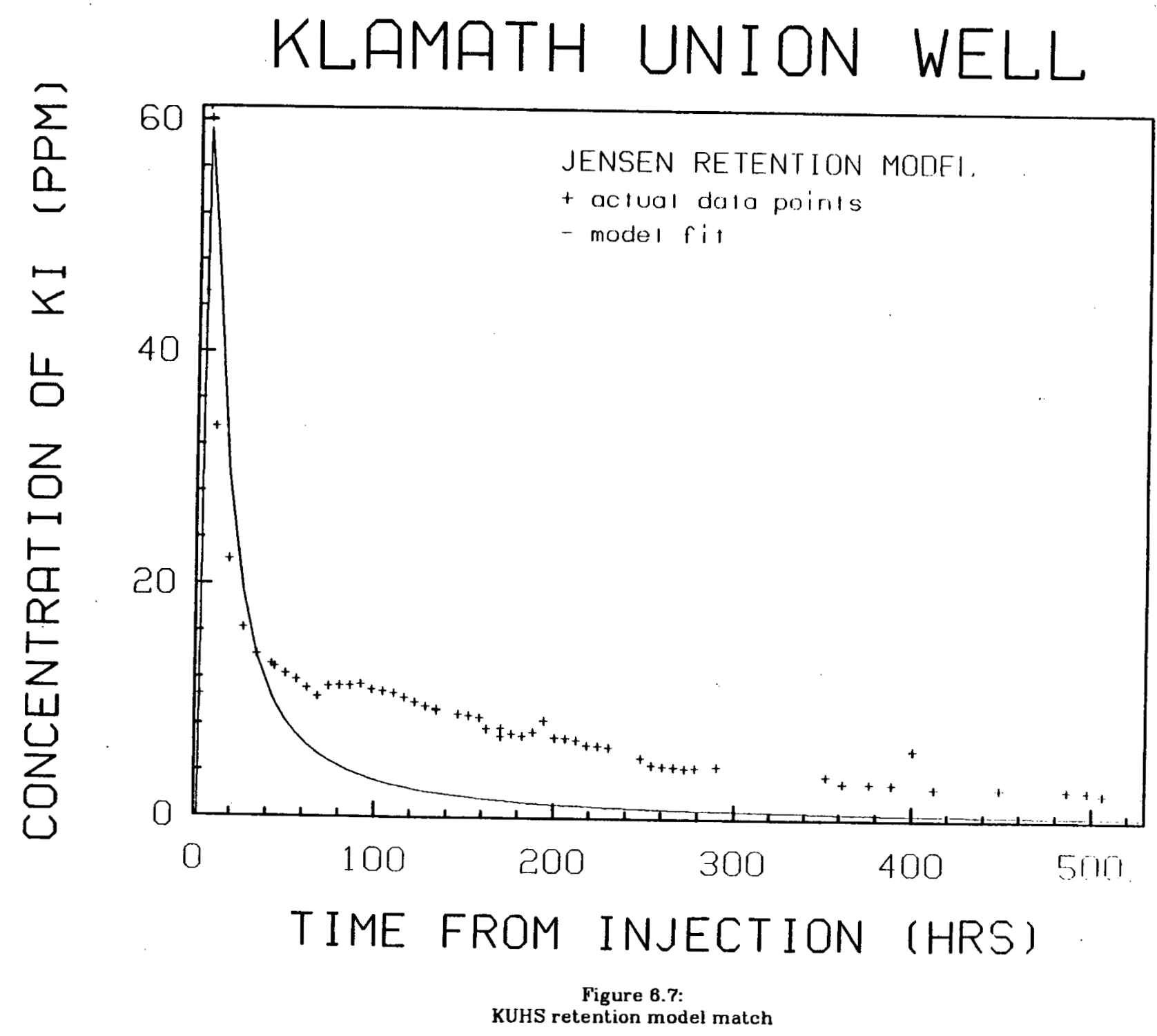




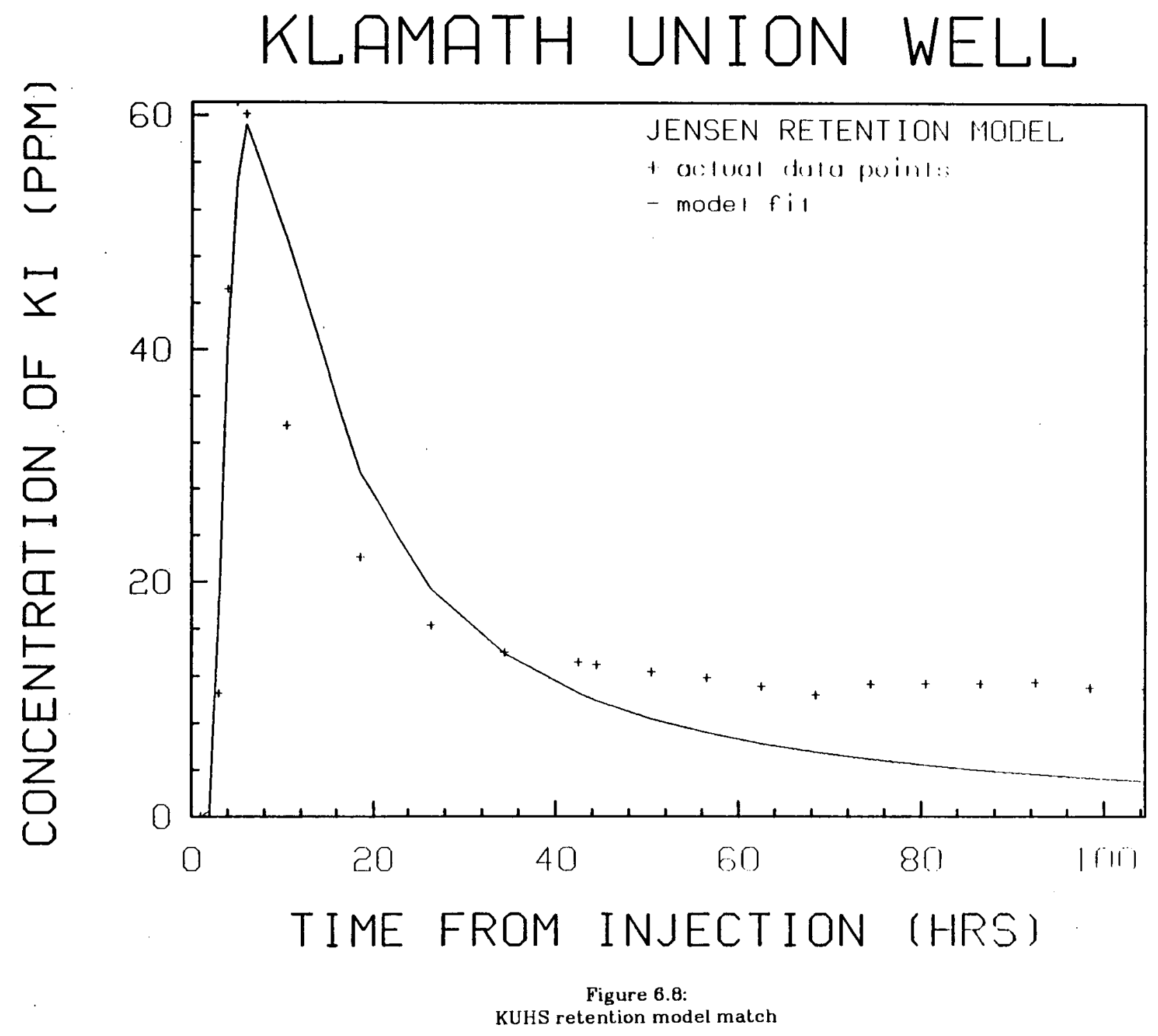




\section{CREAMERY WELL}

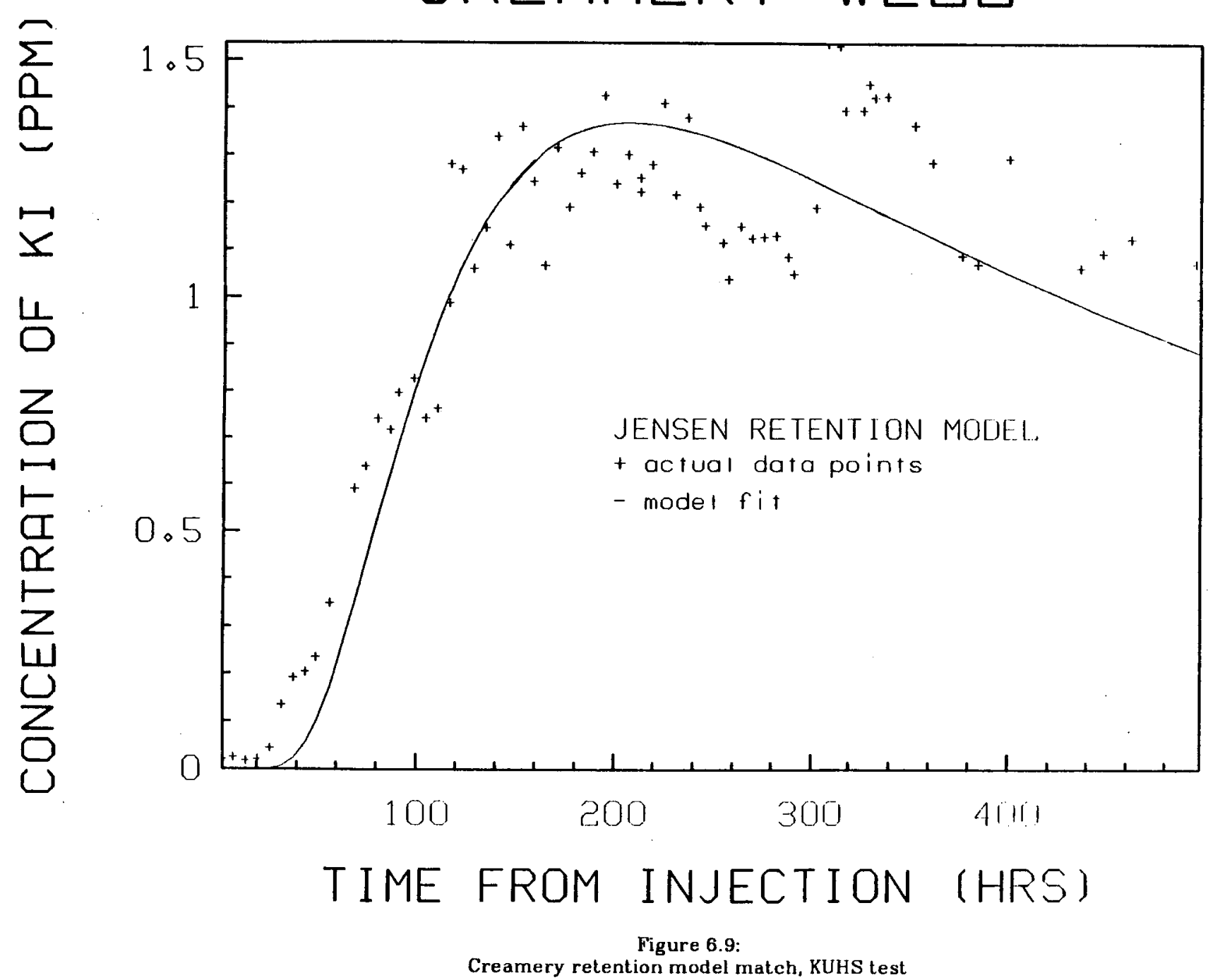




\section{CREAMERY WELL}

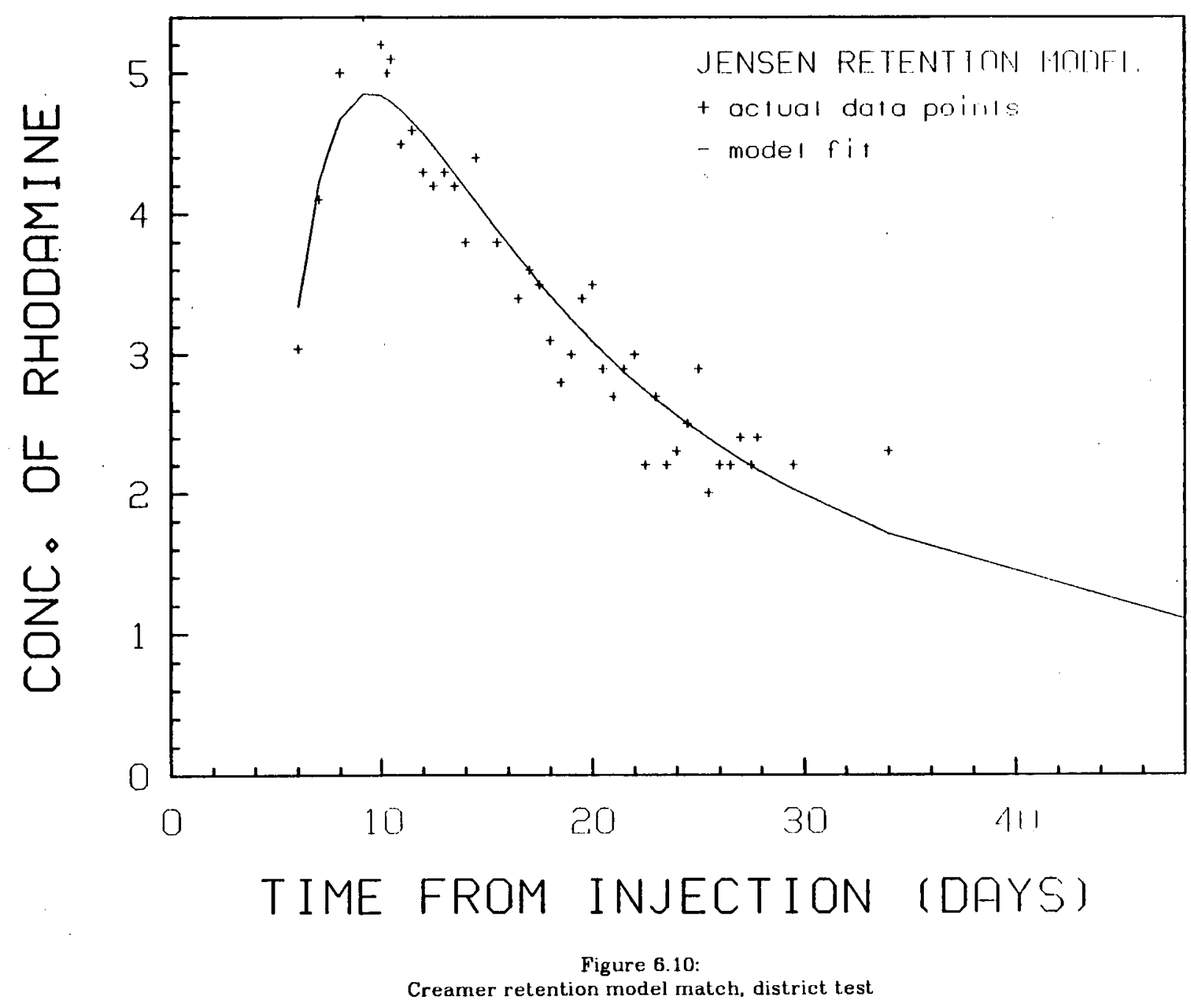




\section{FRIESEN WELL}

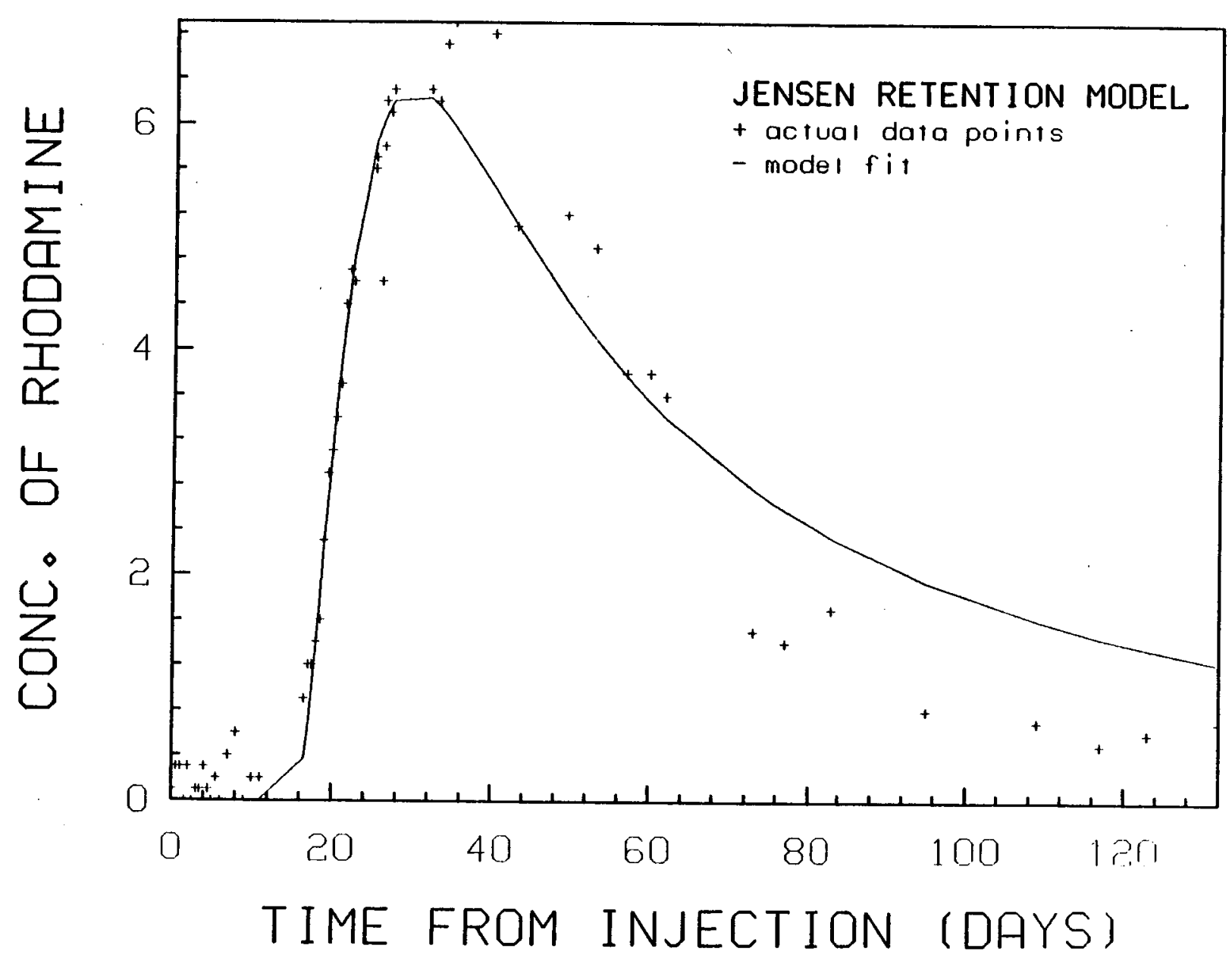




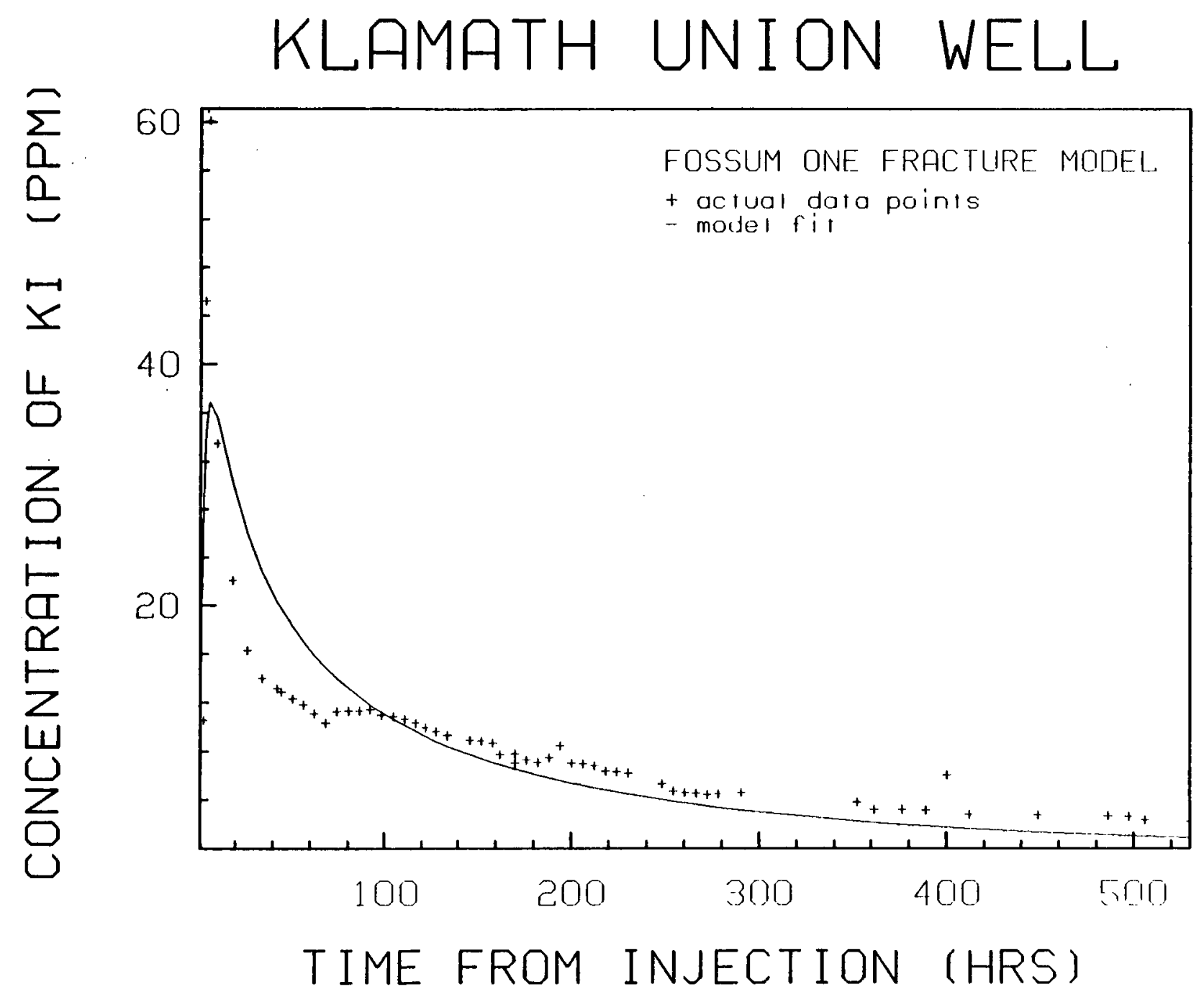

Figure 6.12:

KUHS single flow path model match 


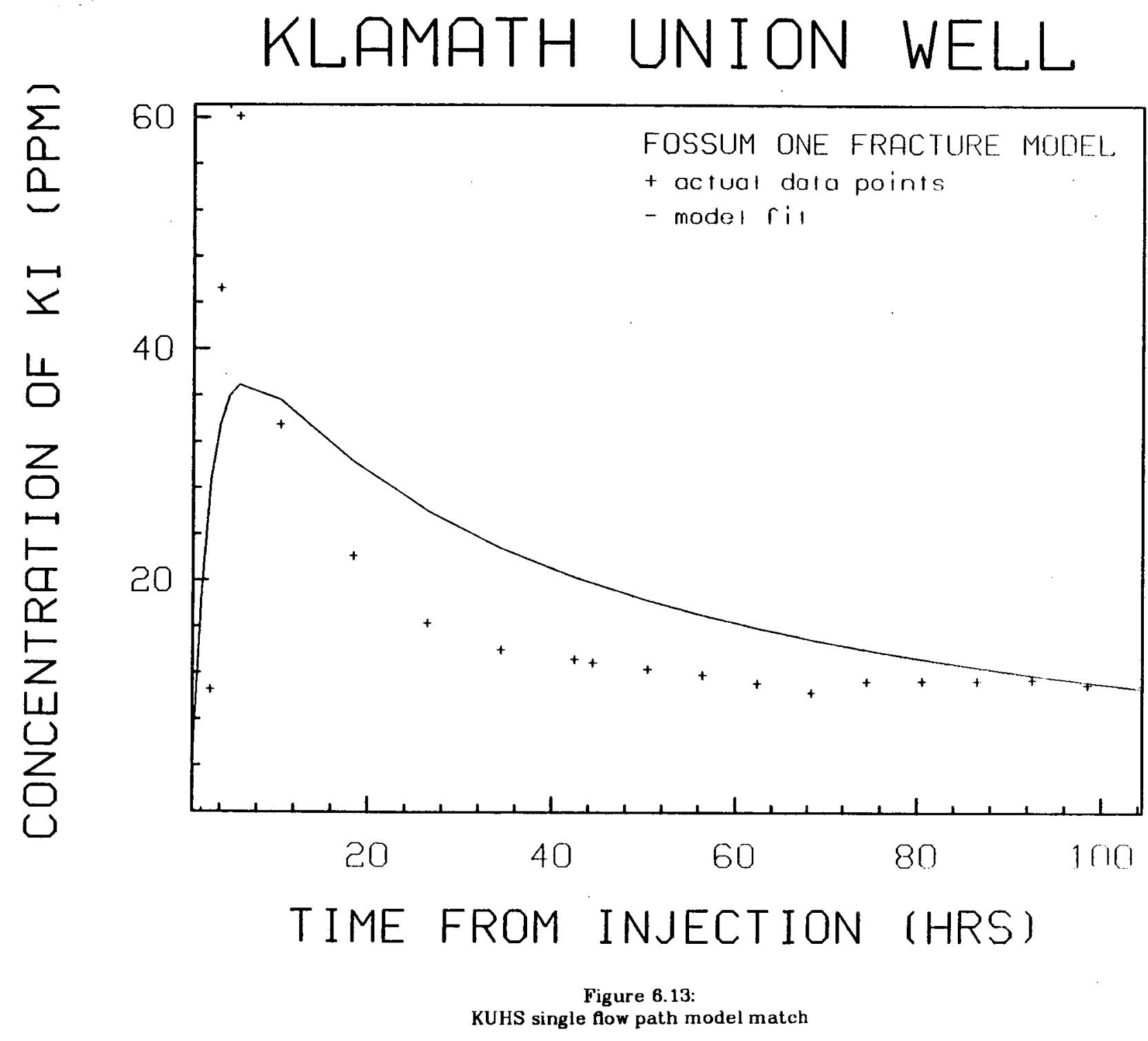




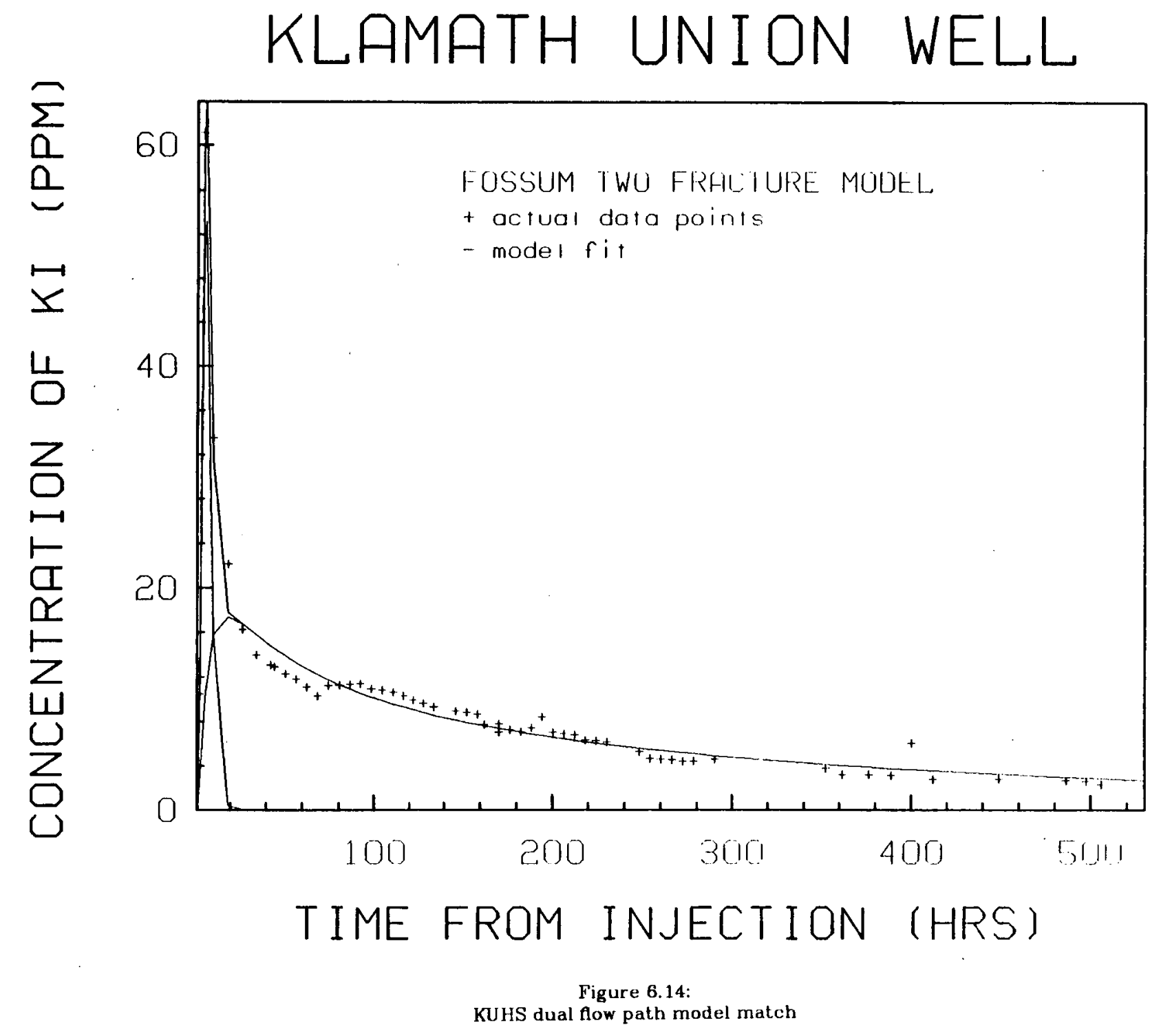




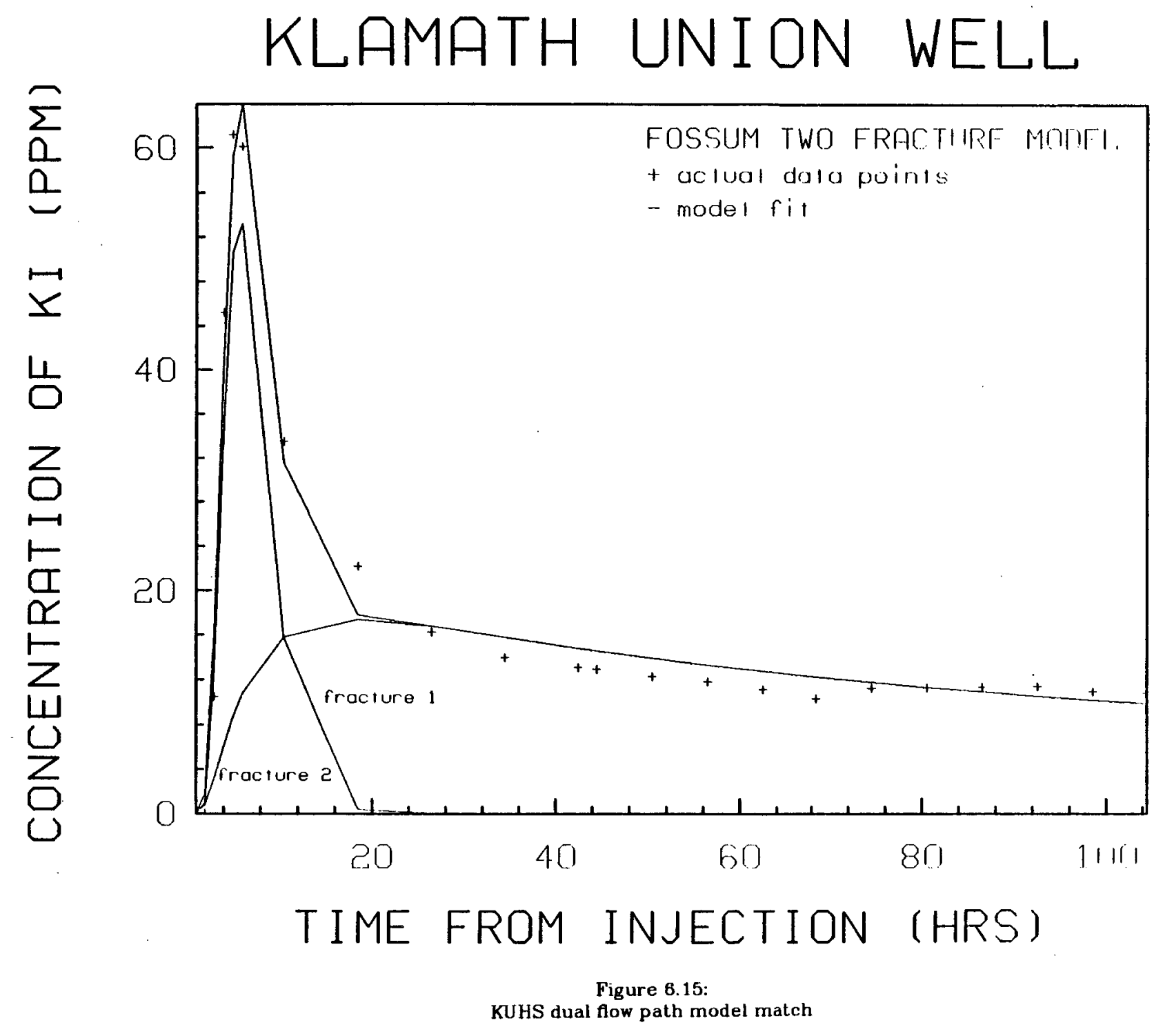




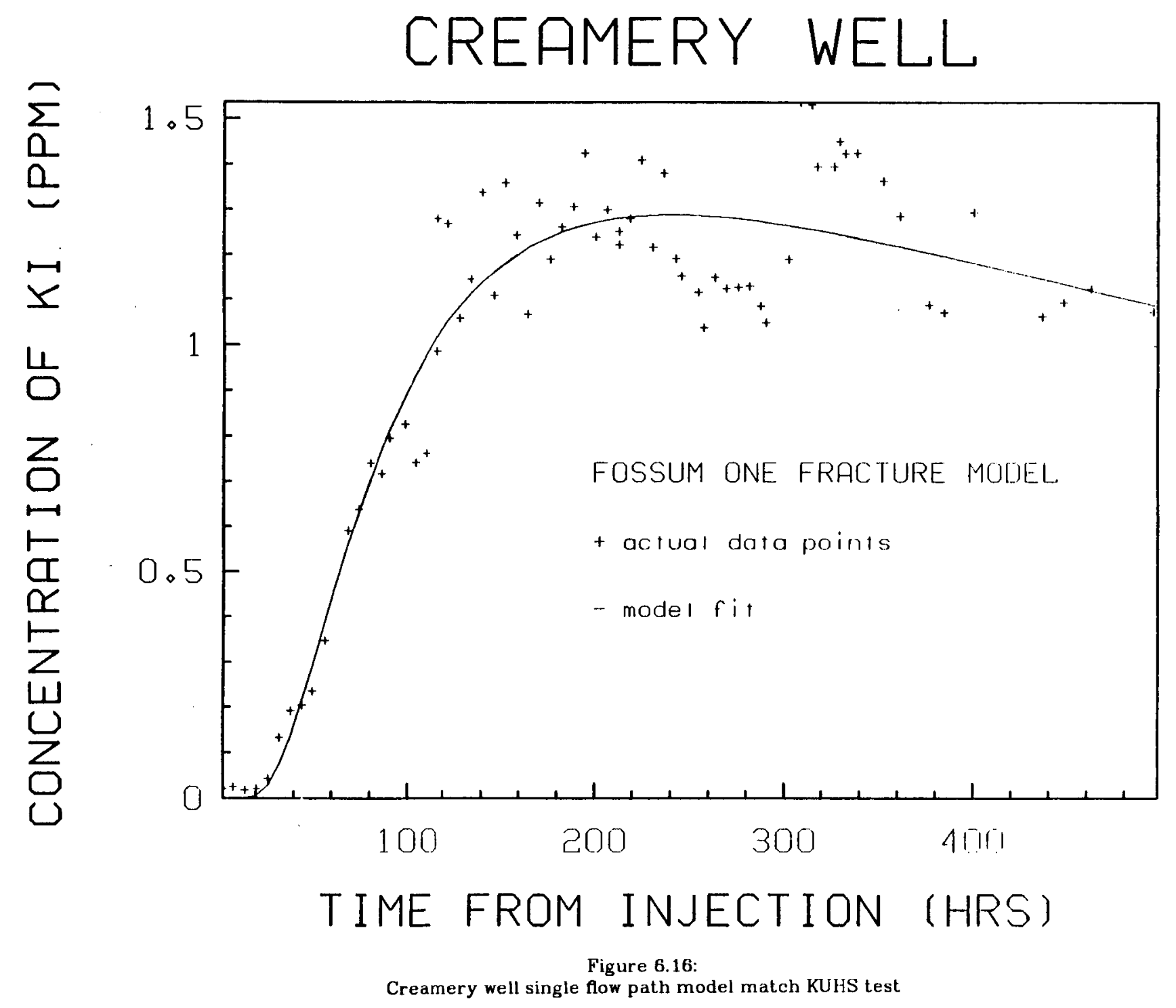




\section{FRIESEN WELL}

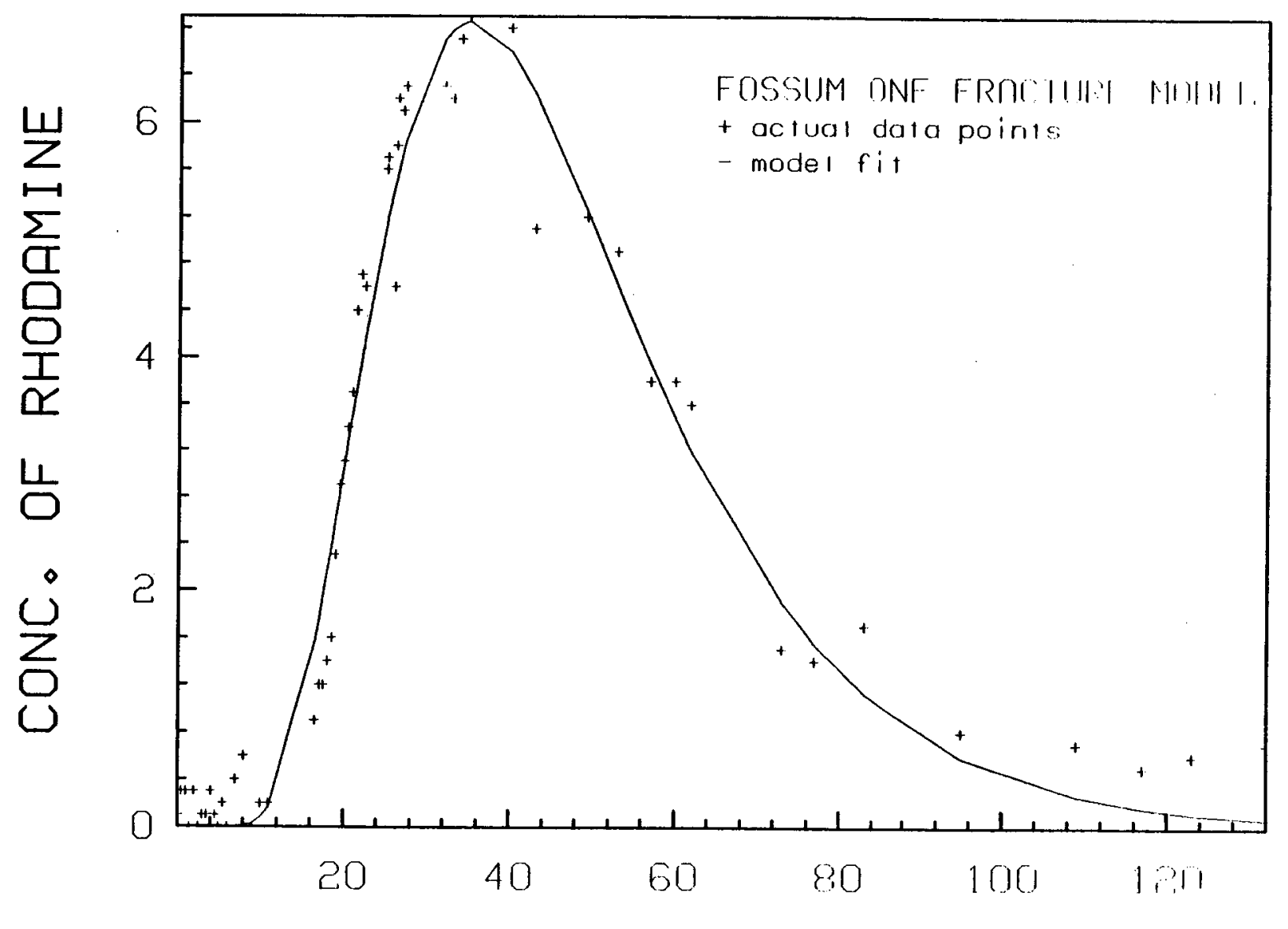

TIME FROM INJECTION (DAYS) 


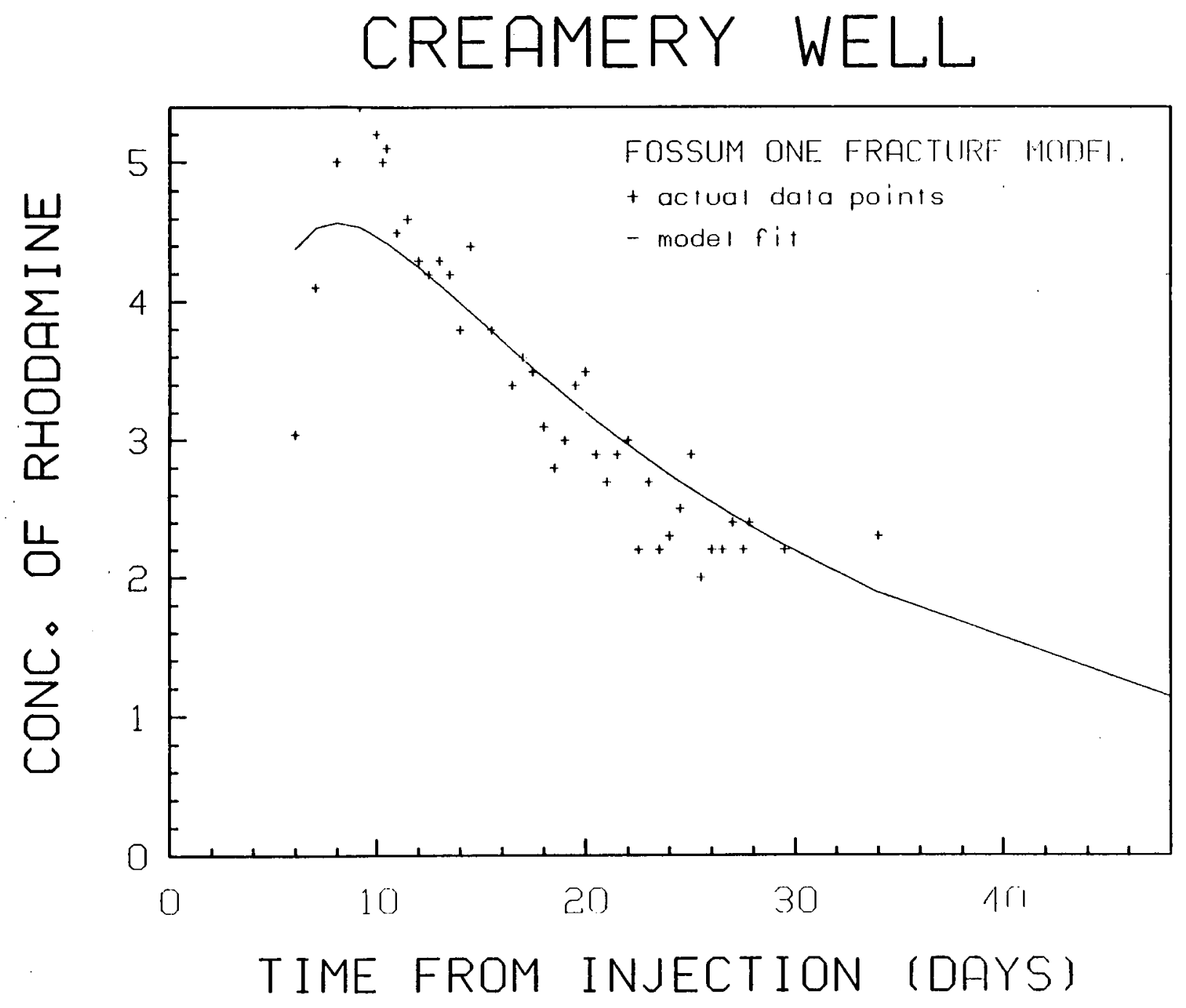

Creamery well single flow path model match district test 


\section{CREAMERY WELL}

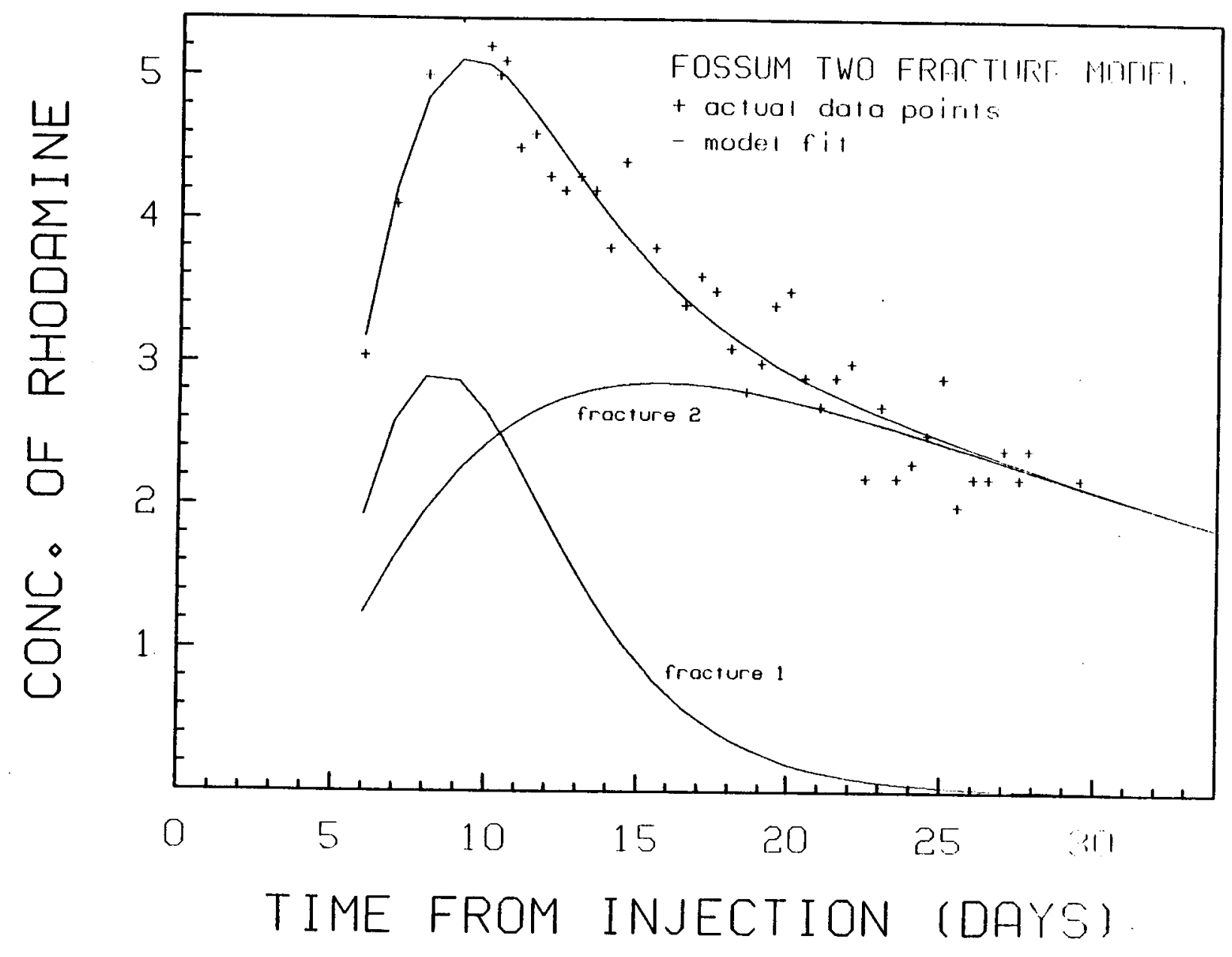




\begin{tabular}{|l|c|c|c|}
\hline \multicolumn{4}{|c|}{ JENSEN MODEL PROGRAM OUTPUT } \\
\hline \hline Vell name & $\alpha_{1}$ & $\alpha_{2}$ & Fig. \\
\hline Creamery & 65.2778 & 13.685 & 6.1 \\
\hline KUHS & 2.740 & 0.9168 & 6.2 \\
\hline (s) Creamery & 2.2890 & 0.4758 & 6.3 \\
\hline (s) Friesen & 1.4220 & 0.0793 & 6.4 \\
\hline
\end{tabular}

TABLE 6.1, RETENTION MODEL OUTPUT

\begin{tabular}{||l|c|c|c|c|c||}
\hline \multicolumn{7}{|c||}{$\begin{array}{c}\text { Well } \\
\text { Name }\end{array}$} & $\begin{array}{c}\alpha_{1} \\
\left(P e_{1}^{-1}\right)\end{array}$ & $\begin{array}{c}\alpha_{2} \\
(u / L)_{1}\end{array}$ & $\begin{array}{c}\alpha_{3} \\
\left(P e_{2}^{-1}\right)\end{array}$ & $\begin{array}{c}\alpha_{4} \\
(u / L)_{2}\end{array}$ & $\begin{array}{c}\text { Figure } \\
\text { Number }\end{array}$ \\
\hline KUHS & 2.0717 & 0.0329 & & & 6.5 \\
\hline KUHS & 0.0772 & 0.162 & 2.211 & 0.012 & 6.6 \\
\hline Creamery & 0.930 & 0.0018 & & & 6.7 \\
\hline (s) Friesen & 0.106 & 0.0255 & & & 6.8 \\
\hline (s) Creamery & 0.627 & 0.0689 & & & 6.9 \\
\hline (s) Creamery & 0.0715 & 0.110 & 0.352 & 0.0451 & 6.10 \\
\hline
\end{tabular}

TABLE 6.2, DUAL FLOW PATH MODEL OUTPUT 


\begin{tabular}{||c|c|c|c|c|c||}
\hline \multicolumn{7}{|c||}{ TRACER DATA FOR KUHS TEST } \\
\hline \hline $\begin{array}{c}\text { Well } \\
\text { Name }\end{array}$ & $\begin{array}{c}\text { Breakthrough } \\
\text { (hours) }\end{array}$ & $\begin{array}{c}\text { Peak Arrival } \\
\text { (hours) }\end{array}$ & $\begin{array}{c}\text { Peak Conc. } \\
\text { (mg/kg) }\end{array}$ & $\begin{array}{c}\text { Dist. } \\
\text { (feet) }\end{array}$ & $\begin{array}{c}\text { Dist. } \\
\text { (meters) }\end{array}$ \\
\hline KUHS & 2.5 & 6.0 & 60 & 250 & 76.2 \\
\hline Creamery & 26.5 & 190 & 1.5 & 600 & 183 \\
\hline \hline
\end{tabular}

TABLE 6.3, TRACER DATA FOR KLAMATH UNION TEST

\begin{tabular}{||c|c|c|c|c|c||}
\hline \multicolumn{7}{|c||}{ TRACER DATA FOR DISTRICT TEST } \\
$\begin{array}{c}\text { Nell } \\
\text { Name }\end{array}$ & $\begin{array}{c}\text { Breakthrough } \\
\text { (days) }\end{array}$ & $\begin{array}{c}\text { Peak Arrival } \\
\text { (days) }\end{array}$ & Peak Conc. & $\begin{array}{c}\text { Dist. } \\
\text { (feet) }\end{array}$ & $\begin{array}{c}\text { Dist. } \\
\text { (meters) }\end{array}$ \\
\hline \hline (s) Creamery & $<9$ & 9 & 5.2 & 600 & 183 \\
\hline (s) Friesen & 16 & 37 & 6.4 & 1000 & 305 \\
\hline
\end{tabular}

TABLE 6.4, TRACER DATA FOR DISTRICT TEST 


\begin{tabular}{|c|c|c|c|c|c|}
\hline \multicolumn{6}{|c|}{ MEAN TRACER VELOCITY BETHEEN WELLS } \\
\hline $\begin{array}{c}\text { Well } \\
\text { Name }\end{array}$ & $\begin{array}{l}\text { Velocity } \\
\text { (ft/min) }\end{array}$ & $\begin{array}{l}\text { Velocity } \\
\text { (m/hr) }\end{array}$ & $\begin{array}{c}\text { Peak Arrival } \\
\text { (hours) }\end{array}$ & $\begin{array}{l}\text { Dist. to Well } \\
\text { (feet) }\end{array}$ & $\begin{array}{l}\text { Dist. to Fell } \\
\text { (meters) }\end{array}$ \\
\hline KUHS & 1.6667 & 15.24 & 6.0 & 250 & 76.2 \\
\hline Creamery & 0.053 & 0.963 & 190 & 600 & 183 \\
\hline
\end{tabular}

TABLE 6.5. MEAN TRACER. VELOCITIES (KUHS TEST)

\begin{tabular}{||c|c|c|c|c|c||}
\hline \multicolumn{7}{|c|}{ MEAN TRACER VELOCITY BETTEEN WELLS } \\
$\begin{array}{c}\text { Well } \\
\text { Name }\end{array}$ & $\begin{array}{c}\text { Velocity } \\
\text { (ft/min) }\end{array}$ & $\begin{array}{c}\text { Velocity } \\
\text { (m/hr) }\end{array}$ & $\begin{array}{c}\text { Peak Time } \\
\text { (days) }\end{array}$ & $\begin{array}{c}\text { Dist. to Well } \\
\text { (feet) }\end{array}$ & $\begin{array}{c}\text { Dist. to Well } \\
\text { (meters) }\end{array}$ \\
\hline \hline (s) Friesen & 0.019 & 0.344 & 37 & 1000 & 305 \\
\hline (s) Creamery & 0.046 & 0.846 & 9 & 600 & 183 \\
\hline
\end{tabular}

TABLE 6.6, MEAN TRACER VELOCITIES BETWEEN WELL (DISTRICT TEST) 


\begin{tabular}{|c|c|}
\hline \multicolumn{2}{|c|}{ CREAMERY WELL (KUHS TEST) } \\
\hline \multicolumn{2}{|c|}{ NUMBER OF DATA POINTS $=69$} \\
\hline $\begin{array}{c}\text { Time from Injection } \\
\text { (hours) }\end{array}$ & $\begin{array}{c}\text { Tracer Concentration } \\
(\mathrm{mg} / \mathrm{l})\end{array}$ \\
\hline $\begin{array}{l}2.660 \\
8.020 \\
14.330 \\
20.330 \\
26.45\end{array}$ & $\begin{array}{l}0.0201 \\
0.0252 \\
0.0176 \\
0.0201 \\
0.0435\end{array}$ \\
\hline $\begin{array}{l}32.45 \\
38.42 \\
44.53 \\
49.66 \\
56.45\end{array}$ & $\begin{array}{l}0.1343 \\
0.1918 \\
0.2055 \\
0.2358 \\
0.3483\end{array}$ \\
\hline $\begin{array}{l}68.83 \\
80.420 \\
74.500 \\
86.480 \\
90.450\end{array}$ & $\begin{array}{l}0.5908 \\
0.7398 \\
0.6376 \\
0.7158 \\
0.7962\end{array}$ \\
\hline $\begin{array}{r}98.500 \\
104.430 \\
110.480 \\
116.470 \\
116.500\end{array}$ & $\begin{array}{l}0.8268 \\
0.7408 \\
0.7628 \\
0.9871 \\
1.2812\end{array}$ \\
\hline $\begin{array}{l}122.400 \\
128.400 \\
134.600 \\
140.370 \\
158.420\end{array}$ & $\begin{array}{l}1.2701 \\
1.0601 \\
1.1463 \\
1.3392 \\
1.2444\end{array}$ \\
\hline $\begin{array}{l}152.570 \\
146.500 \\
164.500 \\
170.500 \\
176.500\end{array}$ & $\begin{array}{l}1.3609 \\
1.1103 \\
1.0676 \\
1.3163 \\
1.1920\end{array}$ \\
\hline $\begin{array}{l}182.420 \\
188.500 \\
194.500 \\
200.500 \\
206.500 \\
\end{array}$ & $\begin{array}{l}1.2629 \\
1.3072 \\
1.4242 \\
1.2399 \\
1.3014\end{array}$ \\
\hline $\begin{array}{l}212.500 \\
212.500 \\
218.500 \\
224.500 \\
230.500\end{array}$ & $\begin{array}{l}1.2239 \\
1.2530 \\
1.2805 \\
1.4092 \\
1.2179\end{array}$ \\
\hline $\begin{array}{l}236.500 \\
242.500 \\
245.500 \\
254.500 \\
\end{array}$ & $\begin{array}{l}1.3808 \\
1.1927 \\
1.1530 \\
1.1166 \\
\end{array}$ \\
\hline
\end{tabular}




\begin{tabular}{||c|c||}
\hline \multicolumn{2}{|c||}{ CREAMERY WELL (KUHS TEST) } \\
\hline \hline \multicolumn{2}{|c||}{ NUMBER OF DATA POINTS $=69$} \\
\hline \hline & \\
Time from Injection & Tracer Concentration \\
(hours) & (mg /) \\
\hline 257.500 & 1.0387 \\
\hline 263.500 & 1.1512 \\
269.500 & 1.1258 \\
275.500 & 1.1292 \\
281.500 & 1.1309 \\
287.500 & 1.0860 \\
\hline 290.500 & 1.0497 \\
302.500 & 1.1908 \\
308.500 & 1.5372 \\
314.500 & 1.5310 \\
317.500 & 1.3958 \\
\hline 326.500 & 1.3956 \\
329.500 & 1.4501 \\
338.500 & 1.4242 \\
332.500 & 1.4226 \\
352.500 & 1.3653 \\
\hline 361.500 & 1.2864 \\
376.500 & 1.0888 \\
384.500 & 1.0717 \\
400.500 & 1.2953 \\
436.500 & 1.0641 \\
\hline 448.000 & 1.0948 \\
462.500 & 1.1261 \\
495.500 & 1.0736 \\
497.500 & 1.0003 \\
\hline & \\
\hline & \\
\hline
\end{tabular}

TABLE A : CREAMERY DATA, KUHS TEST. 


\begin{tabular}{|c|c|}
\hline \multicolumn{2}{|c|}{ FRIESEN WELL (DISTRICT TEST) } \\
\hline \multicolumn{2}{|c|}{ NUMBER OF DATA POINTS $=57$} \\
\hline $\begin{array}{l}\text { Time from Injection } \\
\text { (hours) }\end{array}$ & Tracer Concentration \\
\hline $\begin{array}{l}0.1 \\
0.5 \\
1.0 \\
1.5 \\
2.0\end{array}$ & $\begin{array}{l}0.1 \\
0.3 \\
0.3 \\
0.0 \\
0.3 \\
\end{array}$ \\
\hline $\begin{array}{l}2.5 \\
3.0 \\
3.5 \\
4.0 \\
4.5\end{array}$ & $\begin{array}{l}0.0 \\
0.1 \\
0.1 \\
0.3 \\
0.1 \\
\end{array}$ \\
\hline $\begin{array}{l}5.0 \\
5.5 \\
6.0 \\
7.0 \\
8.0\end{array}$ & $\begin{array}{l}0.0 \\
0.2 \\
0.0 \\
0.4 \\
0.6\end{array}$ \\
\hline $\begin{array}{r}9.0 \\
10.0 \\
11.0 \\
16.5 \\
17.0\end{array}$ & $\begin{array}{l}0.0 \\
0.2 \\
0.2 \\
0.9 \\
1.2 \\
\end{array}$ \\
\hline $\begin{array}{l}17.5 \\
18.0 \\
18.5 \\
19.0 \\
19.5\end{array}$ & $\begin{array}{l}1.2 \\
1.4 \\
1.6 \\
2.3 \\
2.9 \\
\end{array}$ \\
\hline $\begin{array}{l}20.0 \\
20.5 \\
21.0 \\
21.5 \\
22.0\end{array}$ & $\begin{array}{l}3.1 \\
3.4 \\
3.7 \\
4.4 \\
4.7\end{array}$ \\
\hline $\begin{array}{l}22.5 \\
25.0 \\
25.16 \\
26.0 \\
26.16\end{array}$ & $\begin{array}{l}4.6 \\
5.6 \\
5.7 \\
4.6 \\
5.8\end{array}$ \\
\hline $\begin{array}{l}26.33 \\
27.0 \\
27.33 \\
32.0 \\
33.0 \\
\end{array}$ & $\begin{array}{l}6.2 \\
6.1 \\
6.3 \\
6.3 \\
6.2 \\
\end{array}$ \\
\hline $\begin{array}{l}34.0 \\
35.0 \\
40.0 \\
43.0\end{array}$ & $\begin{array}{l}6.7 \\
6.9 \\
6.8 \\
5.1 \\
\end{array}$ \\
\hline
\end{tabular}




\begin{tabular}{|c|c||}
\hline \multicolumn{2}{|c|}{ FRIESEN WELL (DISTRICT TEST) } \\
\hline \hline NUMBER OF DATA POINTS $=57$ \\
\hline Time from Injection \\
(hours) & Tracer Concentration \\
& \\
\hline 49.3 & 5.2 \\
\hline 53.0 & 4.9 \\
57.0 & 3.8 \\
60.0 & 3.8 \\
62.0 & 3.6 \\
73.0 & 1.5 \\
\hline 77.0 & 1.4 \\
83.0 & 1.7 \\
95.0 & 0.8 \\
109.0 & 0.7 \\
117.0 & 0.5 \\
\hline 123.0 & 0.6 \\
132.0 & 0.7 \\
\hline
\end{tabular}

TABLE B: FRIESEN WELL DATA, DISTRICT TEST 


\begin{tabular}{|c|c|}
\hline \multicolumn{2}{|c|}{ KUHS WHL (KUHS TEST) } \\
\hline \multicolumn{2}{|c|}{ NUMBER OF DATA POINTS $=62$} \\
\hline $\begin{array}{c}\text { Time from Injection } \\
\text { (hours) }\end{array}$ & $\begin{array}{c}\text { Tracer Concentration } \\
(\mathrm{mg} / \mathrm{l})\end{array}$ \\
\hline $\begin{array}{l}1.0 \\
2.0 \\
3.0 \\
4.0 \\
5.0 \\
\end{array}$ & $\begin{array}{r}0.013 \\
0.043 \\
10.523 \\
45.228 \\
61.145 \\
\end{array}$ \\
\hline $\begin{array}{r}6.0 \\
10.5 \\
18.5 \\
26.5 \\
34.5\end{array}$ & $\begin{array}{l}60.107 \\
33.500 \\
22.100 \\
16.267 \\
13.970\end{array}$ \\
\hline $\begin{array}{l}42.5 \\
44.5 \\
50.5 \\
56.5 \\
62.5\end{array}$ & $\begin{array}{l}13.141 \\
12.912 \\
12.317 \\
11.833 \\
11.116\end{array}$ \\
\hline $\begin{array}{l}68.5 \\
74.5 \\
80.5 \\
86.5 \\
92.5 \\
\end{array}$ & $\begin{array}{l}10.351 \\
11.277 \\
11.335 \\
11.342 \\
11.414 \\
\end{array}$ \\
\hline $\begin{array}{r}98.5 \\
104.5 \\
110.5 \\
116.5 \\
122.5 \\
\end{array}$ & $\begin{array}{r}10.984 \\
10.866 \\
10.683 \\
10.342 \\
9.922 \\
\end{array}$ \\
\hline $\begin{array}{l}128.5 \\
134.5 \\
134.5 \\
146.5 \\
152.5 \\
\end{array}$ & $\begin{array}{l}9.6123 \\
9.2884 \\
9.3490 \\
8.9100 \\
8.9253 \\
\end{array}$ \\
\hline $\begin{array}{l}158.5 \\
162.5 \\
170.5 \\
170.5 \\
176.5 \\
\end{array}$ & $\begin{array}{l}8.6380 \\
7.7267 \\
7.0154 \\
7.7482 \\
7.2566 \\
\end{array}$ \\
\hline $\begin{array}{l}182.5 \\
188.5 \\
194.5 \\
200.5 \\
206.5\end{array}$ & $\begin{array}{l}7.0739 \\
7.4335 \\
8.4327 \\
6.9979 \\
6.9230\end{array}$ \\
\hline $\begin{array}{l}212.5 \\
218.5 \\
224.5 \\
230.5 \\
\end{array}$ & $\begin{array}{l}6.7554 \\
6.3388 \\
6.2723 \\
6.1459 \\
\end{array}$ \\
\hline
\end{tabular}




\begin{tabular}{||c|c||}
\hline \multicolumn{2}{|c|}{ KUHS FETL (KUHS TEST) } \\
\hline \hline \multicolumn{2}{|c||}{ NUMBER OF DATA POINTS = 62 } \\
\hline \hline & \\
Time from Injection & Tracer Concentration \\
(hours) & \\
\hline 248.5 & 5.2503 \\
\hline 254.5 & 4.6421 \\
260.5 & 4.5445 \\
266.5 & 4.4829 \\
272.5 & 4.3671 \\
278.5 & 4.4203 \\
\hline 290.5 & 4.5477 \\
352.5 & 3.7814 \\
361.5 & 3.1480 \\
376.5 & 3.1494 \\
389.0 & 3.0995 \\
\hline 400.5 & 6.0154 \\
412.5 & 2.7703 \\
449.0 & 2.7380 \\
486.5 & 2.6667 \\
497.5 & 2.6034 \\
\hline 506.0 & 2.3095 \\
530.0 & 2.1918 \\
\hline
\end{tabular}

TABLE C: KUHS PRODUCTION WELL DATA, KUHS TEST 


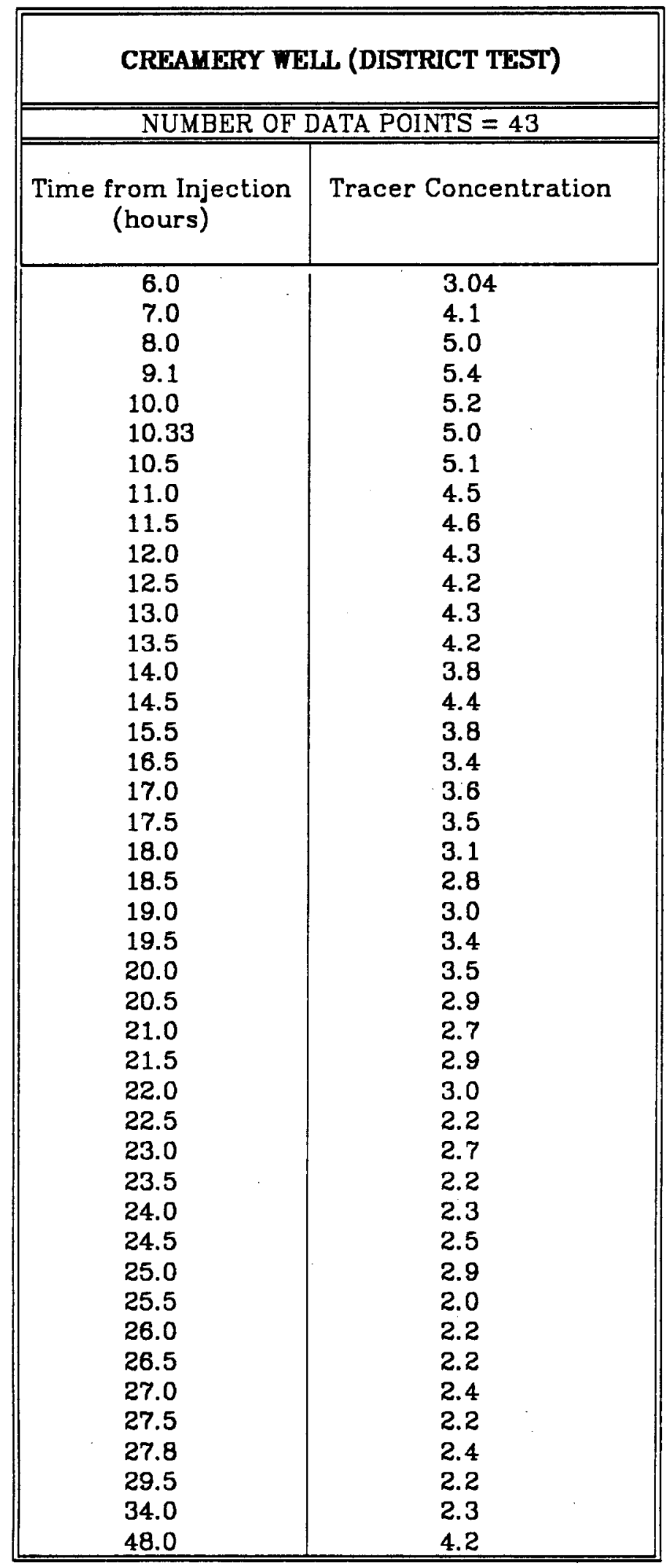

TABLE D: CREAMERY WELL DATA, DISTRICT TEST. 


\begin{tabular}{|c|c|}
\hline \multicolumn{2}{|c|}{ KUHS WEIL (KUHS TEST) } \\
\hline \multicolumn{2}{|c|}{ NUMBER OF DATA POINTS $=249$} \\
\hline \multicolumn{2}{|c|}{ TRACER = FLUORESCEIN } \\
\hline $\begin{array}{l}\text { Time from Injection } \\
\text { (hours) }\end{array}$ & Tracer Concentration \\
\hline 0 & 3.78 \\
\hline 0 & 3.86 \\
\hline 0 & 3.88 \\
\hline 0 & 3.69 \\
\hline 0 & 3.56 \\
\hline 0 & 3.83 \\
\hline 0 & 3.38 \\
\hline 0 & 3.89 \\
\hline 0 & 3.69 \\
\hline 0 & 4.28 \\
\hline 0 & 4.04 \\
\hline 0 & 3.94 \\
\hline 0 & 3.81 \\
\hline 0 & 3.67 \\
\hline 0 & 3.54 \\
\hline 0 & 3.95 \\
\hline 0 & 4.55 \\
\hline 0 & 4.13 \\
\hline 0 & 3.73 \\
\hline 0 & 4.97 \\
\hline 0 & 4.72 \\
\hline 0 & 4.04 \\
\hline 0 & 4.16 \\
\hline 0 & 3.80 \\
\hline 0 & 4.38 \\
\hline 0 & 3.54 \\
\hline 0 & 3.60 \\
\hline 0 & 3.54 \\
\hline 0 & 3.12 \\
\hline 0 & 3.33 \\
\hline 0 & 3.60 \\
\hline 0 & 3.80 \\
\hline 0 & 4.08 \\
\hline 0 & 3.06 \\
\hline 0 & 3.65 \\
\hline 1 & 3.83 \\
\hline 1.0 & 3.49 \\
\hline 1.5 & 3.75 \\
\hline 1.5 & 3.02 \\
\hline 2.0 & 3.68 \\
\hline 2.0 & 3.58 \\
\hline 2.5 & 4.16 \\
\hline 2.5 & 4.58 \\
\hline 3.0 & 9.91 \\
\hline 3.0 & 8.65 \\
\hline
\end{tabular}




\begin{tabular}{|c|c|}
\hline \multicolumn{2}{|c|}{ KUHS WEIL (KUHS TEST) } \\
\hline \multicolumn{2}{|c|}{ NUMBER OF DATA POINTS $=249$} \\
\hline \multicolumn{2}{|c|}{ TRACER = FLUORESCEIN } \\
\hline $\begin{array}{c}\text { Time from Injection } \\
\text { (hours) }\end{array}$ & Tracer Concentration \\
\hline 3.5 & 12.30 \\
\hline 3.5 & 13.7 \\
\hline 4.0 & 21.1 \\
\hline 4.0 & 20.6 \\
\hline 4.5 & 25.8 \\
\hline 4.5 & 27.0 \\
\hline 5.0 & 29.6 \\
\hline 5.0 & 31.8 \\
\hline 5.5 & 31.2 \\
\hline 5.5 & 29.3 \\
\hline 6.0 & 30.7 \\
\hline 6.0 & 30.2 \\
\hline 6.5 & 27.9 \\
\hline 6.5 & 28.3 \\
\hline 7.0 & 27.9 \\
\hline 7.0 & 28.0 \\
\hline 7.5 & 24.4 \\
\hline 7.5 & 25.0 \\
\hline 8.0 & 22.1 \\
\hline 8.0 & 23.0 \\
\hline 8.5 & 21.7 \\
\hline 8.5 & 20.7 \\
\hline 9.0 & 19.5 \\
\hline 9.0 & 19.1 \\
\hline 9.5 & 18.4 \\
\hline 9.5 & 20.0 \\
\hline 10 & 13.7 \\
\hline 10 & 14.5 \\
\hline 10.5 & 13.8 \\
\hline 10.5 & 14.4 \\
\hline 11.0 & 13.0 \\
\hline 11.0 & 13.3 \\
\hline 11.5 & 16.8 \\
\hline 11.5 & 16.5 \\
\hline 12.0 & 16.1 \\
\hline 12.0 & 15.5 \\
\hline 12.5 & 15.3 \\
\hline 12.5 & 15.9 \\
\hline 13.0 & 14.8 \\
\hline 13.0 & 15.6 \\
\hline 13.5 & 15.0 \\
\hline 13.5 & 16.0 \\
\hline 14.0 & 14.3 \\
\hline 14.0 & 13.7 \\
\hline 14.5 & 13.6 \\
\hline
\end{tabular}




\begin{tabular}{|c|c|}
\hline \multicolumn{2}{|c|}{ KUHS WELL (KUHS TEST) } \\
\hline \multicolumn{2}{|c|}{ NUMBER OF DATA POINTS $=249$} \\
\hline \multicolumn{2}{|c|}{ TRACER = FLUORESCEIN } \\
\hline $\begin{array}{c}\text { Time from Injection } \\
\text { (hours) }\end{array}$ & Tracer Concentration \\
\hline 14.5 & 13.7 \\
\hline 15.0 & 10.1 \\
\hline 15.0 & 10.6 \\
\hline 15.5 & 9.8 \\
\hline 15.5 & 10.3 \\
\hline 16.0 & 10.2 \\
\hline 16.0 & 9.4 \\
\hline 16.5 & 12.2 \\
\hline 16.5 & 11.6 \\
\hline 17.0 & 11.4 \\
\hline 17.0 & 10.6 \\
\hline 17.5 & 10.9 \\
\hline 17.5 & 11.0 \\
\hline 18.0 & 11.0 \\
\hline 18.0 & 10 \\
\hline 18.5 & 11.4 \\
\hline 18.5 & 11.2 \\
\hline 19.0 & 9.4 \\
\hline 19.0 & 9.8 \\
\hline 19.5 & 8.9 \\
\hline 19.5 & 8.9 \\
\hline 20 & 9.4 \\
\hline 20 & 10.6 \\
\hline $\begin{array}{l}20.5 \\
20.5\end{array}$ & 10 \\
\hline $\begin{array}{l}20.5 \\
21.0\end{array}$ & 9.3 \\
\hline $\begin{array}{l}21.0 \\
21.0\end{array}$ & $\begin{array}{r}10.2 \\
9.3\end{array}$ \\
\hline $\begin{array}{l}21.0 \\
21.5\end{array}$ & 8.1 \\
\hline 21.5 & 8.5 \\
\hline 22.0 & 8.7 \\
\hline 22.0 & 9.0 \\
\hline 22.5 & 9.0 \\
\hline 22.5 & 8.8 \\
\hline 23.0 & 9.0 \\
\hline 23.0 & 8.8 \\
\hline 23.5 & 9.1 \\
\hline 23.5 & 9.4 \\
\hline 24.0 & 9.8 \\
\hline 24.0 & 8.9 \\
\hline 24.5 & 10.7 \\
\hline 24.5 & 10.5 \\
\hline 25.0 & 10.1 \\
\hline 25.0 & 10.6 \\
\hline 25.5 & 10.9 \\
\hline 25.5 & 10.3 \\
\hline
\end{tabular}




\begin{tabular}{|c|c|}
\hline \multicolumn{2}{|c|}{ KUHS FELL (KUHS TEST) } \\
\hline \multicolumn{2}{|c|}{ NUMBER OF DATA POINTS $=249$} \\
\hline \multicolumn{2}{|c|}{ TRACER = FLUORESCEIN } \\
\hline $\begin{array}{c}\text { Time from Injection } \\
\text { (hours) }\end{array}$ & Tracer Concentration \\
\hline 26.0 & 10.5 \\
\hline 26.0 & 10.5 \\
\hline 26.5 & 9.9 \\
\hline 26.5 & 10.8 \\
\hline 27.0 & 9.5 \\
\hline 27.0 & 11.4 \\
\hline 27.5 & 11.2 \\
\hline 27.5 & 10.8 \\
\hline 28.0 & 10.5 \\
\hline 28.0 & 11.5 \\
\hline 28.5 & 10.9 \\
\hline 28.5 & 10.6 \\
\hline 29.0 & 10.5 \\
\hline 29.0 & 11.1 \\
\hline 29.5 & 10.6 \\
\hline 29.5 & 7.8 \\
\hline 30.0 & 11.4 \\
\hline 30.5 & 10.9 \\
\hline 30.5 & 8.8 \\
\hline 31.0 & 9.6 \\
\hline 31.0 & 8.5 \\
\hline 31.5 & 7.7 \\
\hline 31.5 & 8.6 \\
\hline 32.0 & 8.3 \\
\hline 32.0 & 7.6 \\
\hline 32.5 & 8.1 \\
\hline 32.5 & 7.8 \\
\hline 33.0 & 6.9 \\
\hline 33.0 & 7.6 \\
\hline 33.5 & 7.5 \\
\hline 33.5 & 7.3 \\
\hline 34.0 & 6.7 \\
\hline 34.0 & 6.8 \\
\hline 34.5 & 7.5 \\
\hline 34.5 & 7.2 \\
\hline 35.0 & 6.7 \\
\hline 35.0 & 6.8 \\
\hline 35.5 & 6.8 \\
\hline 35.5 & 7.4 \\
\hline 36.0 & 6.7 \\
\hline 36.0 & 7.9 \\
\hline 36.5 & 7.3 \\
\hline 36.5 & 7.4 \\
\hline 37.0 & 8.0 \\
\hline 37.0 & 8.1 \\
\hline
\end{tabular}




\begin{tabular}{|c|c|}
\hline \multicolumn{2}{|c|}{ KUHS WELL (KUHS THST) } \\
\hline \multicolumn{2}{|c|}{ NUMBER OF DATA POINTS $=249$} \\
\hline \multicolumn{2}{|c|}{ TRACER = FLUORESCEIN } \\
\hline $\begin{array}{c}\text { Time from Injection } \\
\text { (hours) }\end{array}$ & Tracer Concentration \\
\hline 37.5 & 6.6 \\
\hline 37.5 & 7.1 \\
\hline 38.0 & 7.7 \\
\hline 38.0 & 7.6 \\
\hline 38.5 & 7.3 \\
\hline 38.5 & 7.0 \\
\hline 39.0 & 6.9 \\
\hline 39.0 & 7.6 \\
\hline 39.5 & 8.4 \\
\hline 39.5 & 7.3 \\
\hline 43.5 & 5.7 \\
\hline 45.5 & 5.2 \\
\hline 51.5 & 4.7 \\
\hline 59.5 & 5.1 \\
\hline 61.5 & 5.7 \\
\hline 63.5 & 5.2 \\
\hline 69.5 & 3.5 \\
\hline 69.5 & 5.8 \\
\hline 75.0 & 4.5 \\
\hline 78.5 & 4.9 \\
\hline 81.5 & 4.7 \\
\hline 84.5 & 4.8 \\
\hline 87.5 & 5.0 \\
\hline 93.5 & 4.6 \\
\hline 96.5 & 5.0 \\
\hline 98.5 & 6.8 \\
\hline 102.5 & 8.32 \\
\hline 102.5 & 8.74 \\
\hline 106.5 & 6.99 \\
\hline 106.5 & 7.36 \\
\hline 109.5 & 8.39 \\
\hline 109.5 & 8.13 \\
\hline 113.5 & 9.28 \\
\hline 113.5 & 8.91 \\
\hline 117.5 & 8.49 \\
\hline 117.5 & 8.47 \\
\hline 121.5 & 8.11 \\
\hline 121.5 & 7.84 \\
\hline 121.5 & 8.38 \\
\hline 125.5 & 8.30 \\
\hline 125.5 & 6.57 \\
\hline 125.5 & 8.59 \\
\hline 129.5 & 8.18 \\
\hline 129.5 & 7.50 \\
\hline 133.5 & 7.34 \\
\hline
\end{tabular}




\begin{tabular}{|c|c|}
\hline \multicolumn{2}{|c|}{ KUHS WEIL (KUHS TEST) } \\
\hline \hline \multicolumn{2}{|c|}{ NUMBER OF DATA POINTS = 249 } \\
\hline \hline \multicolumn{2}{|c|}{ TRACER $=$ FLUORESCEIN } \\
\hline \hline Time from Injection & Tracer Concentration \\
(hours) & \\
\hline 133.5 & \\
139.5 & 7.76 \\
145.5 & 7.35 \\
151.5 & 7.52 \\
157.5 & 7.43 \\
163.5 & 7.75 \\
169.5 & 7.89 \\
175.5 & 7.08 \\
181.5 & 6.63 \\
187.5 & 7.07 \\
187.5 & 7.27 \\
193.5 & 7.56 \\
199.5 & 7.28 \\
205.5 & 7.06 \\
211.5 & 6.71 \\
217.5 & 7.34 \\
223.5 & 6.62 \\
229.5 & 7.36 \\
235.5 & 6.92 \\
241.5 & 4.09 \\
247.5 & 7.34 \\
253.5 & 5.81 \\
259.5 & 6.42 \\
\hline
\end{tabular}

TABLE E: KUHS PRODUCTION WELL, KUHS TEST, FLUORESCEIN DYE. 
$-105-$

Appendix A

Porous media model computer program. 
IMPLICIT REAL\#B(A-H, C-Z)

DIMENSION A(5001), CON $(5001), T(5001), 5(5001)$

READ (5, *) GM, BETA, BT, TF

OM IS A CONSTANT WHICH DETERMINES THE RELATIVE HIGHT OF THE CURVE TO BE CALCULATED. ITS BASIS IS FOUND IN THE NUMBER. RELATING MASS INJECTED TO DOUBLET FLOW RATE. TO MODEL A GIVEN SYSTEM OM IS MASS (M) DIVIDED BY FLOW RATE (Q).

BETA IS THE OISPERSION CONSTAINT WHICH EFFECTS THE WIDTH OF THE PEAK. PROFILE. THE LARgER BETA IS THE BROADER THE PROFILE. BETA = ZERO CORRESPONDS TO NO DISPERSION OF TRACER.

BT Is a CONSTANT USED TO TRANELATE THE LOCATION of PEAK CONCENTRATION IN RELATION TO THE SET NUMBER OF DATA PDINTS. BY DECREASIHG BT THE RELATIVE LERGTH OF THE AFTER PEAK TIME IS INCREASED.

TF IS SIMPLY USED TO CALIBRATE THE QUTPUT TIMES WITH THAT OF THE DATA SET WHICH IS BEING FITTED.

WRITE (6, 12) GM, BETA 


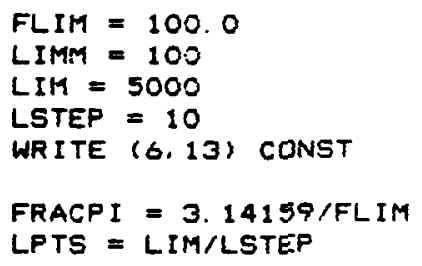

FRACPI IS THE DELTA ANGLE USE IN THE SUMATION OF THE EQUATION CA!_CULATING THE RELATIVE CONCENTRATIONS THE CONSTANT FLIH NEEDS TO BE LARGE DUE TO THE FORM OF THE EQUATION USED BEING UNSTABLE CAUSING CUTPUT TO OSCILATE. THE LARGER FLIM THE SITALLER THE DELTA ANGLE 'FRACPI'

LPTS IS THE NUMBER OF DATA POINTS PRODUCED BY THE PROGRAM NITH THE CONSTANTS SET.

LIMM MUST EQUAL FLIM FOR THE PROGRAM TO RUN CORRECTLY.

WRITE (6, 14) LPTS

DO $20 J=1$, LIM, 10

C

C

$T(\jmath)=J / 3 T$

$S Z=B E \mid A * 16.0 / 15.0$

$F S=F R A C P I / S Q R T(S Z)$

WRITE $(6,13)$ FS

$X S U M=2.0 *(E X P(-(1-T(J)) * 2 /(S Z)))$

SUM $=2.0 *(E X P\{-(1-T(U)) * 2 /(5 Z))$ *FRACTPI/SQRT $(S Z)$

WRITE $(6,13) \times 5 U M$

SUM IS tHe valle of tracer at the angles zero and 2 PI

SUM IS ADDED TO THE CONCENTRATION FROM THE OTHER DIVERGENCE ANGLES BELOW.

THE INNER DO=LOOP (10) CALCULATES THE CONTRIBUTION TO THE - TOTAL SUM CONCENTRATION FROM EACH STREAMLINE DEF INED BY THE DIVERGENCE ANGLE FRACPI.

THE SUMMATION UTILIZES THE SYMETRY OF THE PROBLEIS BY ONLY SUMMING QVER HALF THE CIRCLE AND ITULTIPLYING BY 2. THE MULTIPLICATICN BY 2 IS DONE IN THE CONSTANT 'CONST' SEE REFERENCE FOR DETAILS OF EQUATION FORMULATION.

WRITE $(6,13)$ SUM 
Sune 12, 198?

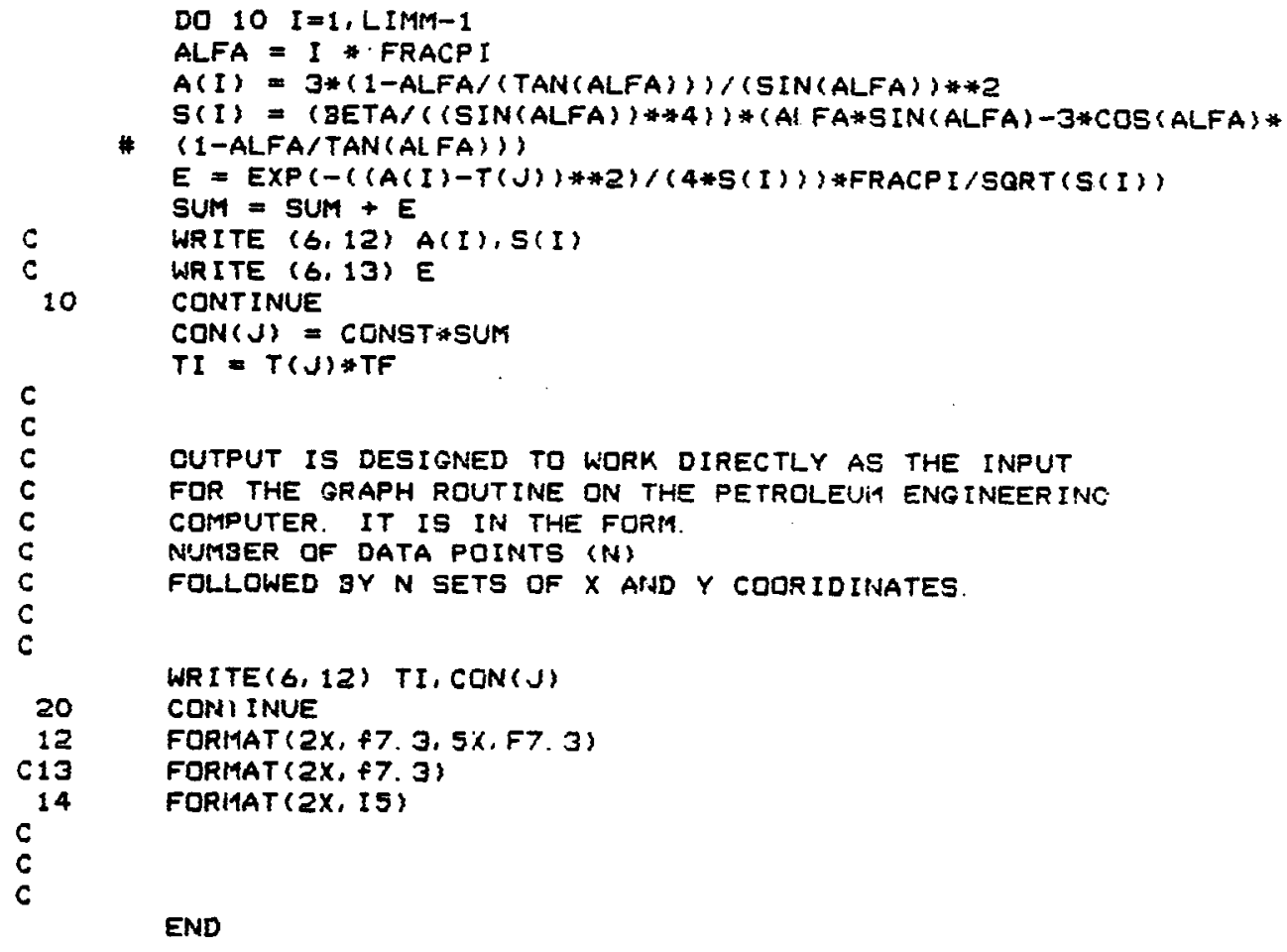

END 